\title{
A CLOSER LOOK AT EDUARDO M. TORNER'S BIBLIOGRAPHIC SURVEY OF SPAIN'S TRADITIONAL MUSIC AND DANCE*
}

Israel J. KATZ

\begin{abstract}
Eduardo M. Torner (1881-1955) was among the most notable pioneers who contributed to the nascent field of ethnomusicology in Spain. His early field researches in Asturias and Galicia yielded exemplary publications and his associates included such outstanding figures as Ramón Menéndez Pidal, Manuel Manrique de Lara, Jesús Bal y Gay, and Kurt Schindler. The two bibliographies contained in this article, which Torner included among the essays in his classic Temas folklóricos: Música y Poesía (Madrid, 1935), represent but a mere sampling of the 4,000 entries he is purported to have gathered concering Spain's traditional music and dance. Fleeing first to Valencia and then to Barcelona at the outbreak of the Civil War, he utlimately sought refuge in London, where he continued his researches until his death. During the transitional period from Valencia to England, he lost his precious collection of photographs, historical documents, and personal manuscripts, together with his massive bibliographical compilation. Here I have reordered the bibliographies from Temas folklóricos, insuring that all his entries are accurate and complete, adding personal comments to Torner's observations, and providing four indices: 1) Abbreviations and publications surveyed; 2) Authors; 3) Geographic locales, and 4) Subject matter.
\end{abstract}

\section{Resumen}

Eduardo M. Torner (1881-1935) fue uno de los más notables pioneros que contribuyeron al surgimiento de la etnomusicología en España. Sus primeras investigaciones de campo en Asturias y Galicia produjeron publicaciones modélicas, y se relacionó por su trabajo con figuras tan eminentes como Ramón Menéndez Pidal, Manuel Manrique de Lara, Jesús Bal y Gay y Kurt Schindler. Las dos bibliografías contenidas en este artículo que Torner incluyó entre los ensayos de su trabajo clásico Temas folklóricos: Música y Poesía (Madrid, 1935), no representan sino una mera muestra de las 4.000 entradas que se cree que recogió relativas a la música tradicional y danzas de España. Huyendo primeramente a Valencia y después a Barcleona al comienzo de la Guerra Civil, buscó por último refugio en Londres, donde continuó sus investigaciones hasta su fallecimiento. Durante el período de traslado de Valencia a Inglaterra, extravió su preciosa colección de fotografías, documentos históricos y manuscritos personales, junto con su enorme compilación de fichas bibliográficas. En este artículo he reordenado las bibliografías contenidas en Temas folklóricos, asegurándome de que todas sus citas sean exactas y completas, he añadido comentarios personales a las observaciones de Torner, y he elaborado también los siguientes índices: 1) Abreviaciones, incluyendo las publicaciones utilizadas; 2) Onomástico; 3) Toponímico; y 4) Materias.

* For their kind assistence and advice I wish to acknowledge my gratitude to: María Amparo Amat Tuduri, Eduardo Anglada, Victoria Eli, Genoveva Gálvez, Nieves Iglesias, Susana Lord Alonso, Emilio Rey García, María José Rucio Zamorano, and Alfredo Valverde (Madrid); Johana Crespí and Josep Martí i Pérez (Barcelona); Joaquín Díaz (Ureña); Modesto González Cobas (Oviedo); Amparo Ranch Salas (Valencia); Joan Parets Sierra (Mallorca); Mary Frances Dunham (New York); and especially to the Cultural Office of the Embassy of Spain (Washington, D.C.) for subventing a two month sojourn (April 15 - June 15th, 2000) in Madrid under the the XIV Convocatoria de becas de investigación, administered by the Ministerio Asuntos Exteriores (Madrid). 


\section{Introduction}

In an earlier article (1991a), I discussed a variety of bibliographical studies dealing both directly and peripherally with Spain's traditional folk music prior to the Civil War (1936-39), but focused primarily on J.B. Trend's contribution of 1921. Trend's study was

unique for its scope, comprising 214 items, ordered alphabetically by author, and containing, apart from its pertinent citations, reviews and references to biographical studies, art music, drama, opera, the zarzuela, Arabic music, contemporary musical performances, literary works, and even Portuguese musical sources (Ibid:: 348).

Although Trend intended his bibliography to serve as a "guide to secular Spanish music," only forty-nine of his citations pertain to studies and collections of orally transmitted music (i.e., merely twenty-three percent of the total). The regions represented included Cataluña (8 items), Vascongadas (6), Asturias (2), the Balearic islands (2), Cantabria (2), Galicia (2), Valencia (2), Andalucía (1), Castile and León (1), and Murcia (1). Twenty-three additional citations concern studies and collections of traditional dances (8 items), popular airs (7), religious songs (1), and such genres as the copla (1), romance (1), seguidilla (1), and threshing songs (1), including the three "classic" surveys: Felipe Pedrell's four-volume Cancionero musical popular español (Valls: Eduardo Casells, 19191922), ${ }^{1}$ and the essays of Rafael Mitjana Gordón, "La Musique en Espagne (Art religieux et art profane)" and Raoul Laparra, "La Musique et la danse populaires en Espagne," which were published in the fourth volume of the Encyclopédie de la Musique et Dictionnaire du Conservatoire (Paris: Librairie Delegrave, 1920). ${ }^{2}$ Most of the regional song collections cited by Trend, although based on traditional material, comprised arrangements for voice and piano.

Eduardo López-Chavarri's Música popular española (Barcelona, 1927), which appeared six years later, contains a bibliography of only 78 items. Concerning this work, one must concur with the judgment of R. Díaz Gómez and V. Galbis López, who wrote:

Aquí es de resaltar su intento de sistematización tan temprano en un campo bibliográfico que no era abundante ni excesivamente científico. En primer lugar, se ocupa de definir el término "canción popular" y de ofrecer sus características y evolución histórica en España. De gran interés son los capítulos finales en los que analiza las posibilidades de evolución del patrimonio cultural folclórico, reflejando el pensamiento nacionalista aprendido de Pedrell. En esta última parte también destaca su estudio de los principales instrumentos y formas de la música popular en España ( $D M E H$, vol. VI, p. $1,045)$.

1. The first two volumes deal with traditional music. Vol. I treats "El canto popular en la vida doméstica," and vol. II, "El canto popular en la vida pública." For a critical overview of Pedrell's studies of traditional music, see J. Martí i Pérez (199192), 211-29.

2. Pp. 1912-2350 and 3353-400, respectively. A Castilian translation of Mitjana's essay, prepared by Antonio Álvarez Cañibano, was published by the Centro de Documentación Musical, under the imprint of the Instituto Nacional de las Artes Escénicas y la Música, Ministerio de Cultura (Madrid, 1993), replete with numerous indices. Although Mitjana dealt primarily with the sacred and secular musical currents from Visigothic times up through the the nineteenth century, he touched upon traditional music throughout his magnificent study. 
Inasmuch as López-Chavarri's contribution gained instant recognition for its emphasis on popular and folk traditions, it appears to have followed the presentation of Mitjana's essay in its historical progression. In its last three chapters, devoted to the nineteenth and twentieth centuries, the roles of traditional vocal, dance, and instrumental music are discussed within Spanish rural life. Moreover, its bibliographic citations did not exceed those of Trend, Pedrell, Mitjana, or Laparra. However, mention was made of institutions that were actively engaged in preserving traditional music.

Among López-Chavarri's predecessors, Pedrell (1841-1922), the eminent musicologist and composer who spearheaded the cause of musical nationalism, became, in fact, the father of modern Spanish musicology. Pedrell's Cancionero, being the last of his great contributions, was, in effect, a life-long project. Among the 171 songs he registered in the first volume were twenty that he recalled from his youth, one of which he obtained from his mother. These, together with the 154 songs in the second volume, were either communicated to him or copied from various regional cancioneros. ${ }^{3}$ Mitjana (1869-1921), a Spanish composer and musicologist who, like López-Chavarri, counted among Pedrell's renowned disciples, devoted the last twelve years of his life to musicological research, focusing particularly on subjects pertaining to the Spanish Renaissance and Golden Age. And, Laparra (1876-1943), a French composer, who drew his thematic material from both Spanish and Basque folk music, did so primarily from published sources. Inasmuch as the latter two figures displayed keen interest in Spain's traditional music, they were ill-equipped to experience its study at first hand. In contrast, the Valencian-born López-Chavarri (1871-1970), who enjoyed a long and vibrant career as composer, journalist, music critic, and musicologist, had actually collected some two hundred specimens of folksongs and dances in the provinces of Valencia and Alicante, but, oddly enough, the whereabouts of his presumed unedited "Cancionero de Valencia" was never fully substantiated. Yet, owing to his wide knowledge of the traditional music throughout his native region, he was invited to participate in several missions of the Cançoner Popular de Catalunya.

It would be foolhardy to neglect the names of other prominent figures in Spain who had concurrently collected and studied traditional music, even though their contributions were primarily regional. Here we should mention the folklorists and writers Antonio Machado y Álvarez (Demófilo) and Francisco Rodríguez Marín (representing Andalucía); Miguel Aranaudos Larrodé (Aragón); Aurelio de Llano Roza de Ampudia and Eduardo M. Torner (Asturias); Francesc Camps i Mercadal, Deseado Mercadal Bagur, and Antonio Noguera (Balearic Islands); Gonzalo Castrillo Hernández,

3. Among his contributors were such notables as Higinio Anglés (Tarragona), Pedro Pablo Bertrán y Bros (Cataluña), José Inzenga (León), Ramón Menéndez Pidal (Asturias and Soria), Antonio Noguera (Mallorca), Nemesio Otaño (Asturias and Santander), Antonio Pont (Mallorca), Juan Pujol [sic Puyol] Alonso (León), José María Sbarbi (Andalucía), and Luis Villalba (Zamora). Eleven tunes were conbritubed by a woman from Sevilla, known only as Doña T.B. The sources from which he copied examples were those of Manuel Milà y Fontanals (Cataluña), Eduardo Ocón and Francisco Rodríguez Marín (Andalucía), and Casto Sampedro y Folgar (Galicia). Additional examples were taken from the 13th-century Cantigas de Santa Maria (4 items) and from Francisco de Salinas's De musica libri septem (Salamanca 1577) (28 items). An in-depth study of the first two volumes of Pedrell, would make an excellent contribution, i.e., tracing the sources of the examples he cited and comparing them with the originals. A comparison of his rhythmically altered example of the nana (vol. I, ex. 2) with the original given in Francisco Rodríguez Marin's Cantos populares españoles (Sevilla, 1882-83), vol. V, "Melodías," no. 3 suggests further inquery into Pedrell's Cancionero. Such a study should also examime the piano accompaniments he provided for both the Cantigas de Santa Marîa and Salinas's examples in terms of his experimental harmonizations. 
Manuel Fernández Nuñez, Dámaso Ledesma, Federico Olmeda, and Rogelio Villar (Castile and León); Francisco Alió, Joan Amades, Francesc Baldelló, Pau Bertrán y Bros, Eusebio Bosch Humet, Francesch Pelay Briz, Aureli Capmany, Joan Llongueres, Lluis Millet, and Francesc Pujol (Cataluña); Marcial del Adalid Gurrea, Santiago Tafall y Abad, and José María Varela y Silvari (Galicia); Rafael Calleja y Gómez, and Nemesio Otaño (Santander); Telesforo de Aranzadi, Resurrección María de Azkue, José Antonio de Donostia, Francisco Gascue, José Manterola, and J.D. J. Salaberry de Mauleón (Vascongadas); and the much-cited song and dance collections of José Inzenga, Lázaro Núñez Robres, and Eduardo Ocón y Rivas. One should also include the eminent Galician composer, pianist, and musicologist José María Varela y Silvari (1848-1926), whose earlier survey of Spain's traditional music proved to be nothing more than limited and superficial in its presentation. ${ }^{4}$

Among these early musical folklorists, it was Eduardo Martínez Torner (1881-1955) who had emerged as a prominent national figure. His pathfinding Cancionero musical de la lírica popular asturiana (Madrid, 1920), cited as the sole contribution from Asturias in both Trend's and LópezChavarri's bibliography, was the first of its kind to study the material from a musical rather than textual standpoint. Torner not only classified and analyzed its 500 melodies and rhythms, he also delineated their musical characteristics in order to describe, with greater validity, traditional Asturian folksong. ${ }^{5}$

Torner began his musical studies in Oviedo and later at the Real Conservatorio de la Música (Madrid), where he concentrated on piano and composition. He returned to Asturias in 1910 to collect and investigate its traditional music. Influenced by Julian Tiersot's writings on French folk music and desirous of seeking further guidance in composition, he left for Paris, in 1912, to enroll at the Schola Cantorum, where he became a disciple of Vincent D'Indy. In Paris he also attended Tiersot's lectures at the École des Hautes Études Social.

At the outbreak of the First World War (late summer 1914) he returned to Oviedo, where he launched his initial lecture-concerts and, thereafter, in other cultural centers throughout Spain which earned him national recognition. Upon his return to Madrid, in 1916, he gained admittance to the Residencia de Estudiantes, where he actively partook in its cultural and intellectual activities. ${ }^{6}$ Concurrently, under a grant from the Diputación de Oviedo, he undertook archival researches on Spanish and foreign cancioneros at various Spanish libraries, and became involved with the Romancero at the Sección de Filología of the Centro de Estudios Históricos (Madrid), at the invitation of Ramón Menéndez Pidal. ${ }^{7}$ That summer he obtained a stipend from the Junta de Ampliación de

4. La música popular española. Estudio crítico acerca de los cantos, bailes e instrumentos populares usados en todas las provincias y pueblos de España. Mondoñedo: Imp. de Hermenegildo Mancebo, 1883.

5. An abridged version entitled "Característica de la música popular asturiana" of pp. xlvii-liv from the Cancionero was published as a brief notice in España, 6/25 (Madrid, 1920), 11-12.

6. In 1924, he dedicated to his "antiguos compañeros" at the Residencia his Cuarenta Canciones españolas (Madrid: Residencia de Estudiantes, 1924), comprising songs which were selected by the students from among the many they sang during their classes and veladas. The collection constituted specific genres emanating from nine regions in Spain, the principal purpose of which was "procurar a nuestros escolares, a quienes va dirigido, un sano goce espiritual e inciciarles en el alto interés artístico que ofrece la tradición musical de nuestro país" (p. xiv).

7. Torner's association with the Centro de Estudios Históricos is well documented in D. Catalán's magnificent two-volume study (2001), passim. 
Estudios to collect ballads in León and Asturias. ${ }^{8}$ And, in the following year (1917) he was awarded an additional stipend to collect ballads and lyrical songs throughout the northern region of Aragón.

Apart from his first publication, La copla, published in 1910, and on-going researches, lecture-concerts, and preparation of the aforementioned Cancionero musical de la lirica popular de Asturias, his activities at the Centro absorbed much of his time during the remaining years of the second decade. At its close, in 1919, he collaborated with Tomás Navarro Tomás in the creation of the Archivo de la Palabra y de la Canción Popular.

Through his close collaboration with Menéndez Pidal, he was named, in 1928, Chief of the Sección de Folklore and, simultaneously, Director of the Archivo de la Palabra, for which he amassed some 2,000 recordings during his continued stewardship. His early archival and Romancero researches yielded the short study Colección de vihuelistas españoles del siglo XVI; estudio y transcripción de las ediciones originales: Narváez, "El Delphin de Música, 1538" (Madrid, 1923), and two short articles "Indicaciones prácticas para la notación de los romances," RFE, X (1923), 38994 and "Ensayo de clasificación de la melodías de romances," in the Homenaje ofrecido a Ramón Menéndez Pidal (Madrid, 1925), vol. II, pp. 391-402. An unedited manuscript Del folklore asturiano (dated 1923) was published much later in J.L. Pérez's edition, Los estudios de folklore en Asturias (Gijon, 1983).

In 1928, Jesús Bal y Gay (1905-1993) became Torner's assistant at the Centro, and in the summer of that year both undertook fieldwork in Galicia. The work continued for four successive summers, yielding a harvest of over 1,200 songs. ${ }^{9}$ In October, Torner's "Bibliographie du folklore musical espagnol" appeared as a short communication in the Actas of the Prémier Congrès des Arts Populaires (Prague, 1938) (see Torner 1930). Comprising 97 citations, it was, nonetheless, his first bibliographic venture. In his brief prefatory remarks, he explained that:

En Espagne, et même hors d'Espagne, on a beaucoup écrit sur ce sujet. Nous présentons notre bibliographie comme un preuve satisfaisante de l'intérêt que nous portons à la musique populaire. items].

Cette bibliographie, assez abrégée, est divisée en deux parts: Théorie [39 items] et Collections [58

This initial bibliography would have been greatly augmented had he added the citations from each of the works he quoted. Although Torner included López-Chavarri's study, he duplicated only five of its citations. Be that as it may, this small contribution contained many items that were not mentioned in any of the aforementioned publications.

Still, Torner proved himself an indefatigable worker, combining all his creative and intellectual talents as collector, lecturer, composer, performer, and choral conductor. With his ongoing involvement in each of these activities, he managed to contribute a brilliant five-part study on traditional Spanish song for Francisco Carreras y Candi's edition, Folklore y Costumbres de Espa-

8. For an overview of Torner's fieldwork in Asturias, see J. A. Cid (1993).

9 . It was not until 1973 that the Cancionero gallego was published by the Fundación Barrié de la Maza through the efforts of José Filgueira Valverde, who contributed its "Prólogo." 
$\tilde{n} a^{10}$ which comprised 1) an introduction, followed by a study of the traditional genres from 2) Andalucía, 3) Galicia, Vascongadas, and Cataluña, 4) Castilla, and 5) Aragón. In each he discussed their musical characteristics and provided ample musical examples, together with accompanying illustrative material.

Further accomplishments at the end of the second and beginning of the third decades, included the premiers of his zarzuelas, La promesa (Madrid, May 1928) and La Maragata (Madrid, March 1931). In the summer of 1930, he accompanied Kurt Schindler at various locations in the provinces of Soria and Logroño, where Schindler was engaged in collecting traditional folksongs and ballads. ${ }^{11}$ In 1932, he was connected with both the Misiones Pedagógicas and the Conservatorio Nacional de Música, serving as Cátedra de Prácticas de Folklore at the latter institution. In 1933, again in collaboration with Bal y Gay, their "Folklore musical" in Terra de Melide (Santiago de Compostela) was published. It contained 36 traditional tunes.

In 1935 there appeared two additional works. The first, written for the Misiones Pedagógicas, where he directed its choruses, was his Metodología del canto y la música (Madrid: Revista de Pedagogía) which includes his earlier transcriptions of selected songs from sixteenth- and seventeenth-century cancioneros. The second and more important Temas folklóricos: Música y poesía (Madrid: Faustino Fuentes) contains eight short articles and two bibliographies which resulted from his researches at the Centro de Estudios. ${ }^{12}$ It is the latter that deserves special attention, particularly for its bibliographies which Torner published under the headings "Fuentes para la investigación" and "Danzas y bailes." This work has for long been out of print and is practically inaccessible outside of Spain.

In the opening paragraphs to "Fuentes," Torner wrote:

El siguiente índice representa el estado actual de la investigación española referente a folklore musical. No es necesario señalar su exigüidad en contraste con la abundancia de obras que sobre esta materia presentan, respectivamente, los demás países de Europa, donde no sólo se investiga el propio folklore, sino que, en no pocos casos, el investigador traspasa las fronteras nacionales en busca de tema interesante. A este respecto, puede decirse que España es país favorecido, obedeciendo sin duda al extraordinario interés que para la cultura moderna ofrece el carácter particular de nuestra música folklórica.

Incluyo en esta lista algunas obras de autores extranjeros, no en demostración de lo antes indicado, sino para favorecer a quien desee tener reunidos los principales trabajos de investigación sobre nuestra música popular. Y digo principales porque de intento excluyo aquí todas las publicaciones de menor importancia; éstas tienen cabida en la Bibliografía del Folklore musical español que preparo

10. The edition was published by Alberto Martín (Barcelona) in 1931. Torner's 159-page essay (pp. 7-166) was included in its second volume.

11. Again in August of 1932, he accompanied Schindler in other locations. See I.J. Katz (1991b:39, and notes 53 and 54).

12. These include "Una romería en Galicia" (pp. 9-17), "Los vihuelistas del siglo XVI" (pp. 21-31), "El cancionero asturiano" (pp. 35-47), "El cancionero sefardî" (pp. 51-58). "Surgencia" (concerning the romance "Mira Nero, de Tarpeya" and its connection with La Celestina) (pp. 61-68), "Góngora y el folklore" (pp. 71-83), "Fuentes para la investigación" (pp. 87-114), "Indicación práctica" (published previously in RFE, X [1923], 389-294) (pp. 117-125), "Ritmos" (discusses "la presencia en nuestro folklore musical de algunos ritmos que, por su reiteración, pueden considerarse como algo establecido tradicionalmente con carácter de fijeza") (pp. 129-41), and "Danzas y bailes" (pp. 145-53). See the review by A. Salazar (1935). 
y que forma un capítulo de la Musicología española, obra de gran extensión, en la que procuro agotar el índice bibliográfico de la investigación española de todos los tiempos y en todos los aspectos de la música, tanto popular como artística. ${ }^{13}$

Agrupo primeramente los trabajos de carácter general; después, como temas concretos, las investigaciones referentes a los antiguos dramas líricos, a los cantos de la Sibila y Ultreya y a las Cántigas de Alfonso el Sabio; sigue luego la bibliografîa regional, incluyendo en la de Galicia las Canciones de amor de Martín Códax, del siglo XIII, y, por último, en grupo aparte, la que trata de los instrumentos músicos.

Here, Torner established his contextual guidelines for the citations that followed. Although his projected Bibliografia would have represented, more convincingly, the then current state of research in traditional music, "Fuentes" should have reflected a "selective, yet tentative listing," which more aptly describes it. Still, unlike the second bibliography "Danzas y bailes," wherein the citations are categorized by region, Torner's haphazard divisions in "Fuentes" are most awkward. Therefore in my revised version of "Fuentes" and the section on "Organología" (concerning musical instruments) ${ }^{14} \mathrm{I}$ listed each citation by author, in alphabetical order. For "Danzas y bailes," I maintained Torner's regional divisions, with slight alterations, including his original introduction.

Following Torner's bibliography, I have provided four indices: 1) Abreviaciones (which includes the publications-proceedings, journals, and periodicals - that are cited throughout); 2) Onomástico (which includes not only the authors, but also others mentioned in each citation); 3 ) Toponímico (the geographic listing of regions, provinces, cities, towns, and villages mentioned in their respective citations); and 4) Materias (the subject matter discussed throughout). A perusal of the third and fourth indices will instantly reveal the breadth and scope of Torner's citations. I have enclosed in brackets Torner's comments, which, in their majority, are informative. I have also enclosed in brackets, preceded by an asterisk (*), my personal comments, description or observations concerning the content of specific items, adding, where appropriate, bibliographical citations which pertain to their respective subjects.

Like the citations in Trend's earlier bibliography, Torner's are, for the most part, incomplete, and even inaccurate. In particular, names of publishers, year of publication, pagination, and even the full names of authors were either lacking or, in various places, misspelled. All my corrections and additions to Torner's entries are given in bold characters. In addition, many of Torner's citations that

13. According to Homero Serís (1954:545), Torner's intended Bibliografía, comprising some 4,000 entries, had been scheduled for publication the following year by the Centro. However, the Civil war intervened and, mysteriously, the original card files, which Torner sent to Barcelona for safekeeping, were never recovered.

14. In the section "Organología," one will find references to manuscripts in the Biblioteca Nacional (Madrid), particularly for items 194, 196, 199, 203-04, and 216, as well as for an earlier reference (no. 101) to Misterios in the Valencian dialect. The distinguished composer and musicologist F.A. Barbieri discussed these and other manuscripts (and documents) in his massive collection of notes and papers, distributed in 135 files (carpetas) which he bequeathed to the Biblioteca Nacional in 1899. We are most fortunate that E. Casares supervised and edited the publication of the entire Barbieri legacy. See especially Barbieri's notes on organology (Casares (1986:I, pp. 217-45). José Subirá called attention to the Barbieri legacy in his article "El deber del musicólogo," Boletín Musical, III, no. 24 (Córdoba, 1930), 9-11. Moreover, it should be noted that Torner undertook a preliminary listing of Barbieri's files (up through no. 85) at the Biblioteca in an astoundingly neglected article "Musicología española," published in Vida Musical, I, nos. 1 and 3 (Madrid, 1923), 2-4 and 4-5, resp. The article was to be continued, but I was not able to locate it. It appears that the journal did not survive beyond 1923. 
were duplicated in the earlier bibliographies of H. Collet (1913), J.B. Trend (1921), E. LopézChavarri (1927), and E.M. Torner (1931), as well as in the subsequent bibliographies of Bal y Gay (1939), H. Serís (1948-1954), J. Crivillé Bargalló (1983); and E. Rey García (1994 and 2001), I have indicated in parentheses, following their respective entries. Moreover, I was particularly surprised to find that, in their majority, they were copied verbatim. Still, I found E. Rey Garcia's excellent and most recent bibliographic citations to be exceptional in their expanded coverage and presentation.

During my attempts to verify each of Torner's citations, I encountered several problems. Those citations preceded by an asterisk (*) could not be located in any of the libraries scattered throughout Madrid, nor via e-mail communication with librarians and reference personnel in numerous regional and academic libraries throughout Spain, nor through foreign and American libraries via the internet. Inasmuch as every item cited in Torner's bibliography was published prior to the Spanish Civil War, four (nos. 2, 131, 258, and 263) could not be located. And, like the unconfirmed citations mentioned by Henry George Farmer's in his article "'Ghosts': An Excursis on Arabic Music Bibliographies," Isis, XXXVI (1945-46), 123-30, I came across three (nos. 35, 83, 115) which were not questioned in other bibliographies. Repeated requests to French libraries could not yield information concerning the item in Larousse Mensuel (no. 135). However, the existence of F. Echevarría's Cantos y bailes de Valencia (Valencia. 1912) (no. 264), which lingered for long in the latter ('ghost') category, has now been verified. It was E. Rey Garcîa (1994:no. 450) who called attention to Antonio Gallego's comments concerning that work. ${ }^{15}$

In all, this was among Torner's important contributions to the early history of Spanish ethnomusicology. For whatever its faults, it was but a step forward toward creating interest in Spain's national and traditional music. What transpired after this and his subsequent meritorious works has been well documented. Still an understanding of Torner's life and works deserves greater clarity and depth. ${ }^{16}$. His place in Spanish music history is indeed central.

\section{References cited}

(B) Bal y Gay, Jesús. 1939. «Espagne», Folklore Musical . Répertoire international des collections et centres de documentation avec notices sur l'état actuel des recherches dans les différents pays et réferences bibliographiques (Paris: Département d'Art, d'Archéologie et d'Ethnologie, Institut
International de Cooperation Intellectuelle), pp. 64-84 (286 items).

Casares Rodicio, Emilio, ed. 1986. Francisco Asenjo Barbieri. Biografías y Documentos sobre música y músicos españoles (Legado Barbieri) . Madrid: Fundación Banco Exterior. 2 vols.

15. Gallego (1990:5) wrote: "Porque la serie de Cantos y bailes de Valencia, en algunos sitios atribuída a "F. Echevarría" y supuestamente publicada en Valencia hacia 1921 [sic 1912, according to Torner], sospecho muy fundamentadamente que no debe ser más que, en todo caso, una nueva tirada del libro de Inzenga, aunque sin la portada general de la serie." By shear luck, I was able to trace the manuscript to the library of the Residencia de Estudiantes (Madrid), whose contents were revealed to me by e-mail.

16. Concerning Torner's life and works, the following sources are recommended: J.A. Gómez Rodríguez (1999), M. González Cobas (2000), M.L. Mallo de Campo (1980 and 1984), A. Muños Toca (1961), and H. Serís (1966). I drew upon these works for my entry on Torner in Groves (2000). 
Catalán, Diego. 2001. El Archivo del Romancero: Patrimonio de la humanidad. Historia documental de un siglo de historia. Madrid: Fundación Ramón Menéndez Pidal, Seminario Menéndez Pidal, Universidad Complutense de Madrid. 2 vols.

Cid, Jesús Antonio. 1993. «El Romancero oral en Asturias. Materiales de Josefina Sela y E. Martínez Torner: Inventario, índices, antología», Revista de Dialectología y Tradiciones Populares, XLVIII (Madrid), 172-245.

(C) Collet, Henri. 1913. «Bibliographie», Le Mysticisme musical espagnol au XVIe siècle. Paris: Félix Alcan (345 items from parte B.-Ouvrages de seconde main, 215 of which deal with musical subjects)

(Cr) Crivillé y Bargalló, Josep. 1983. El foklore musical. Madrid: Alianza Música. (Historia de la Música Española, nº 7) (135 traditional items, + 27 concerning flamenco, and 17 pertaining to organology)

Díaz Gómez, Rafael, and Vicent Galbis López. 2000. «López-Chavarri Marco, Eduardo», DMEH. vol. VI (Madrid), pp. 1043-048.

$D M E H=$ Casares Rodicio, Emilio, José López-Calo, and Ismael Fernández de la Cuesta, eds. Diccionario de la Música Española e Hispanoamericana (Madrid: Sociedad General de Autores y Editores, 1999-2003). 10 vols.

Gallego, Antonio. 1990.«Prólogo», in Salvador Seguí, et al., eds., Cancionero musical de la provincia de Castellón (Valencia: Caja de Valencia, Fundación Caja Segorbe), pp. 5-6.

Gómez Rodríguez, J.A. 1989. «La España de plata de Eduardo Martínez Torner (1888-1955)», Cuadernos de Música y Teatro, $\mathrm{n}^{\circ} 3$ (Madrid), 58-72.

González Cobas, Modesto. 2000. «Martínez Torner, Eduardo Fernando», DMEH, vol. VII (Madrid), pp. 307-10.

Katz, Israel J. 1991a. «J. B. Trend's Little-Known Bibliographical Contribution to the Study of Spain's Traditional Folk Music», Anuario Musical, XLVI (Barcelona), 345-88.

-. 1991b. «Kurt Schindler: la aventura indivudual y colectiva de un cancionero," in Israel J. Katz and Miguel Manzano Alonso, eds. Kurt Schindler: Música y poesía de España y Portugal . Facsimile ed. (Salamanca: Centro de Cultura Traditional,
Diputación / New York: Hispanic Institute, Columbia University), pp. 11-43. (Cuadernos de Notas, no. 3)

-. 2001. «Torner, Eduardo M(artínez)», in Stanely Sadie, ed. The New Revised Grove Dictionary of Music and Musicians (London: Macmillan), vol. XXV, pp. 624-25.

(L-C) López-Chavarri, Eduardo. 1927. «Bibliografía», Música popular española (Barcelona: Labor), pp. 147-50 (79 items, 64 of which pertain to music and dance).

Mallo del Campo, María Luisa. 1980. Torner más allá del folklore. Oviedo: Universidad de Oviedo, Departamento de Arte-Musicología.

- 1984. «Torner y el nuevo planteamiento científico del folklore en España», Revista Internacional de Sociología, XLII/51 (Madrid, 1984), 669-73.

Martí i Pérez, Josep. 1991-92. «Felipe Pedrell i l'etnomusicología», Recerca Musicològica, XI-XII (Barcelona), 211-29.

Muños Toca, Ángel. 1961. Vida y obra de Eudardo M. Torner. Oviedo: Instituto de Estudios Asturianos.

Quijera, José Antonio. 1993. «La gizon dantza de Gipuzkoa», in Javier Sánchez Tabernero, coord., Bailes de Rueda. II Muestra de Música Tradicional «Joaquín Díaz» (Viana de Cega, 28 y 29 de agosto de 1993), pp. 49-59.

(R) Rey García, Emilio. 1994. Bibliografía de folklore musical español. Madrid: Sociedad Española de Musicología. (Catálogos y Documentación, $\mathrm{n}^{\circ}$ 6) (1.526 items)

(R') - 2001. Los libros de música tradicional en España. Madrid: Asociación Española de Documentación Musical. (Colección de Monografías, $\mathrm{n}^{\circ}$ 5) (504 items)

Salazar, Adolfo. 1935. «Torner y sus estudios folklóricos», El Sol (Madrid, 11 Dec.).

Sampedro y Folgar, Casto. 1942. Cancionero musical de Galicia: colección de la Sociedad Arqueológica de Pontevedra, Reconstitución, introducción y notas bibliográficas por José Filgueira Valverde. Madrid: El Museo de Pontevedra. Facsimile ed. La Coruña: Fundación Pedro Barrié de la Maza, Conde de Fenosa, 1982.

Schindler, Kurt, Blas Taracena, and José Tudela. 1930. Cancionero de Soria. Deposited at the Caja de Ahorros y Prestamos de Soria. 
(S) Serís, Homero.1948-1954. Manual de bibliografía de la literatura española. Syracuse, New York: Centro de Estudios Hispánicos, Syracuse University, 1948-1954. 2 vols.

—. 1966. "Prólogo," in Eduardo M. Torner, Lírica hispánica. Relaciones entre lo popular y lo culto. (Madrid: Edit. Castalia), pp. 7-11.

(To) Torner, Eduardo Martínez. 1930. «Bibliographie du folklore musical espagnol», Art Populaire. Travaux artistiques et scientifiques du ler Congrès International des Arts Populaires, Prague 1928 (Paris: Institut International de Cooperation Intellectuelle / Éditions Ducharte), vol. II, pp. 159-61 (768 items).

1. Abd al-Wahhâb [Abdu-l-Wahab], Hasan Husnî. "Le Développement de la musique arabe en Orient, Espagne et Tunisie," Revue Tunisienne, XXV (1918), 106-17. [*Reimp. en Revue al-Fikr, IV/9 (1959), 816-22.] (B, S)

*2. Abellán, Antonio María. "Los populares coros de la Aurora," Cullera, núms. 35-36 (Marzoabril, 1931), ?? [Torner: Estudio sobre esta tradición musical en Jumilla (Murcia).] (B, R, S)

3. Adalid Gurrea, Marcial del. Cantares viejos y nuevos de Galicia: colección de melodías para canto y piano. Madrid: Pablo Martín, 1877 - ca. 1902. Tres series $(15,15,15$ pp.). Series cuarta. La Coruña: Canuto Berea, c. 1902. 22 pp. [24 canciones para canto y piano). [ ${ }^{*} \mathrm{C}$. Sampedro y Folgar 1942:55: Forma, con las colecciones de Hernández e Inzenga, el grupo de las primeras ediciones de música popular gallega.] [*Nueva edición dirigida por Margarita Soto Viso. Marcial del Adalid. Mélodies pour chant et piano. Cantares viejos y nuevos de Galicia (La Coruña: Fund. Pedro Barrié de la Maza, Conde de Fenosa, 1985), pp. 323-411.] [*E. Rey García 1994: núm. 8: Los 13 cantares nuevos son obra de Adalid con textos de su esposa, Fanny Garrido. Los 11 cantares viejas son populares gallegos.] (B, R, R', S, To)

4. Aguilar, Emanuel Abraham, comp. The Ancient Melodies of the Liturgy of the Spanish and Portuguese Jews. Harmonized by Emanuel Aguilar. Preceded by "An Historical Essay on the Poets,
—. 1931. «La canción tradicional española», en Francisco Carreras y Candi, ed., Folklore y costumbres de España (Barcelona: Alberto Martín), vol. II, pp. 7-166.

—. 1935a. «Fuentes para la investigación», Temas folkloricos: Música y Poesía. (Madrid: Faustino Fuentes), pp. 87-114.

—. 1935b. «Danzas y bailes», Idem., pp. 145-53.

(T) Trend, J[ohn] B[rande]. 1921. «Bibliographical Guide to Secular Spanish Music», A Picture of Modern Spain: Men and Music (London: Constable \& Co.), pp. 201-12 (214 items).

Poetry and Melodies of the Sephardic Liturgy" (pp. 1-7) by the Rev. D[avid] A[aron] de Sola. Londres: Wessel and Co., 1857. ii, 23 pp. + iv + 26 pp. (música). [*Véase la edición más adelante por Elias Jessurun, Sephardi Melodies of the Liturgy. Londres: Bevis Marks/Oxford Univ. Press, 1931; E.A. Aguilar, Sephardic Melodies, being the Traditional Liturgical Chants of the Spanish and Portuguese Jew's Congregation. Londres: Oxford Univ. Press, 1931; y la grabación hecha por John Levy, Music of the Spanish and Portuguese Synagogue. Nueva York: Folkways Records and Service Corp. Record Album no. FR8961, 1960. Véase también la entrada sobre Aguilar por Ramón Sobrino en el DMEH (1999), vol. I, pp. 110-11.] (B, C, S)

5. Aguilar y Tejera, Agustín. Saetas populares recogidas, ordenadas y anotadas por... Transcripciones musicales de Francisco Moral León, José Rodríguez Guisado y J. Rivas Gómez. Madrid: Ibero-Americana, 1928. xxvi, 263 pp. ["Música" (pp. 251-59). *Reimp. con introducción por Rafael López Fernández. Sevilla: Portada, 1998. 303 pp.] (B, R', S)

6. Anglés, Higinio. Les «Cántigas» del rei N'Anfós el Savi. Amb la versió catalana del Dr. Josep Ma. Llovera. Barcelona: Imp. d'E. Subirana, 1927. 64 pp. [Reimp. de Vida Cristiana, XIV (1927).] [Torner: Son doce cantigas sobre las fiestas del año más una de loor, con traducción literaria al catalán 
en el mismo metro del original. Transcribe Anglés las melodías razonando su sistema y expone los motivos por los que rechaza el de Ribera.] (B)

7. Anónimo. "Corpus Christi," El Noticiero Sevillano, III/805 (13 de junio de, 1895), 2.

8. Aranzadi Unamuno, Telesforo de. A propósito de algunos 5/8 lapones y castellanos. Buscapié de zortzicos y ruedas. París: Champion, 1910. 16 pp. [Torner: Es un curioso estudio sobre este compás fuera de las Vascongadas.] (B, R)

9. - . "Sobre el origen del 5 por 8 ," RIEB, V/2 (1911), 270-75, plus "A propósito de los 5 por 8 castellanos," 276-81.. (B, R)

10. Arco Garay, Ricardo del. "Misterios, autos sacramentales y otras fiestas en la Catedral de Huesca

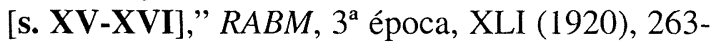
74. (B, S, T)

11. Argain. "Del canto popular religioso del país vasco," MSH, XI/1 (1918), 4-8. (B, R, S)

12. Arnaudas Larrodé, Miguel. Colección de cantos populares de la provincia de Teruel. Prologada (pp. v-xii) por José Artero [firmada Salamanca, abril de 1922]. Zaragoza: Lit. Marín, 1927. xii, 308 pp. (comprende 266 melodías). [*Contiene cantos de los partidos de Teruel (pp. 29-38); Albarracín (pp. 39-49); Alcañiz (pp. 71-132); Calamocha (pp. 146-59): Castellote (pp. 160-77); Hijar (pp. 178-92); Montalbán (pp. 193-209); Mora de Rubielos (pp. 210-34); Valderrobres (pp. 235-60), plus Fantasía para piano sobre cantos populares de la Provincia de Teruel por Miguel Arnaudas (pp. 263-300).] [*Reimp. Teruel: Inst. de Estudios Turolenses de la Excma. DP, Adscrito al CSIC, 1982. Con prólogo de Jesús María Muneta.] (B, Cr, R, R', S, To)

13. Arxiu de tradicions populars. Recollides a Catalunya, València, Mallorca, Roselló, Sardenya, Andora, i Terres Aragoneses de parla catalana. Valerio Serra y Boldú, director. Pròleg de Josefina Roma. Barcelona: Imp. de la Casa Provincial de Ciutat, 1928-1932). 6 cuadernos. [ ${ }^{*} 3^{a}$ ed. Barcelona: José J. de Olañeta, 1986. 7 vols.] [Torner: Contienen buen número de melodías populares a las que acompañan notas y pequeños estudios de la costumbre tradicional en que se ejecutan.] $(\mathbf{B}, \mathbf{S})$

Asenjo Barbieri, Francisco (véase Barbieri, Francisco Asenjo)

Anuario Musical, 59 (2004)
14. Azkue Aberasturi, Resurreción María de. Cancionero popular vasco. Barcelona: A. Boileau \& Bernasconi, 1922-1925. 11 vols. [I. Canciones amorosas (1922; 138 pp.); II. a) Canciones báquicas, b) Canciones cuneras (1923; 74, 43 pp.); III. Danzas (1923; 109 pp.); IV. Danzas sin palabras (1923; 100 pp.); V. Endechas y elegías (1923; 94 pp.); VI. a) Epitalamios, b) Canciones infantiles (1924; 93 pp.); VII. Canciones festivas (1924; 80 pp.); VIII. Canciones narrativas (1924; 81 pp.); IX. a) Canciones de oficio, b) Canciones religiosas (1925; 106 pp.); X. Romances y cuentos (1925; 149 pp.); XI. Canciones de ronda (1925; 90 pp.) + índices $(60 \mathrm{pp})+$. Notas al cancionero (59 pp.) [*Reimp. en 2 vols. con prologue por José Antonio Arana Martija. Bilbao: Euskaltzaindia, 1990] [Torner: Once cuadernos con más de 800 melodías. A cada cuaderno acompaña una introduccíón literaria acerca del carácter de las canciones.] (B, Cr, R, R', S, To)

15. - La música popular vascongada. Conferencia dada en los salones de la Sociedad «Centro Vasco» el día 15 de febrero de 1901 por el Presbítero Dr. D... Bilbao: Imp. y Litog. de Gregorio Astoreca, 1901. 16 + 40 pp., con 14 ejemplos armonizados. $(\mathbf{B}, \mathbf{R}, \mathrm{S}, \mathrm{To})$

16. Baixauli y Biguer, Mariano. "Las obras musicales de San Francisco de Borja conservados en la insigne colegial de Gandía," $R y F$, IV (Septiembre, 1902), 154-70 (con 8 ejemplos musicales); IV (Noviembre, 1902), 273-83. [*Borja (Borgia], Virrey de Barcelona y Duque de Gandía, era un músico consumado.] [Torner: En este trabajo estudia su autor un drama litúrgico cantado que se ejecutaba el jueves y viernes de la Semana Santa, en los siglos XV y XVI, en el convento de Religiosas Clarisas de Játiva, cuya partitura se cree que fue retocada en el siglo XVI por San Francisco de Borja.] (B, C, T)

17. Balaguer y Cirera, Victor. Breves noticias acerca de un drama lírico del siglo XIII (Tragedia de Santa Inés). Apuntes escritos para la Real Academia de la Historia y leídos ante la misma en la sesión del día 24 de enero de 1879. Madrid: Est. de Aribau, 1879. 27 pp. (B, S)

18. Baldelló Benosa, Francesc de Paula. Cançoner popular religiós de Catalunya. Recull de cent melodies de goigs. Barcelona: Boileau \& Bernas- 
coni, 1932. 348 pp. [Torner: Con un prólogo en que se traza la historia de este canto popular.] (B, $\mathrm{Cr}, \mathbf{R}, \mathbf{R}, \mathbf{S}, \mathbf{T})$

19. Barberá, Josep. "Concomitàncies de la cançó popular catalana amb la d'altres països," $R M C, \mathbf{X X}$ (1923), 236-53. (B, R)

20. Barbieri, Francisco Asenjo. "Sobre el Canto de Ultreja. Réplica al escrito del Señor Flore[s] Laguna," Correspondencia Musical, III/143 (21 de septiembre de 1883), 1-8. ["Informe académico" dada 2 abril de 1883 por la RABASF a la RAH. Madrid: M. Tello, 1883. 14 pp. Reimp. en el $B R A B A S F$, III (1883), 132-43.] [Véase núm. 174.] $(\mathrm{B}, \mathrm{C}, \mathrm{S})$

21. - Cancionero musical de los siglos XV y XVI. Transcrito y comentado por... Madrid: Los Huérfanos, 1890. 636 pp. [*Preliminares (p. 554); Cancionero (pp. 57-230): Partituras (pp. 233602); Apéndices (pp. 605-16); Alcance (pp. 61719); Índices (pp. 622-37)] [*Contiene canciones líricas, estrambotes (frottolas), romances, villancicos omnium sanctorum (de elogio, dialogados, doctrinales) polifónicos.] [Torner: Versiones musical y literaria del Canto de la Sibila que se ejecutaba en la catedral de Toledo en los siglos XV y XVI. Publicadas en un apéndice...] [*Reimp. Málaga: Gráficas Urania, 1987. Con un prólogo "El Cancionero Musical de Palacio o Cancionero Barbieri: Presencia histórica" de Emilio Casares Rodicio (pp. vii-xxvii).] (B, C, L-C, S, T)

22. - . "El canto de la Sibila," IMHA, I/7 (30 de abril de 1888), 50-51. (B, C, S, T)

23. Barra, Eduardo de la. Restauración de «El misterio de los Reyes Magos». La página más antigua del Teatro Español. Santiago de Chile: Roma, 1898. 43 pp. (B)

Barrelet, Mina Lahose (véase Lahose-Barrelet, Mina)

24. Bello, Andrés. "Arte métrica" en Opúsculos gramaticales. Parte cuarta (Madrid: Imp. M. Tello, 1890), pp. 255-384. [Contiene una discusión de la seguidilla (pp. 364-71).]

Benito Fernández, Alonso (véase Fernández Alonso, Benito, núm. 62)

25. Benot Rodríguez, Eduardo. Prosodia castellana y versificación. Madrid: J. Muños Sánchez. 1892. 3 vols. [Contiene una discusión de la seguidilla (vol. III, pp. 338-39).] (S)
26. Bergnes, Pablo (Pau). Estudios críticos sobre las canciones catalanas. Perpiñan: G. Soupiac, 1913. 74 pp. [Aparecido antes en Ruscino, núm. 3 (Perpignan, 1912), 237-54.] (B, R, S)

Bergues, Pablo (véase Bergnes, Pablo)

27. Bertrán Bros, Pau [Pablo]. Cançons y folies populars inèdites recullides al peu de Montserrat. Barcelona: A. Verdaguer, Imp. de F. Giró, 1885. xxii, 325 pp. (B, Cr, R, R', S, T, To)

28. Blasco Medina, Francisco Javier. La música en Valencia. Apuntes históricos. Alicante: Sirvent y Sánchez, 1896. 102 pp. [Música popular (siglo XVI) (pp. 24-32); Música religiosa y la música profana (siglo XIX) (pp. 44-57).] (C, R, T)

29. Briz, Francesch Pelay, y Candi Candi. Cansons de la terra. Cants populars catalans col-lecionats per... Barcelona: E. Ferrando Roca, 1866-77. 5 vols. [Vol. I (Barcelona: E. Ferrando Roca, 1866), xlviii 272 pp. (32 cansons); vol. II (Barcelona: Joan Roca y Bros, 1867) (en colaboración con Joseph Saltó), xx, 257 pp. (32 cansons); vol. III (Barcelona: Alvar Verdaguer, 1871), 275 pp. (34 cansons); vol. IV (Barcelona-París: Alvar Verdaguer-Maissoneuve, 1874), 264 pp. (37 cansons); vol. V (Barcelona-París: Alvar Verdaguer-Maisonneuve, 1877), 304 pp. (38 cansons). [*E. Rey García 1994:núm. 224: Según el P. Luis Villalba, es el primer estudio folklórico serio que se publicó en España. Importante por ser una de las obras pioneras de recopilación de la música popular en Cataluña.] (B, Cr, R, R', S, T, To)

30. Brown, Irving. Deep Song: Adventures with Gypsy Songs and Singers in Andalusia and Other Lands with Original Translations. Nueva York y Londres: Harper \& Brothers Publishers, 1929. xii, 355 pp. [Bibliografía (pp. 330-36).] (B, S)

31. Caba, Carlos y Pedro. Andalucía: su comunismo y su cante jondo (Tentativa de interpretación). Madrid: Biblioteca Atlántico [Imp. Zoia Ascasibar], 1933. 303 pp. [*DMEH (1999) vol. II, p. 820): La obra fue censurada, quedando su título como Andalucía y su cante jondo. Es interesante no solo por su estudio del cante, sino por el análisis sociológico sobre cómo se consideró éste entre los intelectuales de la época, principalmente entre los de la Generación del 98.] (B, S)

32. Calleja y Gómez, Rafael. Cantos de la montaña. Colección de canciones populares de la provincia 
de Santander. Recopiladas y armonizadas por... Precedidas de dos cartas de los maestros Don Ruperto Chapí y Don Tomás Bretón y de diversos artículos y poesías de los Sres... [*Para sus nombres enteros, véase E. Rey García 2001:126]. Madrid: Imp. Asilo de Huérfanos del Sagrado Corazón de Jesús, 1901.90 pp. (179 cantos para canto y piano) [Reimp. Madrid: Ricardo Rodríguez, 1923. 213 pp., con tres melodías adicionales.] (B, Cr, R, R', S, T, To)

33. Camps i Mercadal, Francisco. (pseud. Francesc D'Abranca). Folklore menorquí: De la Pagesía, Mahón: Imp. M. Sintes Rotger, sucesor de B. Fábregues y de M. Parpal, 1918. 2 vols. [*Reimp. Ciutadella: Conseill Insular de Menorca, Entitat Local d'es Migjorn Gran, 1987. 175 pp. Con un prólogo por Francesc Florit Nin.] [Torner: Extensa recopilación literaria con cuatro transcripciones musicales en el vol. II.] (B, R, R' $\mathbf{S}$ )

Las canciones de Puerta Santa... (véase Tafall y Abad, Santiago, núm. 162).

34. Cançoner Popular de Catalunya, Obra del Cançoner Popular de Catalunya. Materials. Barcelona: Imp. Elzeviriana. [Barcelona: Fund. Concepció Rabell i Cibils, Vda. Romaguera, 1926-1929. 3 vols. (564 documentos musicales). Vol. I, fasc. 1 (1926), 96 pp.; fasc. 2 (1928), 97, 484 pp.; vol. II (1928), 460 pp.; vol. III (1929), 492 pp.] [Vol. I: "Memories de missions de recerca, estudis monogràfics, cròniques" (1928), 383 pp.; vol. II: "Memories de missions de recerca, estudis monogràfics, crònica" (1928), 455 pp.; vol. III: "Memories de missions de recerca, crònica" (1929), 487 pp.] [Torner: Van publicados tres volúmenes, los cuales no constituyen aún el cancionero popular de Cataluña propiamente dicho, sino un conjunto de estudios y observaciones preliminares. Representa, desde luego, este Cançoner, el mayor esfuerzo realizado hasta ahora en España para la recogida y estudio del folklore musical.] (B, Cr, R, R', To)

Cantares populares gallegos (véase Demófilo, núm. 50)

«Cante jondo», El (Cante primitivo andaluz) (véase Falla, Manuel de, núm. 61)

34bis. Cants populars segons musica del siglo XIV. Montserrat: PP. Benedictinos. (B, To)

*35. Capmany i Farrés, Aurelio. Pasado y porvenir de la canción popular. (Barcelona, 1920). Conferen- cia. Folleto. [*Hay una versión de más temprano: "Passat i pervenir de la cançó popular," Excursions (1917).] (B, R, S)

36. Carreras y Bulbena, José Rafael. Idea del que foren musicalment els joglars, trobadors i ministrils en terres de parla provençal i catalana. Barcelona: Tip. L'Avenç, 1908. 66 pp. [También en $R M C$, V/52 (1908), 57-62; V/53 (1908), 97-99; V/54 (1908), 111-14; V/56 (1908), 143-47; núm. V/57 (1908), 158-62).] (B, C, L-C, S, T)

37. Castrillo Hernández, Gonzalo. Estudio sobre el canto popular castellano. Prólogo de D. Conrado del Campo. Epílogo de D. Eduardo López-Chavarri. Palencia: Imp. de la Federación CatólicoAgraria, 1925. 137 pp. (B, L-C, R, S, To)

38. - . "Notas bibliográficas para el estudio del canto popular en Castilla la Vieja," Résumés du Congrès International des Arts Populaires, Prague, 1928 (París, 1930), p. 105. [También en Arte Populaire, vol. II, pp. 151-53.] (B, R, S)

39. - . "Modalidad, forma, ritmo y armonía en las canciones típicas de Castilla la Vieja," Ibid., pp. 105-07. [También en Arte Populaire, vol. II, pp. 151-53.] (B, R, S)

40. Cejador y Frauca, Juilio. La verdadera poesía castellana. Floresta de la antigua lírica popular. Madrid: RABM, 1921-1926. 10 vols. [Contiene una discusión de la seguidilla: "Ritmo descendente. Seguidillas" en vol. I, pp. 223-45.] (S)

41. Chabás, Roque. "El drama lírico de la Virgen de Elche (1370)," El Archivo, IV/8 (1890), 203-14. [*Reeditado por José Massot i Montaner en su Teatre medieval $i$ del Renaixement (Barcelona, 1893); reimp. Barcelona:: Edicions 62, 1983.] (B)

42. Chía, Julià de. La música en Gerona. Apuntes históricos sobre la que estuvo en uso en esta ciudad y su comarca desde el año 1380 hasta mediados del siglo XVIII. Gerona: Paciano Torres, 1886. 124 pp. [*Con un Apéndice/Memoria titulado "Copia de la carta con la que el Maestro D. Francisco Asenjo Barbieri contestó á la consulta que le hizo el autor de esta Monografía sobre los instrumentos musicales que aparecen en la documentación de nuestro archivo municipal" (pp. 97-122).] (B, C, L-C, R, S, T)

43. Collet, Henri, and Luis Villalba. "Contribution a l'étude des «Cantigas» d'Alphonse la Savant," $\mathrm{BHi}, \mathrm{XIII} / 3$ (1911), 270-90. (C) 
44. Consueta o director pera la gran funsió de vespra y Dia de la Mare de Deu de la Asumpsió Patrona de Ells. Pera els Mestres de Capella. [Torner: Copia de los textos literario y musical y una reproducción fotográfica. En la Biblioteca de Cataluña, manuscrito 793. Papeles de Pedrell.]

Consuetas catalanes (véase Llabrés, Gabriel, núm. 100)

45. Correas, Gonzalo. Arte grande de la lengua castellana compuesta en [Salamanca] 1626. Publicado por el [Sr. D. Cipriano Muños Manzano] Conde de la Viñaza. Madrid: Ricardo Fé, 1903. xxvi, 324 pp. [*Reimp. más adelante. Madrid: CSIC, 1954. 500 pp.; contiene una discusión de la seguidilla.]

46. Correia López, Edmundo. "Música de clérigos e jograis segundo os poemas de "cuaderna vía»," $R A B M, \mathrm{XXXI/10-12} \mathrm{(1927),} \mathrm{421-35.} \mathrm{[Torner:} \mathrm{Es}$ un interesante estudio en el que se señala el sentido folklórico-musical de los poemas medievales catellanos y su evidente influencia en la lírica portuguesa.] (B, R)

47. Cotarelo Valledor, Armando."Romancero popular gallego: Gaiferos de Mornaltan; A noite de San Juan; A flor d'agua," Ultreya, núm. 3 (1919), 3336; núm. 4 (1919), 51-62. [*C. Sampedro y Folgar 1942:56: Interrumpida la publicación de la revista, tan sólo vieron la luz el plan y algunos romances aislados.] (B)

48. Daux, L'abbé Camille. Le Pélerinage à Compostelle et la Confrèrie des Pèlerins de Monseigneur Saint-Jacques de Moissac. Avec Planches, Chansons notées et Carte-Routière. París: Honoré Champion, 1898. 249 pp. [*Reimp. Geneva: Slatkine, 1981.] (B, S)

49. Davillier, Charles. L'Espagne. Ilustrée de 309 gravures dessinées par Gustave Doré. París: Créte Fils, 1874. 799 pp. [Contiene una discusión de la seguidilla, p. 396f.] [*Sobre esta obra, véase Enrique C. Ablanedo, "La música y la danza en el libro Viaje por España de Gustave Doré y del Barón Charles Daviller," Revista de Musicología XIV/1-2 (1992), 389-407.]

50. Demófilo [Antonio Machado y Álvarez]. "Cantares populares gallegos," El Porvenir, Segunda época (3 de enero de 1881), 1.

51. Díaz Cassou, Pedro. Pasionaria murciana. La Cuaresma y la Semana Santa. Costumbres, romancero, procesiones, esculturas y escultores, cantos populares, folklore. Con música de los maestros D. Antonio López Almagro y D. Mariano García López. Madrid: Imp. de Fortanet, 1897. xii, $250+13$ pp. [*5 transcripciones musicales, pp. 1-13 al final del libro): Salve de la aurora (pp. 1-4); Rosario de la aurora (pp. 5-6); Pasión de cuaresma (p. 7); Correlativa (pp. 9-13); Saetas, etc. (pp. 215-27). Ed. Fascs. reimp. en Tradiciones y costumbres de Murcia (Almanaque folklórico, refranes, canciones y leyendas). Murcia: Academia Alfonso X el Sabio, 1982. pp. 11-218.] (B, R, R' S, To)

52. Díaz Rengifo, Juan. Arte poética española con vna fertilissima silua de consonantes comunes, propios, esdruxulos, y reflexos, y vn diuino estimulo del amor de Dios (Salamanca, 1592). 364 pp. [2 ${ }^{\mathrm{a}}$ ed. Madrid: Iuan de la Cuesta: a costa de Blaz Gonçalez Pantoja, 1606. [12], 364 pp. [ $3^{\mathrm{a}}$ ed. Madrid: Viuda de Alonso Martín: a costa de Domingo Gonçalez, 1628, [12], 324, 40 pp. [*Reimp. Madrid: Imp. de Francisco Martínez, 1644 y Barcelona: Imp. María Martínez, 1759; aumentada en esta última impresión por Joseph Vicens (pseud. de P. Diego García de Rengifo) con dos tratados: uno de Avisos y Reglas: otro de asonantes; con cuarenta y ocho capítulos; con un compendio de toda el Arte Poética y casi cinco mil consonantes. Reproducción facsímil con Epílogo por Antonio Martialanis. Madrid: Ministerio de Educación y Ciencia, Dirección General del Patrimonio Artístico y Cultural, 1977. 441 pp. [Hay una discusión de la seguidilla en Cap. 52.] (S)

53. Donostia, José Antonio de. Euskel Eres-Sorta. Cancionero vasco). Madrid: UME, 1919. iv, 222 pp. (Comprende 393 melodías) (B, Cr, R, R', S, To)

54. - De música popular vasca. Dos Conferencias [leídas en la Sala de la Filarmónica de Bilbao]. Bilbao: Jesús Álvarez-UME, 1918. 49 pp., plus 35 pp. (de música). (B, R, R', S, To)

55. - Cómo canta el vasco. Conferencia [leída en el Nuevo Teatro de Vitoria el día 25 de septiembre de 1921, en la sesión de clausura de la Semana Agrícola Alavesa]. Bilbao: Editorial Eléxpuro Hermanos, 1921. 29 pp. (con melodías). [Euskol-kaskuntza / Sociedad de Estudios Vascos. D. Ángel de Apraiz leyó la conferencia en su lugar. Texto reproducido en su libro (con Francisco Madina), 
De música vasca (Buenos Aires: Ekin, 1943. 155 pp.] (B, R, R', S, To)

56. Echegaray, Carmelo de. "Orígenes de nuestra música popular y sus relaciones con la métrica," RIEB, X (1919), 1-27. (B, R, S)

57. Elústiza, Juan Bautista de. Estudios musicales. Artículos, estudios folklóricos, trabajos de investigación histórica, críticas, ensayos, etc. Sevilla: Imp. de la Guía Oficial, 1917. vii, 200 pp. [Torner: Por muerte prematura del autor, no llegó a publicar el $2^{\circ}$ tomo. En este $1^{\circ}$, tratan de folklore musical los capítulos titulados: "La música en las obras de Cervantes" (pp. 33-103); "El pregón popular sevillano" (pp. 125-59); y "La música popular andaluza" (pp. 163-69).] (B, R, S, T)

Enríquez Ureña (véase Henríquez Ureña, Pedro, núm. 86)

58. Escalada y Carabias, Ramón. Estudio-discurso acerca de la música popular española. Salamanca: Est. Tip. de Oliva, 1894. 78 pp. Discurso compuesto y leído por. D. Ramón Escalada y Carabias en la solemne apertura del curso de 1894 a 1895 en la Escuela de N. y B.A. de S. Eloy. (B, R, S)

59. Espadaler Colomer, J[oan] B[aptista]. La música del meu poble. Barcelona: A. Artís, 1912. 88 pp. [*1. En el món de la música (pp. 7-12); 5. La nacionalitat musical (pp. 31-36); 6. El ball (pp. 3742); 7. La sardana (pp. 43-53); 12. J[osep] A[nselm] Clavé (pp. 79-84).] [Torner: Estudio sobre la música popular catalana.] $(\mathbf{B}, \mathbf{R}, \mathbf{S})$

Estella-Lizarra, Hilario (véase Olazarán de Estella, Hilario, núms. 208, 276-78)

60. Fabiani y Díaz de Cabria, Juan. La música popular en la época de Goya. Zaragoza: Tip. del Hospicio 1927. 12 pp. (Publicaciones de la Junta Organizadora del Centenario de Goya, vol. X) [*Conferencia leída en el Centro Mercantil, Industrial y Agrícola de Zaragoza, el día 12 de mayo de 1926.] (B, R)

61. Falla, Manuel de. El «cante jondo» (Canto primitivo andaluz). Sus orígenes. Sus valores musicales. Su influencia en el arte musical europa. Granada: Editorial Urania, 1922. [*Reimp. en E. Molina Farjado, Manuel de Falla e el cante jondo (Granada: Urania, 1962), pp. 209-26 y en M. de Falla, Escritos sobre música y músicos. Debussy, Wagner, el cante jondo. Madrid: Espasa-Calpe, 1950, pp. 137-62. Traducción francés por M. Coindreau en RevMus, IV/3 (1923), 256-62] [Torner: Folleto publicado con motivo de la celebración del primer concurso de «cante jondo», organizado por el Centro Artístico de Granada.] (B, Cr, L-C, R, S, To)

62. Fernández Alonso, Benito. "El alalá," IGA, III (Madrid, 18 de abril de 1881), 130. [Torner: El autor considera este canto de origen árabe.] $(\mathbf{B}, \mathbf{R})$

63. Fernández Núnez, Manuel. Las canciones populares y la tonalidad medieval. Aclaraciones a la obra 'Las Cantigas' de Alfonso el Sabio escrita por D. Julián Ribera. El Escorial: Imp. del Real Monasterio de El Escorial, s.a. [*Reimp. en $C D$, CXXXVIII (1924), 273-83; 343-52; CXXXIX (1924), 30-38, 97-110, 353-60; CXL (1925), 10213; CXLI (1925), 426-35; CXLII (1925), 422-34; CXLIII (1925), 134-45, 209-21.] [Torner: Es un juicio crítico de la transcripción que hace Ribera de la música de las Cantigas de Alfonso el Sabio.] (B, R, To)

64. - Folk-lore leonés (Canciones, romances y leyendas de la provincia de León, e indicaciones históricas sobre la vida jurídica y social en la Edad Media). Madrid: Imp. del Asilo de Huérfanos del Sagrado Corazón de Jesús, 1931. 111, 104 pp. (contiene 160 melodías). [*Reimp. León: Edit. Nebrija, 1980.] (B, Cr, R, R', S)

65. Fernández Vallejo, Felipe Antonio. Memorias y disertaciones, que / podrán servir al que, lescribir la historia / de la iglesia de Toledo, / desde el año $M L X X X V /$ en que conquistó dicha / ciudad el rei don / Alonso VI de / Castilla. MS 224 de la Real Academia de Historia. ix, 707 pp. [*Memoria Ia: Prevenciones al que escriba la historia de la Santa Iglesia de Toledo desde el siglo XI (pp. 1-42); Disertación Ia: Sobre la constitución formal de la Iglesia (pp. 45-89); Memoria II: Estado antiguo y presente del Templo Toledano (pp. 93-144); Disertación IIa: Sobre la dedicación de la iglesia (pp. 147-83); Memoria III: Monasterio de S. Servando (pp. 185-217); Disertación IIIa: Dudas sobre el juicio de los misales gótico y latino (pp. 221-68); Memoria III [IV]: Subcesión de los arzobispos (pp. 271-320); Disertación IVa: Falsa conspiración de los canonigos contra el Arzobispo D. Bernardo (pp. 323-52); Memoria V: Dignidades (pp. 355474); Disertación Va: Sobre la música (pp. 477535); Memoria VI: Librería (pp. 539-84); Diserta- 
ción VIa: Sobre las representaciones poéticas en el Templo, y Sybila de la noche de Navidad (pp. 587643); Memoria VII: Biblia Goda (pp. 645-83); Advertencias al Tomo $1^{\circ}$ de Memorias y disertaciones para la Historia de la Iglesia de Toledo desde el año de 1085 (pp. 685-707).] [Torner: Manuscrito de hacia 1785 conservado en la Academia de la Historia.] [*Sobre esta obra véase J.E. Gillet, "The 'Memorias' of Felipe Fernández Vallejo and the History of the Early Spanish Drama," en Essays and Studies in Honor of Carleton Brown (Nueva York: New York Univ. Press, 1940), pp. 246-80.] (B)

Ferrer Guinat (véase Ferrer Ginard, Andreu)

66. Ferrer Ginard, Andreu. Folk-lore balear. Ciutadella: Viuda de Salvador Fábregas, 1914; Artá: Tipografía Católica de A. Ferrer Guinart, 192426). 3 vols. [*Vol. I. Rondaies de Menora; vols. IIIII. Cançons populars menorquines] $(\mathbf{B}, \mathbf{R}, \mathbf{S})$

67. Figueras Pacheco, Francisco. "La música popular de Alicante," en Francisco Carreras y Candi, ed., Geografía general del Reino de Valencia.. Vol. IV: Provincia de Alicante (Barcelona: Tip. Atlas Geográfico / Alberto Martín, 1927), pp. 220-26. [*Cap. IV. 1. Su carácter y organización (pp. 220-21); 2. Les cordaes (pp. 221-22); 3. Las danzas (pp. 222-23); 4. Los moros y cristianos (pp. 223-25); 5. Les festes de carrer (pp. 225-26)] (B, $\mathbf{R}, \mathbf{S})$

68. Filgueira Valverde, José. A Festa dos Maios: Papeletas de Folklore Galego. La Coruña: Seminario de Estudos Galegos; Imp. Lar, 1927. 63 pp., con 4 ejemplos musicales entre pp. 38-39). [*Separata de Arquivos do Seminario de Estudos Gallegos: Bibliografía (pp. 53-62).] [Torner: Interesante estudio, literario y musical, de esta costumbre en Galicia.] (B, R, S)

69. Fischer, Christian August. Reise von Amsterdam über Madrid und Cadiz nach Genua in den Jahren 1797 und 1798. Nebst einem Anhänge über des Reisen in Spanien. Berlin: Johann Friedrich Unger, 1799. xxii, 526 pp. [ $2^{\mathrm{a}}$ ed., 1801. xxii, 534 pp.; lo más reciente ed. Heidelberg: Palatina, 1998] [Torner: Trata de la música popular espanola y cita (pp. 199-203) como muy interesante la obra Modo fácil para aprender el ayre Bolero en la guitarra y arreglar la voz. Madrid: Imp. de Fernández y Compa., s.a.] (B, R)
70. Flores Laguna, José. Canto de los peregrinos fla mencos. Facsímil del original del Papa Calixto II. Traducido á notación moderna. s.l.: Imp. de J. Cruzado, 1882. 8 pp. [*Reimp. Heidelberg: Palatina, 1998]

71. - ;Ultreja! Canto de los peregrinos flamencos al Apostol Santiago. Tomado del célebre códice de Calixto II (siglo XII). Madrid: F. Echevarría, 1883. [*Al Apostal Santiago el Mayor Himno de los milagros Año 1134 (p. 1); Magister Americão Picaud (pp. 2-4): Canto de los peregrinos flamencos al sepulcro de Apostal Santiago el Mayor, plus retranscripción de los textos escrito a mano.] (S)

72. - . "El Canto de Ultreja," La Corresponencia Musical, III/134 (26 de julio de 1883), 3-4; III/135 (2 de agosto), 3-4; III/136 (9 de agosto), 3-4; III/138 (23 de agosto), 3-4; III/139 (30 de agosto), 4-5; III/140 (6 de septiembre), 3-4; III/141 (13 de septiembre), 3-4.

73. Font de Anta, Manuel. "Cante gitano. Modelos clásicos recogidos, transcritos y armonizados para canto y piano por...," La Canción Popular, I/9 (1922), Suplemento de 23 pp.] (B, R, R')

74. Foulché-Delbosc, R[aymond]. "Séguidilles anciennes," $B H i$, VIII/25-28 (1901), 309-31. (S)

75. Fuentes Agulló, Francisco. Epítome histórico de Elche desde su fundación hasta la venida de la Virgen inclusive, y traducción literal de la Fiesta. Elche: F. Santamaria, 1855. 25 pp. (Traducción (pp. 15-25). [Reimp. Elche: Imp. de Modesto Aznar, 1896. 28 pp.] (B)

76. Fuentes y Ponte, Javier. Memoria histórico-descriptiva del Santuario de Nuestra Señora de la Asunción en la ciudad de Elche. Lérida: Mariana, 1887.114 pp. (B)

77. Gascue Murga, Francisco. "Origen de la música popular vascongada. Boceto de estudio," RIEB, VII/1 (1913), 67-98; VII/2 (1913), 193-260; VII/4 (1913), 498-539); plus un apéndice titulado "El compás quebrado del zortzico" (pp. 540-58). [Reimp. como folleto. París: Honoré Champion, 1913. 143 pp.] (B, R, S, T, To)

78. - . "De música vasca: La simetría y el compás 5 por 8," $E A, \mathrm{VI} / 123$ (1916), 85-90; VI/124 (1916), 100-25; VI/125 (1916), 133-45. [*Reimp. como folleto: De música vasca. La simetría y el compás 5 por 8. San Sebastián: Martin, Mena y Cie., 1916. 27 pp.] (B, R, T) 
79. - Influencia de la música árabe en la música castellana. Conferencia dada en el Círculo de Bellas Artes y de Bilbao (15 de abril de 1916). Bilbao: Garmendia y Ca. / Corazón de Jesús, 1917. 49 pp. (10 ejemplos musicales) (B, L-C, R, S, T)

80. - . "Materiales para el estudio del folklore músico vasco. Las gamas célticas y las melodías populares euskaras," RIEB, IX (1918), 42-65. [Reimp. como folleto: Materiales para el estudio del folklore músico vasco. Las gamas célticas y las melodías populares euskaras. San Sebastián: Imp. Martín y Mena, 1917. 26 pp.] (B, L-C, R, T, To)

81. Gevaert, François-Auguste. "Rapport á Mr. le Ministre de l'Intérieur sur l'état de la musique en Espagne," Bulletin de l'Académie Royale des Sciencies, des Lettres et des Beaux-Arts de Belgique, XIX, Partie 1 (1852), 184-205. (B)

82. Gil García, Bonifacio. Cancionero popular de Extremadura. Contribución al folklore musical de la región. Valls [Cataluña]: E. Castells / Badajoz: Imp. de la Excma. DP, 1931. 172 + xiii + 235 pp. [Torner: Interesante colección de 404 melodías con estudio y notas sobre la Personalidad de la música extremeña.] (B, $\mathbf{C r}, \mathbf{R}, \mathbf{R}$ ', $\mathbf{S})$

*83. Gómez Rodríguez, Jerónimo. Breves consideraciones acerca de la música popular española en los siglos XVI, XVII y XVIII (Madrid, s.a.) (B, R, S)

84. Hanssen, Federico. La seguidilla. Santiago de Chile: Imp. Cervantes, 1909. 104 pp. [Véase también "La seguidilla, estudio de su origen, forma, etc.," AUCh (Septiembre-octubre, 1909), 697-796. Reimp. como La seguidilla. Santiago de Chile: Imp. Cervantes, 1909. 104 pp.] [Torner: En el cap. 30 trata de La ejecución musical de la seguidilla (pp. 59-61); en cap. 31, El sistema de transcripción musical que empleo en el presente trabajo (pp. 61-62); en cap. 32, Colecciones de melodias que se cantan," (pp. 62-63).] (B, R, T, To)

85. Hemsi, Alberto. Coplas sefardies (Chansons Judéo-espagnoles). Alexandria, Egypt: Édition Orientale de Musique, 1932-38. Fascicles 1-5; Aubervilliers, France: Author, 1969-73; fascicles 6-10. [*Series I (Op. 7): España 1492 - Rodi, 1932 (1932), vii + vii, 16 pp.; Series II (Op. 8): España 1492 - Rodi, 1932 (1933), xii, 28 pp.; Series III
(Op. 13): España 1492 - Salónica 1932 (1934), xviii, 27 pp.; Series IV (Op. 18): España 1492 Salónica 1932 (1935), xxiv, 34 pp.; Series V (Op. 22): España 1492 - Esmirna 1937 (1938), xxx, 27 pp.; Series VI (Op. 34: España 1492- Esmirna y Anatolia 1920 (1969), xiv, 28 pp.; Series VII (Op. 41: España 1492 - Esmirna y Anatolia 1920 (1970), xi, 26 pp.; Series VIII (Op. 44): España 1492 - Esmirna y Anatolia 1920 (1972), viii, 28 pp.; Series IX (Op. 45): España 1492 - Istanbul 1933 (1972), vi, 29 pp.; Series X (Op. 51): España 1492 - Medio-Oriente 1928 (1973), xvii, 36 pp. [*Véase José Subira, "El orientalismo del compositor A. Hemsi," Ritmo, núm. 64 (1933), 3-4 y núm. 65 (1933), 4 y también "Romances y refranes sefardíes," Estudios dedicados a Menéndez Pidal, (Madrid, 1954), vol. 5, pp. 319-33.] [Torner: Es una colección interesantísima desde el punto de vista histórico de nuestro folklore musical, muchos de cuyos temas antiguos conservan aún hoy los judíos españoles diseminados por el Oriente de Europa y por el Norte de Africa.] (B, R, R', S)

86. Henríquez Ureña, Pedro. La versificación irregular en la poesía castellana. Prólogo de Ramón Menéndez Pidal. Madrid: Jiménez y Molina, 1920. vii, 338 pp. [2 $2^{\mathrm{a}}$ ed., Madrid: JAEIC, CEH, 1933. x, 369 pp. [*Cap. II $b$ : Castilla. Las primeras seguidillas (pp. 79-81); Origen de la seguidilla; probablemente, castellano (p. 81); Forma de la seguidilla (pp. 82-83); La seguidilla en el Cancionero de Herberay (pp. 83-85); Seguidilla y endecha (pp. 85-88); Cap. IIIb. Los poetas populares y vulgares (1475-1600): La seguidilla: comienzos de su evolución (pp. 163-64); Las seguidillas del Cancionero musical (pp. 164-69); La seguidilla popular a través del siglo XVI (pp. 169-79); Cap. IV a) Los tipos de versificación en la poesía culta y en la popular y vulgar: El esplendor de la seguidilla (pp. 213-21); La seguidilla regular (pp. 22126)]

87. Herrera y Chiesanova, Adolfo. Auto lírico-religioso (música del siglo $X$ ) en dos actos, representado todos los años en la Iglesia parroquial de Santa María de Elche, los días 14 y 19 de agosto. Le precede una carta del maestro Felipe Pedrell y un escrito de.... Madrid: Establ. Tip. de José Lacoste, 1905. 16 + 20 pp (de música). (B) 
Historia de Elche (véase Ibarra y Ruiz, Pedro, núm. 89)

88. Hurtado, José. Cien cantos populares asturianos, escritos y armonizados para canto y piano por __. Precedido por una carta de D. Emilio Arrieta. Madrid: A. Romero-Capellanes, 1890; Bilbao: UME, 1890. iii, 80 pp. [*Reproducido en Gabriel Martínez García, 50 años de cancioneros asturianos armonizados (1885-1935) (Oviedo: IEA, 1989), pp. 143-229.] (B, Cr, R, R', S, To)

89. Ibarra y Ruiz, Pedro. Historia de Elche, escritura a la vista de los más fidedignos testimonios y contemporáneos estudios. Alicante: Archivo Municipal, 1885. xv, 328 pp. [Manual de la historia de Elche. Alicante: Vicente Botella, 1895, 328 pp.; reproducción de la de 1895: Alicante: Manuel Pastor y Torres, 1982. [Torner: En el cap. 31 describe la Fiesta de Agosto y la ceremonia del Misterio.]

90. - Lo Misteri d'Elig (El Misterio de Elche). Manual del curioso espectador de la representación de la famosa fiesta, compuesto para que sirva de guía y claro conocimiento. Primera edición de su más antiguo Consueta. Autores escogidos: D. Gaspar Soler Chacón, del texto lemosín, D. Claudiano Phelipe Perpiñán, de la traducción. Publicada por el archivero y cronista de la ciudad Pedro Ibarra y Ruiz. Alicante: Lucentum, 1929. 47 pp. [Reimp. Elche: Atenea, 1953] (B)

Incenga (véase Inzenga y Catellanos, José)

91. Inzenga y Castellanos], José. Cantos y bailes populares de España: Galicia. Madrid: Antonio Romero y Andía, 1888. xxii, 80 pp. 47 pp. (42 melodías para canto y piano). [Reimp. Madrid: UME, c. 1928. 47 pp.] (B, Cr, R, R', S, T, To)

92. - Cantos y bailes populares de España: Murcia. Madrid: Antonio Romero y Andía, 1888. xii, 60 pp. (20 melodías para canto y piano) [Reimp. Mardid: UME, c. 1928.45 pp.] (B, Cr, L-C, R, R', S, T, To)

93. - Cantos y bailes populares de España: Valencia. Madrid: Antonio Romero y Andía, 1888. 50 pp. (18 melodías para canto y piano). [Reimp. Madrid: UME, c. 1928). (B, Cr, R, R', S, T, To)

94. Irruarízaga, Luis. Cancionero popular del Rosario. Madrid: Corazón de María, 1918. 16 pp. [Torner: Cuaderno que contiene 10 Rosarios de la Aurora de diversas regiones.] (B, R, To)
95. Kahn, Máximo José (pseud. Medina Azara). 'Cante jondo' y cantares sinagogales," $R O$, VIII/88 (1930), 53-84. [Torner: Es este, sin duda, el trabajo más interesante que hasta ahora se ha publicado sobre el «cante jondo» y el «cante flamenco».] (B, $\mathbf{C r})$

96. Koeckert, M. Gustave. La canción popular en España. Conferencia [dada en la Sociedad de Artes de Ginebra]. Madrid: Cosano, 1926). 32 pp. [Véase BILE, núm. 800.] (B, R)

97. Lahose-Barrelet, Mina. Mallorkinische Volkslieder und Tänze. Gesammelt von Mn. Antoni Jusep Pont (Mallorkin. Geistl.), hrsg. u. erläut. (Hamburg, 1922). 221 pp. [Tesis: "Volkslieder und Volkstänze auf Mallorca," Iberia, V/1-2 (1926), 49-59. ["Es ist die erster und bischer einzige Sammlung mallorkanischer Volkslieder und Tänze."] $(\mathbf{B}, \mathbf{R}, \mathbf{S})$

98. Ledesma Hernández, Dámaso. Folk-lore o Cancionero salmantino. Preámbulo de Tomás Bretón (pp. 7-11). Madrid: Imp. Alemana, 1907. 263 pp. (396 melodías). [*Reimp. Salamanca: Imp. Provincial, 1972.] (B, Cr, L-C, R, R', S, T, To)

99. López-Chavarri Marco, Eduardo. Música popular española. Barcelona: Labor, 1927. 152 pp., plus 16 pp. láminas. $2^{a}$ ed. 1958. [Los capítulos son: 1. La cancíon popular (pp. 9-12); 2. La canción popular hispana (pp. 13-28); 3. Juglares y trovadores (pp. 29-51); 4. La música popular en los siglos XVI y XVII (pp. 52-59); 6. La vida musical española en el Renacimiento (pp. 60-71); 7. La música popular de baile y los instrumentos hasta el siglo XVII (pp. 72-83); 8. La música popular y el teatro (pp. 84-95); 9. Siglos XIX y XX (pp. 96-127); 10. Los instrumentos populares a principios del siglo XX (pp. 128-32); 11. La música popular española y sus futuras posibilidades (pp. 133-46). Bibliografía (pp. 147-50).] [Torner: Es de suma utilidad este manual para adquirir una idea de conjunto de nuestro folklore musical históricamente considerado.] (B, $\mathbf{C r}, \mathbf{R}, \mathbf{S})$

100. Llabrés y Quintana, Gabriel. "Repertorio de "Consuetas» representadas en las iglesias de Mallorca (siglos XV y XVI)," RABM, $3^{\mathrm{a}}$ época, V/12 (1901), 920-27; "Consueta del Juy (número 11 de la colección)," VI/6 (1902), 456-66; "Consueta de la Representació de la tentació que fonch feta a Ntr. Sr. Xpt., ara novamente 
feta per lo reverend Para Fra. Cardils, Mestre en Theología," VII/8 (1903), 127-34. (B, C, S, T)

101. - "Música de tres Misterios en valenciano, cuya composición se calcula anterior al año 1672: [1. De Sant Cristofol; 2. De Adam y Eva; 3. El Rey Herodes.]." [Torner: Los originales son propiedad de D. José Enrique Serrano, para quien hice esta traducción de la música en noviembre de 1890.- Fr. A. Barbieri, Bibl. Nac. Mss. 14036 (Papeles de Barbieri). La traducción comprende cinco hojas de papel de música escritas por ambas caras. Son composiciones a 2 y 4 voces.]

102. Llongueras Badía, Juan. Els Cants de la Passió. Exhortació poemática per a ésser dita i predicada en el temps de la Passió $i$ Setmana Santa. Barcelona: Tip. Emporium, 1928. 251 pp. (B, Cr, R, R', S, To)

103. - Cançoner popular de Nadal. Barcelona: Ed. Balmes, Foment de Pietat, 1931. 198 pp. (70 melodías). [2ª ed. Barcelona: Balmes, 1946. 199 pp. y $3^{\text {a }}$ ed., 1956. 223 pp.] (B, Cr, S, T, To)

104. Llorens de Serra, Sara. El cançoner de Pineda. Barcelona: Editorial Alta Fulla, 1931. xiv, 359 pp. (280 cantos populares y 210 tonadas). Vol. 1 del Folklore de la Maresma. (B, R, R', S)

105. Manterola Beldarrain, José de. Cancionero basco. Poesías en lengua euskara reunidas en colección, ordenadas en séries, y acompañadas de traducciones castellanas, juicios críticos, noticias biográficas de los diversos autores, y observaciones filológicas y gramaticales. 2 vols. San Sebastián: Juan Osés, 1877-78. Vol 3. San Sebasián, 1880. Antonio Baroja, 1880. [*Vol. I (1877): Poesías amorosas (xv, 91 pp., plus 3 melodías); vol. II (1878): Poesías varias (88 pp., plus 2 melodías para voz y piano); vol. III (1880: Poesías festivas y satíricas (x, 89 pp., plus 2 melodías. [*Reimp. San Sebastián: Sendoa, 1981 y Bilbao: E. Villar-Wilsen, 1981. 3 vols. [470, 460, 500 pp.] $(\mathbf{B}, \mathbf{C r}, \mathbf{L}-\mathrm{C}, \mathbf{R}, \mathbf{R}$ ', S, To)

106. Margellí, Antonio. "Las Cantigas de Alfonso el Sabio. Su notación en calores," Ritmo, II/19 (1930), 1-4; II/20 (1930), 2-5; II/22 (1930), 1-3; II/23 (1930), 2-3. [*Reimp. en $R E c l$, III (1931), 176-97.]

Martín Codax (véase Vindel, Pedro, núm. 185)

107. Martín González, Casto. "Detalles folklóricos de un pueblo de Toledo (Peña Aguilera). Canciones y danzas," Résumés du Congrès International des Arts Populaires, Prague, 1928 (París, 1930), p. 110. (B, R, S)

108. Martínez Hernández, Antonio. Antología musical de cantos populares españoles y un suplemento de cantos populares portugueses. Prólogo de José Subirá Puig. Barcelona: Isart Durán, 1930. xv, 246 pp. [Torner: Contiene 242 melodías, de las cuales nueve corresponden a Portugal.] (B, $\mathbf{C r}, \mathbf{R}$, $\left.\mathbf{R}^{\prime}, \mathbf{S}\right)$

Medina Azara (pseud. de Kahn, Máximo José, véase núm. 95)

Memoria de D. José González Torres de Nava (véase núm. 279)

Memorial que D. Juan Espina envió a D. Felipe IV (véase núm. 204)

109. Méndez Bejarano, Mario. La ciencia del verso. Teoría general de la versificación con aplicaciones a la métrica española. Prólogo del Dr. Antonio Atienza Medrano. Madrid: Lib. General de Victoriano Suárez / Imp. de Fortanet, 1907. 454 pp. [2 $2^{a}$ ed., 1908] [Incluye una discusión de la seguidilla.] (S)

110. Millet, Lluis. El cant popular religiós. Conferència [llegida en el Palau de la Música Catalana en sessió solemne del III Congrés Nacional de Música Sagrada el día 23 de noviembre de 1912]. Barcelona: Heinrich y Ca., 1912. 48 pp. + 12 pp. (18 ejemplos musicales). [Reproducido en su libro, Pel nostre ideal. Recull de d'escrits de Lluis Millet (Barcelona: Joaquim Horta, 1917), pp. 185-225.] [Traducido en castellano por Francisco Pujol.] (B, L-C, R, S, T, To)

111. _. De la canço popular catalana. Barcelona: Bloud \& Gay, 1917. 81 pp. [Conferència II de la sèrie organitzada per la molt il-lustre Junta de Dames de Barcelona. Llegida el día 19 de decembre de 1917. Amb exemples musicals que foren interpretats per elements de l' «Orfeó Catalá», sota la direcció d'en Francesc Pujol.] (B, L-C, R, T, To)

Lo Misteri d'Elig (véase Ibarra y Ruiz, Pedro, núm. 90)

Misterio de Elche (véase Consueta o director...); véase núm. 44)

112. Mitjana Gordon, Rafael. Discantes y contrapuntos. Estudios musicales (crítica e historia). Valencia: F. Sempere 1905. 214 pp. (C, L-C, T) 
113. - . "Le mystère d'Elche et les orígines du theâtre lyrique," Encyclopédie de la Musique et Dictionnaire du Conservatoire. Première parte. Tomo IV. Espagne-Portugal (París: Libraire Delagrave, 1920), pp. 1941-945. [*Véase también "El «Misterio» de Elche," Ritmo, III/42 (1931), 1-4 y III/4344 (1931), 2-3.] [Torner: Puede verse también un estudio de Mitjana sobre el mismo tema en su obra Discantes y contrapuntos. (Valencia, 1905)," pp. 119-38.] (S, T)

114. - . "La Musique en Espagne (Art religieux et art profane)," en Albert Lavignac, ed., Enciclopédie de la Musique et Dictionnaire du Conservatoire. Première parte. Tomo IV. Espagne-Portugal (París: Libraire Delagrave, 1920), pp. 1913-2350. [*Traducido en castellano como Historia de la música en España. "Prólogo" por Antonio Martín Moreno. Edición a cargo de Antonio Alvarez Cañibano. Madrid: Ministerio de Cultura. Centro de Documentación Musical. Inst. Nacional de las Artes Escénicas y la Música, 1993. xiii, 469 pp. + índices (pp. 473-580). (B, L-C, S, T)

Molins (Marqués de) (véase Roca de Togores y Carrasco, Mariano, núm. 148)

*115. Montolíu de Togores, Manuel. La canço popular. Conferència. Barcelona, 1926. [Torner: Curiosa disertación sobre la canción popular, tomando como tipo la catalana «El mariner».] (B, R)

"Música popular gallega..." (véase núm. 263)

116. Noguera Balaguer, Antonio. Memoria sobre los cantos, bailes y tocatas populares de la Isla de Mallorca. Barcelona: Tip. Victor Berdós i Feliú, 1893. 72 pp. (con 25 melodías). [También en su Ensayos de crítica musical, pp. 3-95.] [2 $2^{\mathrm{a}}$ ed. Palma de Mallorca: Tip. de Felipe Guasp, 1894. 117 pp. [Obra laureada con el Primer Premio ofrecido por S.A.R. la Serma. Infanta Doña Isabel, en el segundo Concurso de la IMHA.] (Cr, L-C, R, R', S, T)

117. - Ensayos de crítica musical. Con prólogo de Juan Alcover y Maspons. Palma de Mallorca: Est. Tip. de J. Tous, 1908. xv, 362 pp. [*Memoria sobre las cantos, bailes y tocatas populares (pp. 395); La canción popular y las nuevas nacionalidades musicales (pp. 99-124); La música en las fiestas de San Alonso (pp. 191-94); y un estudio sobre
«El Canto de la Sibila» en Mallorca (pp. 261-66).] (B, L-C, S)

118. Núñez de Prado, Guillermo. Cantaores andaluces (Historias y tragedias). Barcelona: Maucci, 1904. 290 pp. [ ${ }^{*} 2^{a}$ ed., 1979; $3^{\text {a }}$ ed., 1987; $4^{a}$ ed., 1987] [Torner: Biografías de cantaores e interesantes noticias de canciones de Málaga y Levante, carceleras, soleares, siguirillas gitanas, etc.] (B, S)

119. Ocón y Rivas, Eduardo. Cantos españoles. Colección de aires nacionales y populares para canto y piano formada e ilustrada con notas explicativas y biográficas por... (Málaga: Autor y Leipzig: Breitkopf und Härtel, 1874). vii, 100 pp. ( 29 cantos) $\left[2^{\mathrm{a}}\right.$ ed., $1884 ; 3^{\mathrm{a}}$ ed., $1888 ; 4^{\mathrm{a}}$ ed., 1906. Notas explicativas en castellano y en alemán.] (B, Cr, L-C, R, R', S, T, To)

Olazarán de Estella, P. Hilario (véase núms. 208, 27678)

120. Olmeda, Federico. Folk-lore de Castilla o Cancionero popular de Burgos. Obra premiada en los juegos florales celebrados en Burgos en 1902 por la universidad y prensa de esta población y costeada en la publicación por su DP. Sevilla: Librería Ed. de María Auxiliadora, 1903 [1904]. 217 pp. (308 melodías). [*Reimp. Burgos: DP, 1975.] $(\mathbf{B}, \mathbf{C r}, \mathbf{L}-\mathrm{C}, \mathbf{R}, \mathbf{R}$, S)

121. Ormaechea, Nicolás de. "De la música y letra popular al acento. I. El zortzico: su ritmo. II. Influencia de las melodías gregorianas," RIEB, XI (1920), 174-85. (B, R)

122. Ortiz Díaz, Daniel Luis. "Los estribillos y canciones del Valle de Iguna (Santander)," Résumés $d u$ Congrès International des Arts Populaires, Prague, 1928 (París, 1930), p. 117. (B, R, S)

123. Otaño [Eguino], [José María] Nemesio. El canto popular montañes. Prólogo de Felipe Pedrell. Santander: Talleres Tip. de J. Martínez, 1915. 63 pp. (con ejemplos musicales). [Conferencia dada en el Teatro Principal de Santander el 19 de abril de 1914.] (B, R, R', S, T, To)

124. Palau Boix, Manuel. Elementos folklóricos de la música valenciana. Estudio sobre las canciones u danzas populares de la región valenciana, premiado en los Juegos Florales de "Lo rat penat" con el premio de la Excma. Diputación el año 1924. Valencia: Tip. Moderna, 1925. 24 pp. [1 $1^{\mathrm{a}}$ ed., Valencia, 1903.] (B, R, S) 
125. Pedrell, Felipe. "Folk-lore musical castillan du XVIe siècle," SIMG, I/3 (1900), 372-400. [*Traducido como "Estudio sobre una fuente de Folklore musical castellano del siglo XVI," Lirica nacionalizada. Estudios sobre el folk-lore musical (París: Librería Paul Ollendorf, 1913), pp. 211-63.] [Torner: Análisis de los dos últimos libros del al obra de Francisco de Salinas De Musica Libri Septem, empresa en Salamanca en 1577.] (B, C, L-C, R, S, To)

126. - . "La Festa d'Elche ou le drame lyrique liturgique «La Mort et l'Assomption de la Vierge»," SIMG, II/2 (1901), 203-52 (música, pp. 235-52). [*Véase también La festa de Elche ó el drama lírico litúrigico "La Muerte y la Asunción de la Virgen». Traducción de A.A.S. Elche: Mozas, 1951.] (B)

127. - . "La Festa d'Elche, ou le drame lyrique liturgique espagnol. Le Trépas e l'Assomption de la Vierge" (conférence destinée aux fêtes musicales de la Schola Cantorum Montpellier) La Tribune de Saint-Gervais, XI/10-11 (1905), 289-322; XI/12 (1905), 353-68 [Torner: Un detallado análisis del Misterio de Elche.]

128. - . La Festa d'Elche ou le drame lyrique liturgique espagnol. Le Trépas et l'Assomption de la Vierge. Documents pour servir à l'historie des origines du théâtre musical. París: Bureau de la Schola Cantorum, Société Française d'Imprimerie et de Librairie, 1906). 51 pp. [Conference destinée aux Fêtes musicales et populaires de la Schola Cantorum a Montpellier.] (B, C, S)

129. - La cançó popular catalana, la lírica nacionalisada y l'obra de l'Orfeó Català: il-lustracions $y$ notes breus. Barcelona: Societat la Neitipia, 1906. 60 pp. [Torner: Opúsculo con ilustraciones musicales. Contiene: I. Precedents y fonts de folklore musical; a) antichs y generals; b) moderns y especials (pp. 5-12); II. Elements musicals y carácter de la cançó catalana (pp. 12-15); III. Reintegració de la cançó popular al Art. y desvetllament de la lírica nacionalisada catalana (pp. 16-25); IV. L'obra del Orfeó Català (pp. 26-37).] (B, R, S)

130. - Lírica nacionalizada. Estudios sobre el folklore musical. París: Paul Ollendorf, 1913. 296 pp. [*Contiene también: La música en el folk-lore catalán (pp. 5-9); Cansons populars catalanas (recogidas y armonizadas por Francisco Alió) (pp.
23-28); Viejas canciones (pp. 175-79); La cultura musical seiscentista catalana (pp. 265-96).] (B, R, $\mathrm{S}, \mathrm{T})$

*131. - . "En San Marcial de Marratxi (Mallorca) y el Canto de la Sibila. Una nueva versión," MSH (Bilbao, Marzo, 1910) y como "Una nueva versión del «Canto de la Sibila», en su Lírica nacionalizada (París, 1913), pp. 205-10. (S)

132. - "Los cantos flamencos (Disquisiciones acerca del origen de este cante andaluz)," en su Lírica nacionalizada (París: Paul Ollendorf, 1913), pp. 11-15. (S)

133. - . "Folklore musical hispano," Arxiu d'Etnografia i Folklore de Catalunya: Estudis i Materials, núm. 1 (1916), 23-48. Conferencia-Audición dado durante el Curso de 1915-1916. [*Temas: I. Orientaciones sobre el folk-lore musical. El criterio etnográfico en la clasificación (pp. 23-30); II. «Las Cantigas de Santa María» (pp. 30-37); III. Las influencias del romance en el canto popular hispano (pp. 37-48).] (B, R, To)

134. - "La canción popular en los vihuelistas españoles seiscentistas," Arxiu d'Etnografía i Folklore de Catalunya: Estudis $i$ Materials, núm. 2 (1916), 61-88. Conferencia. (B, R, S)

*135. - . "Curso sobre la historia musical y étnica de la canción popular," Larousse Mensuel (Marzo, 1924). [*Publicado originalmente como "Història musical i ètnica de la canço popular," EUC, III (1907), 233-39, 319-25, y 523-30.] (B, R)

136. - . "Notes sur la chanson populaire espagnole et sur les documents relatifs au folk-lore espagnol," RevMus, V (1905), 142-46. (B, R, S)

137. - Cancionero musical popular español. Valls: Eduardo Casells, 1919-1922. 4 vols. [Vol. I (1919), 113, 151 pp.; vol. II (1920), 287 pp.; vol. III (1921), vi, 47, 233 pp.; vol. IV (1922), viii, 22, 149, + iii pp.).] [*2a ed. Barcelona: Boileau, 1948. 4 vols.; $3^{\mathrm{a}}$ ed. Barcelona: Boileau, 1958. 4 vols.]

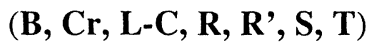

Pelay Briz, Francisco (véase Briz, Francesc Pelay, núm. 29)

138. Pol, A[ntonio] (Un Conrador). Folk-lore musical Mallorquin. Barcelona: Boileau, 1917. 2 vols. [Vol. I: Colección de canciones populares de Mallorca (23 pp.); vol. II: Colección de bailes típicos de Mallorca (15 pp.) (Para canto y piano).] [2a ed. 1925.] (B, Cr, R, R', S, To) 
139. Pujol, Francisco (Francesc). El Cant de la Sibil.la. Barcelona: L'Avenc, 1918. 23 pp. [Conferència llegida pel seu autor al Centre Excursionista de Catalunya. El exemples musicals foren cantats per la Srta. N'Andreua Fornelis)," BCEC, nos. 285-86 (Barcelona, 1918), 5-23; también en $R M C$, XVI/ 181-83 (1918), 1-18] [Torner: Con transcripción musical de varias versiones.] (B, L$\mathrm{C}, \mathrm{S}, \mathrm{T}$ )

140. - - "El vol d'una cançó," $R M C, \mathrm{XXVII/314}$ (1930), 49-56; XXVII/315 (1930), 114-22; XXVII/316 (1930), 145-52; XXVII/317 (1930), 202-07; XXVII/319 (1930), 297-302; XXVII/321 (1930), 411-15. Conferencia. [Torner: Curioso estudio sobre la divulgación en Cataluña y Baleares de la canción conocida con los nombres de «El bon caçador» o «El caçador i la pastoreta».] $(\mathbf{B}, \mathbf{R})$

141. Puyol Alonso, Julio. Cantos populares leoneses. Nueva York: Inst. de las Españas en los Estados Unidos, 1905. (12 canciones populares) [*Véase también $R H i$, XII/41 (1905), 250-58. Reimp. Nueva York: Kraus Reprint, 1961.] (B, R, S, To)

142. Ribera y Tarragó, Julián. La música de las «Cantigas». Estudio sobre su origen y naturaleza, con reproducciones fotográficas del texto y transcripción moderna. Madrid: Tip. de la Revista de Archivos, 1922. $156+345$ pp. [Véase también su Historia de la música árabe medieval... (Madrid, 1927).] (B, L-C, R)

143. - La música andaluza medieval en las canciones de trovadores, troveros y minnesinger. Madrid: Revista de los Archivos, 1923-1925. 3 vols. Madrid: Estanislao Maestre, 1924. [*Reimp. Nueva York: AMS Press, 1974.] [Torner: En las páginas preliminares de su obra $L a$ música de las «Cantigas» ofrece Ribera multidud de datos históricos del mayor interés para el estudio de la música tradicional andaluza.] $(\mathbf{B}, \mathbf{L}-\mathbf{C}, \mathbf{R})$

144. - . "De música y métrica gallegas," Homenaje ofrecido a Menéndez Pidal: Miscelánea de estudios lingüisticos, literarios y históricos (Madrid: Hernando, 1925), vol. III, pp. 7-35. [Torner: Es un notable estudio sobre la melodía de la muiñeira y su arraigo y extensión en la lírica general española y europea.] (B, R, To)

145. - - Historia de la música árabe medieval y su influencia en la española. Madrid: Voluntad,
1927. 355 pp. [Ejemplos musicales, pp. 342-48; bibliografía, pp. 349-51] (Colección de Manuales Hispania, Vol. I - Serie G) [*Reimp. Nueva York: AMS Press. 1975. Reimp. con revisiones. Prólogo y semblanza biográfica por Emilio García Gómez (Madrid: Mayo de Oro, 1985), 200 pp.] [*Esta edición consta del texto de la traducción abreviada de Ribera, La música de las «Cantigas» hecha por Eleanor Hague y Marion Leffingwell en Music in Ancient Arabia and Spain: being La música de las Cantigas. Stanford: Stanford Univ. Press, 1929. Reimp. Nueva York: Da Capo Press, 1970.] (B)

146. - . "Para la historia de la música popular," BRAH, CV (1927), 47-65. [Reimp. también en su Disertaciones y opúsculos (Madrid: Estanislao Mestre, 1928), pp. 252-74.] [Torner: Estudio comparativo de las canciones americanas y españoles] (B, R)

147. Riemann, Hugo. Folkloristische Tonalitätsstudien. I. Pentatonik und tetrachordale Melodik im schottischen, irischen, walisischen, skandinavischen und spanischen Volksliede und im gregorianischen Gesänge. Leipzig: Breitkopf und Härtel, 1916. 112 pp. (B, L-C, R)

148. Roca de Togores y Carrasco, Mariano (Marqués de Molins). "Las vicisitudes de la vieja Elche," Discurso leído en la Academia de la Historia en la recepción pública del Marqués de Molins el día 29 de junio de 1869. Madrid: Imp. y Estereotipia de M. Rivadeneyra, 1869. 99 pp. (firmada Madrid, 6 de Marzo de 1869.) [*Tiene también el título "Antigüedades de Elche." Publicada en Obras de... la Academia Española (Madrid: Fund. de M. Tello, 1890), vol. V, pp. 263-95.] (B)

149. Ruiz de Lihory, José (Baron de Alcahalí). $L a$ música en Valencia. Diccionario biográfico y crítico. Valencia: Establ. Tip. Doménech, 1903. xlii, 445 pp. [Torner: Contiene interesantes noticias relacionadas con el Misterio de Elche.] (B, C, L-C, $\mathbf{R}, \mathbf{S})$

150. Saldoni y Remendo, Baltasar. Efemérides de músicos españoles así profesores como aficionados. Madrid: D.A. Pérez Dubrull, 1860, xvii, 262 pp. [2a ed. revisada y aumentada, con el título nuevo Diccionario biográfico-bibliogáfico de enfemérides de músicos españoles. (Madrid, 18681881). 4 vols. [*Reimp. Barcelona: Isidro Torres, 1890; 4 vols. con 36 retratos. Vol. I, xviii, 343 pp; 
vol. II, xii, 589 pp.; vol. III, vi, 435 pp.; y vol. IV, vi, 445 pp.; Ed. facsímil. Ed. por Jacinto Torres, Madrid: Ministerio de Cultura, Centro de Documentación Musical, 1986 (386, 595, 400, 627 pp., respect. + Índices del Diccionario... 176 pp. $(\mathbf{C}, \mathbf{S}$, T)

151. Salinas, Francisco. FRANCISCI SALINAE BVRGENSIS / ABBATOS SANCTI PANCRATII de Rocca Scalegna in regno Neapolitano, et in Academia Salmaticensi / Musica Professoris, de Musica libri Septem, in quibus eius doctrince / veritas tam qua ad Harmoniam, quam quae ad Rhythmum / pertinet, iuxta sensus acrationis iudicium osten- / ditur, et demonstratur. / CVM duplici Indici Capitum \& Rerum. / Salmanticae / Excudebat Mathias Gastius. M.D.LXXVII. Impreso, (8) f.; 438 pp.; (9) f.; [*Ed facs. Macario Santiago Kastner, ed., Kassel: Bärenreiter, 1958. Para la traducción castellana, véase Ismael Fernández de la Cuesta, Francisco Salinas. Siete Libros sobre la música. Madrid: Ed. Alpuerto, 1983. 775 pp. + indice general (12 pp.). Véase también Arthur M. Daniels, De Musica Libri Septem of Francisco Salinas, diss. (Los Angeles: Univ. of Southern California, 1961).] (B, C, L-C, R, R', S, T)

152. Sbarbi y Osuna, José María. El refranero general español, parte recopilado, y parte compuesto. Madrid: A. Gómez Fuentenebro, 1874-1878.10 vols. [*Solo 400 copias publicadas. Reimp. Madrid: Atlas, 1980. Hay una discusión de la seguidilla en la introducción a vol. IV.] (S)

153. Schuchardt, Hugo. "Die Cantes flamencos," ZRPh, V (1881), 249-322. [*Reimp. Halle: E. Karras, 1881.74 pp. Véase también Los cantes flamencos (= Die Cantes flamencos). Edición, traducción y comentarios de Gerhard Steingress, Eva Feemstra y Michaela Wolf. Sevilla: Fund. March, 1990. 257 pp.] (S)

154. Serra i Boldú, Valeri. Llibre popular del Rosari. Folklore del Roser. Barcelona: Foment de Pietat Catalana, 1917. 208 pp. (con ejemplos musicales). [*I. Cobles de desperta i Misteris del Rosari (pp. 73-83); II. Goigs comuns de tot any (pp. 3591); III. Goigs propis de Advent i Quaresma (pp. 93-98); IV. Goigs dolors i glòries (pp. 99-104); V. Altres goigs varis (pp. 105-8); Etnografía Rosaria$n a$; II. Cançons de les majorales del Roser en bateigs, bodes i altres festes (pp. 131-43, con ejem- plos musicales).] [Torner: Es una monografía del Rosario en Cataluña, con reproducción de varias tonadas.] (B, R)

155. Soriano Fuertes y Piqueras, Mariano. Historia de la música española desde la venida de los fenicios hasta el año de 1850. Madrid: Martín y Salazar, 1855-1859. 4 vols. [Vol. 1, p. 186 contiene una discusión de la seguidilla.] (R, $\mathbf{S}, \mathbf{T})$

156. Subirá Puig, José. Música folklórica y erudita: sus entrongues. Valladolid: Imp. Castellana, 1933. 16 pp. Conferencia [pronunciada el día e de junio en el Teatro Calderón de la Barca.] (B, C, R, S)

157. Suñol y Baulenas, Gregori [Gregorio] María. "Els cants dels romeus (segle XIVe)," Analecta Montserratensia, I (1917), 100-92. [*Incluye "Danza de la primera veu" (p. 134); "Dansa de la Mort" (pp. 184-88); y "Dansa Moral" (pp. 18892).] [Torner: Es un documentado estudio de unas páginas de música que se encuentran en el manuscrito de Montserrat conocido con el nombre de «Llibre vermell».] $(\mathbf{B}, \mathbf{R}, \mathbf{T})$

158. - . "El cant religiós popular," Revista Montserratina, V/11 (1911), 696-99. [Citado por Torner como vol. VIII.] (B, R, To)

159. - . "Cantigues de Montserrat del rei Anfós X, dit «El Savi»," Analecta Montserratensia, V (1922) [1924]), 361-417. [Torner: Se publicó este trabajo coincidiendo con el centenario de Alfonso el Sabio. La versión musical de las sies Cantigas que inserta fue revisada por el musicógrafo F. Ludwig y responde a la teoría ritmico-modal. Dice Suñol que no es este sistema el único posible pero que "ofrece más sólidas garantías ya comprobadas en la práctica, que el ideado por el Sr. Ribera."]

160. Tafall y Abad, Santiago. "La tonalidad y el ritmo en la música popular de Galicia," Galicia Histórica, I/3 (1901), 180-83; I/4 (1902), 265-76; II/7 (1903), 496-507. (B, R)

161. - . "Las canciones de los ciegos ante la Puerta Santa," BRAG, XI/128 (1919), 205-10; XI/ 129 (1919), 235-42. (B)

162. - . "Las Canciones de la Puerta Santa en los años de Jubileo Compostelano," El Ideal Gallego (25 de julio de 1926), 25.

163. Tejada, Carlos S. de. Algo sobre música árabe y los cantos andaluces en Tlemcen. Melilla: Tip. el 
Telegrama del Rif, 1918. Folleto de 12 pp. (firmada Oran, March 1918). (B, R, S)

164. Torner, Eduardo Martínez. Cancionero musical de la lírica popular asturiana. Madrid: Tip. Nieto, 1920. xlii, 278 pp. (500 melodías) [*Reimp.: Oviedo: IEA, 1971, 1986 y 2000. lxii, 278 pp., con un ensayo biográfico sobre "Eduardo Martínez Torner (1888-1955)" por Modesto G. Cobas (pp. vii-xxi).] [Introducción: I. Algunas notas sobre el origen de la música popular" (pp. xxvii-xxx); "II. El ritmo de la música popular" (pp. xxxi-xxxiv); III. "Ensayo de una clasificación musical de las melodías populares" (pp. xxxv-xlv); IV. "Característica de la canción asturiana" (pp. xlvii-liv); V. "Interés del folklore musical. -Desaparición de los primitivos documentos populares y sus causas. -Conclusión" (pp. lv-lxii) plus los apendices: 1: "Notas a las canciones" (pp. 199-251); II, "Clasificación de las canciones por su aplicación" (pp. 255-56); II. "Principales vocablos y frases en bable contenidos en este cancionero" (pp. 259-76).] (B, Cr, L-C, R, R', S, T, To)

165. - Indicaciones prácticas sobre la notación musical de los romances. (Madrid: JAEIC, CEH (1923), pp. 27-33. [También en RFE, X (1923), 389-94.] (B, R, S, To)

166. - - "Ensayo de clasificación de las melodías de los romances," Homenaje ofrecido a Menéndez Pidal: Miscelánea de estudios lingüisticos, literarios y históricos. (Madrid: Hernando, 1925). Vol. II, pp. 391-402. (B, R, S, To)

167. - . "La canción tradicional española," en Francisco Carreras y Candi, ed., Folklore y costumbres de España (Barcelona: Alberto Martín, 1931), Vol. II, pp. 7-166. (B, Cr, R, S)

168. Tort i Daniel, Jacint E. Noticia musical del «Lied» o cançó catalana. Barcelona: Imp. de Heinrich y $\mathbf{C}^{\mathrm{a}}$., 1892.42 pp. [Extraído del $B C E C$, II/4 (Enero-marzo, 1892), Parte I (41-49); núm. 5 (Abril-junio, 1892), Partes II y III (47-58); núm. 6 (Julio-septiembre, 1892), Partes IV y V (18-29); III/11 (Enero-marzo, 1893), Partes VI y VII (3442).] (B, R, S)

169. Trend, J[ohn] B[rande]. The Music of Spanish History to 1600. London: Oxford Univ. Press, 1925. xv, 288 pp. [*Los capítulos incluyen: The Moors (pp. 9-37); The Visigoths and Mozárabes (pp. 38-52); Alfonso el Sabio (pp. 52-65); Early
Galician Music (pp. 66-85); Early Catalan Music: (pp. 86-95); The Music of the Romancero in the Sixteenth Century (pp. 96-119); Madrigals and Villancicos (pp. 120-32); Juan del Encina. Morales and Victoria (pp. 133-70)] [Torner: Les precede una introducción en la que el autor presenta ideas originales acerca de la influencia que la cultura árabe ejerció sobre nuestra música nacional. Señala las diferencias que, a su juicio, existen entre el «cante jondo» y el «cante flamenco» y hace curiosas observaciones acerca del «orientalismo» de estos cantos, el cual, para Trend, reside más en la manera de ejecutarlos en su esencia misma.] (B, $\mathrm{Cr}, \mathrm{L}-\mathrm{C}, \mathrm{R}, \mathrm{S}$ )

170. - . "The Mystery of Elche," $M L, \mathrm{I} / 2$ (1920), 14557. (T)

171. - . "Music in Spanish Galicia," $M L$, V/1 (1924), 15-32. [*Sampedro y Folgar, Cancionero, p. 58: Visión de conjunto de lo histórico y lo folklórico en la música de Galicia, con catorce ejemplos habilamente seleccionados.] [Torner: De interés para la historia de la música religiosa y profana en España y en particular de la folklórica gallega.] (B, R)

172. - Spain from the South. London: FromeButler and Tanner, 1928. xi, 256 pp. [Torner: Trata extensamente de la música popular andaluza.] (B, R, S, To)

173. - . "The Performance of Music in Spain," PMA, LV (1928-1929), 51-76. [Torner: Constituye un compendio histórico en el que se nos da a concocer, desde un punto de vista original, cómo se ejecutaba la música en España en las diferentes épocas comprendidas entre los siglos IX y XVIII inclusives. El investigador no se limita a copiar lo que dicen los manuscritos o a las exposiciones de los teóricos, no siempre claras y suficientes, sino que, a fin de obtener una visión más ámplia y también más segura de lo que era la música española en aquellas épocas y cómo se ejecutaba, fija su atención en las representaciones de instrumentos y ejecutantes que se encuentran en la escultura, los marfiles, miniaturas, etc., y en descripciones coetáneas en prosa o verso.] $(\mathbf{B}, \mathbf{R}, \mathbf{S})$

174. " ¡Ultreja! Canto de los peregrinos flamencos al Apóstol Santiago (Códice de Calisto II, folio CXCII)" Galicia Diplomática, II/1 (8 de julio de 1883), 6-8; II/2 (15 de julio), 16; II/3 (22 de 
julio), 23; II/6 (12 de agosto), 47-48; II/7 (19 de agosto), 55-56; II/8 (26 de agosto), 63-64; II/9 (8 de septiembre), 70-71; y II/10 (8 de septiembre), 79-80. [*Es el informe de D. Franciso Asenjo Barbieri dado por la RABASF a la RAH. Véase también los núms. 71 y 72.] (S)

175. Urquijo, Julio de. "El Misterio de la Pasión representado en Fuenterrabía. El año 1602," RIEB, III (1909), 331-39 [Con motivo de la publicación de «Helène de Constantinopla».] (B)

176. Valladar, Francisco de Paula. Apuntes para la Historia de la música en Granada» desde los tiempos primitivos hasta nuestra época. Granada: Tip. Comercial, 1922. 88 pp. (B, R, S)

177. van der Straeten, Edmond. La Musique aux Pays-Bas avant le XIXe siècle. Documents inédits et annotés. Compositeurs, virtuoses, théoriciens, luthiers; opéras, motets, airs nationaux, academies, maitrises, livres, portraits, etc. Avec planches de musique et table alphabétique. Bruselas: C. Muquardt, Librairie Européene, 1867-1888. 8 vols. [*Vol. I (1867), xii, 321 pp.; vol. II, xii, 423 pp. Brussels: G-A. Van Trigt, Éditeur-Libraire; vol. III (1973), xiv, 365 pp.; vol. IV (1878) xvi, 442 pp.; vol. V (1880), xxi, 442 pp.; vol. VI (1882) [Les musiciens néerlandais en Italie], xii, 597 pp.; vol. 7 (1885) [Les musiciens néerlandais en Espagne]; ler Partie, xvii, 550 pp.; Vol. VIII (1888), 2e Partie, xi, 581 pp. (C)

178. Varela Lenzano, Indalecio. Estudio sobre los orígenes y desarrollo de la música popular gallega. Lugo: DP, 1892. 58 pp. [ ${ }^{*} \mathrm{C}$. Sampedro y Folgar 1942:58: Esquema histórico de la música gallega que, sin aportación de novedades, representa una estimable oposición a las fantasías divulgadas por Varela Silvari y sus seguidores.] $(\mathbf{B}, \mathbf{R}, \mathbf{S})$

179. Varela y Silvari, José María. La música popular española. Estudio crítico e histórico acerca de los cantos, bailes é instrumentos populares usados en todas las provincias y pueblos de España. Mondoñedo [Lugo]: Imp. de Hermenegildo Mancebo, 1883. 139 pp. [*Contiene: "Observaciones generales acerca de la música popular” por M. Soriano Fuentes (pp. 11-20); Galicia (pp. 21-41); Asturias (pp. 42-47); León (pp. 48-49); Provincias vascas (pp. 50-54); Castilla (pp. 55-59); Cataluña (pp. 6078); Islas Baleares (pp. 79-84); Valencia (pp. 8591); Alicante (pp. 92-97); Murcia (pp. 98-103);
Andalucía (pp. 104-19); Aragón (pp. 120-24); Los bohemios españoles (artículo adicional) (pp. 12529); Consideraciones finales (pp. 130-34); Conclusión (pp. 135-39).] [*Esta obra resultó de unas observaciones precipitadas en una revista hispanoamericana (sin nombre) entre los años 1864 o 1865, reproducidas más tarde en La España Musical (1874), y más recientemente en El Eco Musical.] $(\mathbf{B}, \mathbf{R}, \mathbf{S})$

180. Verdú, José. Colección de cantos populares de Murcia, recopilados y transcritos por... Barcelona: Vidal Llimona y Boceta, 1906. 128 pp. (contiene 40 melodías para canto y piano). [Reimp. Madrid: Orfeo Tracio, c. 192?.] (B, Cr, R, R', S, To)

Viaje literario a las iglesias de España (véase núm. 281)

181. Vidal, Pierre. Cançoner català de Rosellò y de Cerdanya. Perpignan: Imprimerie-Librairie A. Julia, 1885-1888. 5 folletos. [*1 (1885): Corrandes (33 pp.); 2 (1885): Cansons del pandero (23 pp.); 3 (1887): Balls y ballades y contrapàs llarch (31 pp.); 4 (1888): Cansons populars (66 pp.); 5 (1888): Relació de la vida del pastor (28 pp.); Cada folleto contiene un léxico catalán-français.] $(\mathbf{B}, \mathbf{S})$

182. Vidal Rodríguez, Manuel. La Tumba del Apóstol Santiago. Santiago: Seminario C. Central, 1924. 229 pp. [Torner: El cap. XXIII: Literatura Jaco$b e a$, trata de los himnos de los peregrinos. Transcripciones musicales.] (S)

*183. Vidal y Valenciano, Cayetano. "El tránsito y la Asunción de la Virgen," Diario de Barcelona, núm. 224 (12 agosto, 1870), 8, 133ff; núm. 238 (26 agosto, 1870), 8, 613ff; núm. 244 (1 septiembre, 1870), $\mathbf{5 , 8 1 4 f f ~ [ * R e i m p . ~ e n ~ O b r a s ~ c o m p l e t a s ~}$ de Milà y Fontanals, Vol. VI, pp. 320-40; con el texto del Misterio (pp. 341-47) [*Reproducido de l'Epítome histórico de Elche desde su fundación hasta la venida de la Virgen inclusiva por Francisco Fuentes Agulló. Elche: M. Santamaría, 1855.] (B)

184. Villar, Rogelio. "Cantos y bailes populares leoneses," $\boldsymbol{R} \boldsymbol{M H A}, \mathbf{V I I} / 13$ [= 2a época] (1915), 3-6. (B, L-C, R, S, To)

185. Vindel, Pedro, ed. Martin Códax. Las siete canciones de amor. Poema musical del siglo) XII. Publicase en facsímil, ahora por primera vez con algunas notas recopilados por.... Acompañado de nueve fotograbados. Madrid: [Suceso- 
ra de Munesa], 1915. 14 pp. + facsímiles en detalle sobre fotografías restauradas ( $25 \mathrm{pp}$. sin números). [ ${ }^{*}$ C. Sampeldro y Folgar 1942:52: Tirada limitada, de la cual se pusieron a la venta diez ejemplares; y en p. 79, n. 99, nos dijo que Vindel "dió noticia del hallazgo en la revista Arte Español, III (1914), 27-31.”] [Torner: Estas canciones, de las que sólo seis tienen la música, fueron descubiertas y publicadas por don Pedro Vindel en 1915 en reproducción fotográfica del original. Pertenecen a los primeros años del siglo XIII y constituyen hasta ahora el documento más antiguo de nuestra música profana de carácter conservada por la tradición escrita.] (B)

186. Ximénez Cos, Eduardo. Música de los cantos populares de Valencia y su provincia. Transmitidos al papel y coleccionadas, por el Pfr. de música valenciano,... (Fechada: Valencia 10 de abril de 1873). Ms. inédito. [*Preámbulo por Emiliano Teipero: Cantos populares de Valencia y su provincia. Los instrumentos que acompañan a estos cantos son: guitarra, guitarró, octavilla, cítara (todas guitarras), donsaina (como la dulzaina), tabolet (tamboril). 1. La alcantina; 2. La jota del Carrér; 3. El ú y el dos; 4. Jota valenciana; 5 . El paño moruno; 6. El punto de la Habana; 7. Les Albáes; 8. La Xáquera vella; 9. Lama-Organa, danza; 10. El faito, episodio del Ball de Torrent; 11. Para procesiones] [Torner: Es esta, sin duda, la colección más notable de canciones valencianas. Ignoro el lugar y año de su impresión, pues yo he manejado sólo el manuscrito original que se conserva en la Biblioteca Nacional (Madrid) con la signatura M. 1020.] (B, R, R', S)

\section{ORGANOLOGÍA}

187. Amades, Juan. "La cornamusa a Catalunya,"

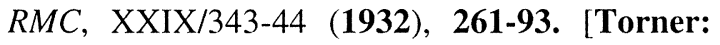
Estudio histórico sobre este instrumento.] (B, R)

188. Apraiz Buesa, Ángel de. "Instrumentos de música vasca en el Alto Aragón," RIEB, XIII (1922), 553-59. [Torner: Se refiere el autor a un tamboril especial de seis cuerdas que se templan con clavijas.] (B, R, S)

189. - . "Más tamboriles de cuerdas en la región pirenaica," RIEB, XV (1924), 183-87. (B, R)
190. Arana Pérez, Ramón de (Pizzicato). "De folklore: Solo de gaita," BRAG, VI/43 (1911), 16168; VI/44 (1911), 204-07; VI/45 (1911), 224-31. [Véase la $R M B$, III/8 (1911), 177-89. [Torner: Noticia de las representacines iconográficas de la gaita gallega.] $(\mathbf{B}, \mathbf{C}, \mathbf{R})$

191. - . "De folk-lore: Solo de gaita (Coda)", Almanaque de Ferrol (1910) y BRAG, V/53 (1911), 118-26. (B)

192. Aranzadi Unamuno, Teleforo de. "Alboka y albogues (Dos pies para un banco musical-transfilológico)," Euskal-Erria, LXXIV/1147 (29-II1916), 152-58. [Reproducido en el BCMHAN (1915), 239-44.] (B, R)

193. Bajoncillo. [Torner: "El instrumento músico que en esta edad se llama bajoncillo, fué inventado por Francisco Valdés, natural de Asturias, músico de instrumentos de cámara y Real Capilla del rey nuestro señor D. Felipe IV, y maestro de su ministriles. Floreció, siendo eminente en su arte, en los reinados de Felipe III y IV." Así consta en unos (el cuarto de cuatro) Apuntes históricos tomados de un "libro escrito por D. Lázaro Díaz del Valle, cronista de S.M. en la época de Felipe IV" y publicados en la $R G M, \mathbf{I I} / \mathbf{8}$ (Madrid, 24 febrero de 1868), 36.]

194. Barbieri, Francisco Asenjo. [Torner: Notas y facsímiles de instrumentos antiguos de música. Constan en un legajo de papeles manuscritos que se guarden en la Biblioteca Nacional con el número 140683. Las noticias están tomadas de varias obras de la literatura castellana. Los facsímiles, finalmente dibujados a lápiz, son principalmente de los códices de las Cantigas de Alfonso el Sabio.]

195. Bermudo, Fray Juan. Declaración de instrumentos musicales. (Osuna: Juan de León, 1549). [2 ${ }^{\mathrm{a}}$ ed. (Osuna, 1555)] [*Conocido también como Comiença del libro llamado declaraciõ de instrumentos musicales] [Véase H. Anglés y J. Subirá 1946, vol. I, p. 448] [*Documenta Musicología, 11. Erste Reihe: Druckschriften-Faksimiles. Faksimile Nachdruck herausgegeben von Macario Santiago Kastner. Kassel: Bärenreiter-Verlag, 1957. Association Internationale des Bibliotheques Musicales. Internationale Gesellschaft für Musikwissenschaft. Ed. facsímil. Madrid: Arte Tripharia, 1982] [Torner: Esta obra es de capital importancia para el estudio de la organografía musical espa- 
ñola. Se describen y analizan en ella con toda minusciosidad el arpa, la vihuela e instrumentos similares, la flauta, la dulzaina y el órgano.] (B, LC, S)

196. Bofarull Saratorio, Manuel de. [Torner: Apuntes tomados en el Archivo de la Corona de Aragón referentes a cuestiones musicales. Siglo XIV. Manuscrito autógrafo que se conserva en la Biblioteca Nacional con el número 14060. Solicitó Barbieri de Bofarull, archivero en el de la Corona de Aragón, las noticias que pudieran encontrarse en este Archivo referentes a música. Este diligente archivero remitió a Barbieri una buena colección de copias de documentos del siglo XIV interesantes para la historia de la música española en la Corte del rey de Aragón D. Juan I. Entre los instrumentos músicos se citan: arpa, bombarda, cítara, cornamusa, chalamía, xalamía o xelemía, exaquier, jábeca o jabega, neo canon, órgano, rabel, rabena, rota, trompeta, viola, y un instrumento semblant dorguens qui sona ab cordes.]

197. Bosch Humet, Eusebio. Organología general de todos los instrumentos musicales. Madrid: Idelfonso Alier, ca. 1918. 240 pp. [Torner: Ilustrada con 119 dibujos de instrumentos antiguos.] (B, R, S)

198. "Capiteles con músicos en el Palacio de Gelmirez, en Santiago (siglo XII)," Vida Gallega, XI/123 (1919), desde la portada correspondiente a la página 21. [*Título de la página: El Palacio de Gelmirez. Nuevos detalles arquitectonicos del palacio románico de orden civil más importante de Europa. Obras de restauración costeadas por el Cardenal Herrera bajo la inteligente y entusiasta dirección del Canonigo D. Manuel Cairo. La página solo contiene fotos. Pie de foto: Capiteles que representan reyes y músicos.]

199. Chía, Julián de. Relación rectificada de los instrumentos músicos que asistieron a las antiguas procesiones y fiestas públicas celebradas en Gerona, con expresión de los años en que respectivamente fueron apareciendo en ellas, según resulta de los documentos existentes en el archivo municipal (Gerona, 1883). [Torner: Manuscritos que su autor envió a Barbieri como contestación a preguntas que éste le hacía sobre instrumentos antiguos de música. Se conserva en la Biblioteca Nacional con el núm. 14.068. Los 35 instrumentos que se citan pertenecen a los siglos XIV, XV y XVI.] [Véase núm. 43. "Memoria: Instrumentos musicales" (pp. 97-122).]

200. Cifras para arpa, de fines del siglo XVII à principios del XVIII (B. N. Madrid, M-816) [*1. Tonada: «Cupidillo desleal» (1-1a); 2. Tonada: «Filiz Divina» (2); 3. Tonada: «Después que tebi una noche» (2a-3); 4. Diferencias de las folías (3a-f); 5 . Diferencias des Marizapalos (4a-5); 6. Minuette (5a); 7. «San Juan de Lima» con sus diferencias (67a); 8. La gaita francesa (8-9a); 9. «Oyes Belisa» y sus diferencias (10-12); 10. Pasacalles de quinto tono (12a-13); 11. Pasacalles de octavo tono con sus diferencias (13a-14a); 12. Tonada (15-16a); 13. Paradetas (17); 14. Pasacalles de séptimo tono (17a); 15. Siguidillas (18-19); 16. Clarines (19a23); 17. «Canzon» flamenca aclarinada (23-24a); 18. La jota (25); 19. La jotta (26-27); 20. Solo umano «Oies oies manguilla» (17a-28a); 21. Minuet de primer tono (29-29a); 22. Otro primer tono (30); 23. Otro de quinto tono de diablo (2929a); 24. Otro [Minuet] (29a); 25 Otro primero (30); 26. Minut (sic, por Minuet «De los zelos los desvelos» (30a); 27. Aria de Colisco «A saltado esta mi pecho» (31-32a); 28. Solo humano de Durón (33-34a); 29. Aria «El Dios de los raios» (35-35a); 30. Minut (sic, por Minuet «Alevoso niño engañoso Dios» (36); 31. Otro tono humano de Durón: «Que quieres amor maltratame» con estribillio y coplas. Al final. Pasacalles de este tono (37a); 32. Lamentazión de la Reina de Umgaría (38-38a); 33. Tonada umana «Yo soy un maestro de coches» con introducción y colas (39-39a).]

201. Clavi-harpa. [Torner: El instrumento que llaman clavi-harpa, fue inventado por Juan Hidalgo, músico de arpa en la Real Capilla del rey nuestro señor D. Felipe IV, en cuyo tiempo floreció, siendo eminente músico y compositor de lindo gusto, de tonos divinos y humanos.] [*Véase "Apuntes históricos," en la $R G M, \mathrm{II} / 8$ (Madrid, 24 febrero de 1868), 36.]

202. Garnault, Paul. "Le Tambourin et le galoubet en Pays Basque et dans la Péninsule Ibérique," RIEB, XXII (1931), 123-30. (B)

203. Instrumentos de música tasados por Juan de Rojas Carrión, violero en Madrid a 13 de mayo de 1602. [Torner: Con este título se guarda en la Biblioteca Nacional entre los papeles manuscritos 
que pertenecieron a Barbieri, con el número 14017, una copia de la «tasación hecha en Madrid el 13 de mayo de 1602 ante el escribano Cristóbal Herroche y en presencia de Antonio Voto, guardajoyas de S.M. por Juan de Rojas Carrión, violero, Alonso de Morales, corneta de la Real Capilla y José de Isasi, organista». Se citan en este documento «cinco bihuelas de arco, la una muy grande y las otras cuatro pequeñas de madera de Alemania». "Cuatro violones grandes, medianos y pequeños, hechos en China." "Una tiorvia de trece órdenes." Otra "con dos cabezas, de hechura de laud.". «Un laúd con la cabeza más derecha que los ordinarios." "Otro laud como el dicho, un poco menor, de ocho órdenes." Otro de diez órdenes; dos de siete órdenes; otro pequeño. "Un bandurria de cuatro órdenes, la tapa de enebro y la barriga de una concha natural de tortuga." Otra bandurria de cuatro órdenes.]

204. Memorial que D. Juan Espina envió a D. Felipe $I V$. [Torner: Este memorial parece escrito en Sevilla el año 1692. El original se conserva en la Biblioteca Nacional de Lisboa, secc. de mss. con la sig. ${ }^{a}$ H.6.38. en tomo en fol. pergamino que contiene varios mss. musicales. Nota puesta por Barbieri a esta copia que se conserva en la Biblioteca Nacional con el número 14075. Es muy interesante. Señala una guitarra trasteada científicamente por Espina, teniendo en cuenta los tonos y semitonos. Entre los varios músicos que se nombran figura el Maestro Capitán.]

205. Menéndez Pidal, Ramón. Poesía juglaresca y juglares. Aspectos de la historia literaria y cultural de España. Madrid: JAEIC, CEH, 1924. viii, 488 pp. [Torner: Es de gran utilidad para el estudio de la organografía musical española por describir los instrumentos usados por los juglares.] (B, $\mathbf{R}, \mathbf{L}-\mathrm{C}, \mathrm{S}$ )

206. Nassare, Fr. Pablo.Escvela mvsica segvn la practica moderna: / divida en primera y segunda parte, / esta primera continene quatro libros, / El primero / trata del sonido armonico, de svs / divisiones $y$ de sus efectos / El segvndo, del canto llano, de zv vso en la / iglesia, y del prouecho espiritual que produce. / El Tercero, / del canto de organo, y del fin, porqve / se introduxo en la iglesia, con otras advertencias necessarias. / El qvatro, / de las proporciones que se contraen de / sonido à fondo; de las que han de llevar cada instrumento / músico; y las observancias, que han de tener/los artifices de ellos.... Zaragoza: Herederos de Diego de Larvmbe, 1724. 501, [10] pp. [Torner: Cap. 14.-En que se trata de las dimensiones de los instrumentos músicos en general; Cap. 15.-De las proporciones que deben guardar los artífices en las fábricas de los instrumentos Arpa, Vihuelas, Guitarras y todo instrumento de arco. Cap. 16.-De las proporciones que deben observar las artífices en los instrumentos de Claviórganos, Clavicordios, Clavicímbalos, Espinetas. Monocordios y Cítaras; Cap. 17.-De los instrumentos flatulentos y de las proporciones que se deben observar en ella. Cap. 18.-En que se trata la disposición de la cañutería en los Organos y de las proporciones que se deben observar en ella. Cap. 19. - En que set trata las proporciones con que se han de trabajar las partes materiales y esenciales de un Organo. Cap. 20.-En que se trata la afinación de los Organos en toda especie de cañutería.] [Véase Almonte C. Howell, Jr., 'Pablo Nasarre's Escuela música: A Reappraisal," en James W. Pruett, ed., Studies in Musicology : Essays in the History, Style, and Bibliography of Music in Memory of Glen Haydon (Chapel Hill: Univ. of North Carolina Press, 1969), pp. 80-108.] (B, S)

207. Olazarán de Estella, Hilario. "Txistu: lo que es y cómo se toca," $E A$, XVIII/300 (1928), 456-65, 8 pp. (música). [También separata de 14 pp.] (B, R) *208. - Método de txistu. Tratado de flauta vasca. Nueva ed. aumentada (Bilbao, 1933). [*Véase su Tratado de txistu y gaita. Pamplona: Diputación Foral de Navarra, 1972.] (B)

209. Pedrell, Felipe. Emporio científico e histórico de organografía musical antigua española. Barcelona: Juan Gili, 1901. ix, 147 pp. [*Preliminares (pp. 7-35); Parte primera: Enumeraciones de instrumentos (pp. 36-80); Parte segunda: Descripción y construcción de instrumentos (pp. 81-117); Parte tercera: Acoplamiento polifónico de los instrumentos (pp. 118-36).] (B, C, Cr, R, T)

210. Requeno, Vicente [Vicenzo]. Il tamburo, stromento di prima necesita pel regolamento delle truppe. Rome: Luigi Perego Salvioni, 1807. 93 pp. [Torner: Opúsculo en el que estudia el autor este instrumento y trata de su importancia en el conjunto musical.] 
A Closer Look at Eduardo M. Torner's Bibliographic Survey of Spain's Traditional Music and Dance

211. Roda, Cecilio de. Ilustraciones del Quijote. Los instrumentos músicos y las danzas. Las canciones. Madrid; Bernardo Rodríguez, 1905. 47 pp. Conferencias [dadas en el Ateneo de Madrid los días 1 y 13 de mayo de 1905, con ocasión del tercer centenario del Ingenioso Hidalgo Don Quijote de la Mancha.] (B, C, R, S, T)

212. Sanz, Gaspar. Instrucciones de música sobre la guitarra. [*Reproducción en facsímil de los libros primero y segundo de la tercera edición (1674) y del libro tercero de la edición octava (1697). Prólogo y notas de Luis García-Abrines. Zaragoza: Institución Fernando el Católico de la Excma. DP, CSIC, 1952. 134 pp.] [*Instrucción de música sobre la guitarra española y método de los primeros rudimentos hasta tañerla con destreza. Compuesto por el licenciado Gaspar Sanz, argonés, natural de la villa de Colanda, Bachiller en Teología por la insigne Univ. de Salamanca.]

213. Serrano y Fatigati, Enrique. Instrumentos músicos en las miniaturas de los códices españoles siglos X al XIII. Madrid: Imp. de San Francisco de Sales, 1901. 49 pp. Discurso (pp. 1-30). [Torner: Reproduce numerosas miniaturas de los siglos X al XIII.] (B, C, R, S, T)

214. Soriano Fuertes, Mariano. Música árabe-española y conexión de la música con la astronomía medicina y arquitectura. Barcelona: D. Juan Oliveres, 1853. $133 \mathrm{pp}$. [Torner: Traduce una relación de instrumentos músicos usados por los árabes andaluces y escrita por el Cadí Mahamud Ibrahim Axelehi. En las páginas 33 a 35 aparece un extracto de la definición que hace Alfarabi de algunos instrumentos músicos.] $(\mathbf{B}, \mathbf{C}, \mathbf{T})$

215. Tratado del 'ud árabe, modo de templarlo y acompañar el canto según los diversos metros, y explicación de los ocho sonidos, expresándolos por las ocho primeras letras del alfabeto: 4 fols.; trae un grosero dibujo del laud en carmin. [Este ms., compuesto casi por entero de poesías en diversos metros y sobre varios asuntos, puede dividirse en esta forma (5 partes).] [*Véase Francisco Guillén Robles, ed., Catálogo de los Mss. árabes existentes en la Biblioteca Nacional de Madrid (Madrid: Tello, 1889), Ms. 334, no 2 Poesías árabes. 137 folios. Este tratado se precidido y seguido por «poesías árabes».] [Torner: Enseña este tratado la manera de acordar el instrumento y de acom- pañar el canto y explica los ocho sonidos de la escala, expresados por las ocho primeras letras del alfabeto. Contiene un curioso grabado que reproduce el mástil del instrumento, en el que están señaladas las diversas cuerdas y sobre ellas, indicado con cifras árabes, el sitio en que se deben pulsar para obtener el sonido deseado. La fecha de este manuscrito parece ser la del siglo XV. La tablatura musical tiene alguna analogía con la empleada en el siglo XVI por los vihuelistas.] [*El tratado "Ma'rifat al-na-ghmât al-thamân" se describido y traducido en inglés por Henry George Farmer, An Old Moorish Lute Tutor (Glasgow: The Civic Press, 1933), pp. 2-9.]

216. Truchado, Fr. Raimundo. [Torner: En la sección de manuscritos de la Biblioteca Nacional, número 14.009, hay una carta dirigida a Barbieri por don Patricio Herencia, anticuario, firmada en Toledo en 1874, comunicando a aquél haber adquirido un órgano construído en 1625. Hace del instrumento la siguiente descripción: «En un cajón de pino sobre tres pies, de figura de piano de cola, o sea estrecho de arriba, hay cigüeña o manubrio que mueve por medio de correones cuatro ruedas a la vez; sobre ellas caen las cuerdas, que son de tripa en número de cuarenta y cinco, colocadas en la forma de la oblicuidad de las ruedas. A estas cuerdas las cogen unos ganchitos de alambre cuando se tocan las teclas, que las acercan a las ruedas, que a su paso y con el movimiento de ellas las hacen sonar. Es decir, al revés de los pianos, pues los macitos de éstos dan en las cuerdas y estas otras acercan las cuerdas para que suenen. Su extensión 4 octavas, octava corta. Su número 45 teclas: 18 negras y 27 blancas. Su inventor Fray Raimundo Truchado, según la leyenda que tiene la tapa por dentro, y el año dicho (1625), y en la cual hay pintado, todo por dentro, las tres gracias y el Jardín de Versalles, todo de mérito. Tal es la descripción; me han dicho pudiera llamarse Piano-Violon-chuelo por sus efectos músicos, pero en la realidad nadie le ha podido dar nombre seguro, pues no conocen otro igual."']

217. Valverde, Joaquín. La flauta, su historia, su estudio. Madrid: Suc. Rivadeneyra, 1886. 162 pp.

218. Villaamil y Castro, José. "Algunas notas acerca de la representación de gaiteros en los monumen- 
tos de Galicia," Galicia Histórica, I/1 (1901), 3335. $(\mathbf{R})$

Ximénez, Eduardo (véase núm. 186)

\section{DANZAS Y BAILES}

Torner: En [esta sección]... reúno los principales trabajos literarios que tratan de las danzas y bailes de carácter popular y actuales en nuestro folklore. Quiero decir con esto, que no se hallará aquí la literatura referente a las danzas y bailes antiguos: Zarabanda, Chacona, Rugero, etc., etc. Su inclusión alargaría demasiado [esta sección] y por otro lado puede encontrarse en su mayor parte en algunas obras de investigación, como en la de [Emilio] Cotarelo y Mori [véase núm. 221]. No ocurre esto, en cambio, con los trabajos aquí reunidos.

Sobre coreografía española de los siglos $\mathrm{XV}$, XVI y XVIII, prepara el Centro de Estudios Históricos un amplio estudio en el que se recogen más de quinientos títulos de danzas y bailes, sus referencias, históricas, descripción de su técnica coreográfica y transcripción y análisis de su música. Figurará en esta obra un extenso indice bibliográfico con inclusión de aquellas publicaciones extranjeras en que se alude a algún aspecto de nuestra antigua coreografía.

En la siguiente relación distribuyo los trabajos por regiones. No hay grupo aparte para los de carácter general por la sencilla razón de que aún no se ha publicado nada notable en este sentido, pues el excelente trabajo de [Aurelio] Capmany [véase núm. 219], más se refiere a lo antiguo que a lo folklórico actual, y los demás que pudieran citarse son sumamente elementales e incompletos y sus noticias fueron tomadas de varios de los regionales que aquí constan.

[Los siguientes] son las principales fuentes informativas sobre nuestra danza folklórica. Pueden consultarse también los cancioneros regionales señalados en el capítulo dedicado anteriormente a la bibilografía de la canción y en los cuales figura una sección dedicada a los bailes y danzas.

219. Capmany [i Farrés], Aureli. "El baile y la danza," en Francisco Carreras y Candi, ed., Folklore y costumbres de España (Barcelona: Casa Ed. Alberto Martín, 1931), vol. II, pp. 169-418. (B, Cr, R, S)
220. Charbonnel, Raoul. El baile. Cómo se bailaba y cómo se baila. Parte ténica por la señora Berta Bernay, profesora en la ópera. Parte musical por los señores don Francis Casadesús y don Jules Maugué. Traducido del ed. francés por Antonio Sánchez Pérez. París: Garnier Fréres, 1901. x, 462 pp. [Hay una discusión de la seguidilla (pp. 387-90).]

221. Cotarelo y Mori, Emilio. Colección de entremeses, loas, bailes, jácaras y mogigangas, desde fines del siglo XVI a mediados del XVIII. Madrid: Casa Editorial Bailly / Balliére, 1911. 2 vols. (Nueva Biblioteca de Autores Españoles, vols. 17 y 18). $(\mathbf{B}, \mathbf{R}, \mathbf{S})$

"Danzas del Corpus en Sevilla" (véase Minos, núm. 223)

Soriano Fuertes y Piqueras, Mariano [Véase núm. 155: Vol 1, cap. VI (pp. 172-97) que pertenece a las danzas y bailes.]

\section{Andalucía}

222. Más y Prat, Benito. "Bailes de palillos y flamencos," en su La tierra de María Santisima. Colección de cuadros andaluces. Ilustraciones de J. García y Ramos (Barcelona: Sucesores de N. Ramírez y C $C^{a}$ Editores, 1891), pp. 121-42. [2 ${ }^{\mathrm{a}}$ ed. Sevilla: Bienal de Arte Flamenco, Fund. Machado, 1988.] (B, S)

223. Minos. "Las danzas del Corpus en Sevilla," Noticiero Sevillano, III/789 (28 de mayo de 1895), 2-3; III/792 (31 de mayo), 2; III/798 (6 de junio), 3; III/804 (12 de junio), 1. (T)

224. Otero Aranda, José, Tratado de bailes de sociedad, regionales españoles, especialmente andaluces, con su historia y modo de ejecutarlos. Sevilla: Tip. de la Guía Oficial, 1912. 250 pp. [*Contiene: "Antes de empezar" por Manuel Chaves (pp. 58); "Introducción" (pp. 9-11); De los bailes en general y en particular, Bailes de Sociedad. Caps. I-XXV (pp. 12-95); Bailes regionales españoles: Caps. I: Sevillanas (pp. 96-127); II: Las peteneras (pp. 127-40); III: Las manchegas (pp. 140-52); IV: Soleares de Arcas (pp. 152-64); V: El Ole Bujague (pp. 164-74); VI: La gracia de Sevilla (174-79) con música por (José) Otero (Aranda) y (Luis) Sopeña (entre pp. 174-75); VII: El vito (pp. 179-97); VIII: Los panaderos (pp. 198-211); IX: El garrotín (pp. 
211-19), con música por Otero y Sopeña (entre pp. 212-13); X: La Farruca (pp. 219-23); XI: El tango (pp. 223-28), con música por Otero y Sopeña (entre pp. 224-25); XII: Las marianas (pp. 228-32); XIII: Las guajíras (pp. 232-39, con música por Otero y Sopeña (entre pp. 232-33).] [*Ed. Facs. Madrid: Asociación Manuel Pareja-Obregon, 1987.] (B, S)

225. Pabanó, F. M. Historia y costumbres de los gitanos: colección de cuentos viejos y nuevos, dichos y rimos graciosos, maldiciones y refranes netamente gitanos: diccionario español-gitano-germanesco: dialecto de los gitanos. Barcelona: Montaner y Simón, 1915. $191+4$ folios +135 pp. [*Reimp. Madrid: Giner, 1980.] [Torner: Se ocupa de los cantos y bailes a partir de la pág. 75.] $(\mathbf{B}, \mathbf{S})$

226. Rosa y López, Simón de la. Los seises de la catedral de Sevilla. Ensayo de investigación histórica. Sevilla: Imp. de Francisco de P. Díaz, 1904. xi, 372 pp. [*Reimp. Sevilla: Colegio Oficial de Aparejadores y Arquitectos Técnicos de Sevilla, 1982. $\mathrm{xv}, 372$ pp.] (B, C, R, S, T)

227. Trend, John Brande. "The Dance of the Seises at Seville," $M L$, II/1 (1921), 10-28. (B, S, T)

\section{Aragón}

228. Arnaudas Larrodé, Miguel. La jota aragonesa. Una opinión sobre su origen, su forma musical y su ejecución. Zaragoza: Tip. «La Editorial», 1933. 16 pp. [También en el BABASL, núm. 15] [Torner: Cree el autor que la Jota aragoneza "no puede tener mayor antigüedad que la de finales del siglo XVIII o principios del XIX". Se basa para afirmarlo en que el nombre Jota no aparece citado antes en ningún documento ni en libros de música, entre éstos el del aragonés Gaspar Sanz Instrucciones de música sobre la guitarra (véase núm. 212). Pero precisamente un siglo antes del tiempo señaldo por Arnaudas para la presencia de este baile en Aragón, aparecen dos Jotas en un manuscrito de "Cifras para Arpa, de fines de siglo XVII a principios del XVIII" (véase núm. 200), que se conseva en la Biblioteca Nacional con la signatura M-816. La ortografía de sus nombres es en una como hoy y en la otra así: Jotta. La Jota aragonesa no empezó a divulgarse hasta el siglo XIX, como número en el algunas tonadillas y más tarde con la zarzuela, y el hecho de que el aragonés Gaspar Sanz no la incluya en sus Instrucciones debe explicarse teniendo en cuenta que sólo da aquellos bailes y danzas que en su época formaban el repertorio más generalmente conocido y usado: Zarabandas, Chaconas, Folías, Gallardas, etc., y en el momento mismo en que empezaban a perder el carácter popular para convertirse en danzas y bailes de salón.]

229. Domínguez Berrueta, Juan. "La jota aragonesa," Résumés du Congrès International des Arts Populaires (Prague, 1928) (París, 1930), p 117. [También en Arte Populaire, Vol. II, 187.] [Torner: Impugna el pretendido origen árabe de la jota.] (B, R)

230. García-Arista y Rivera, Gregorio. La jota aragonesa (etimología, historia y carácter). Con breve reseña de la fiesta y discurso del Excmo. Sr. Alcalde de la ciudad). Discurso del Mantenedor leído en los Juegos florales de Zaragoza (13 noviembre de 1919). Zaragoza: Imp. del Hospicio Provincial, 1919. 29 pp. (Libreria Publicaciones de «La Cadiera», vol. CLII). [Torner: Se refiere casi principalmente al origen del nombre jota, que considera derivado del antiguo verbo castellano $\operatorname{sotar}$ (saltar).] (B, R, S)

231. Lozano González, Antonio. "Genero popular... jota aragonesa," en su La música popular religiosa y dramática en Zaragoza: desde el siglo XVI hasta nuestros días. (Zaragoza: Julián Sanz y Navarro, 1895), pp. 5-14. [*Cap. I: Jota aragonesa. Lo que enseña la tradición. Opinión del señor [Ruperto] Ruiz de Velasco. Lo que es y será la jota. Fiesta llamada de la jota. Guitarristas. Cantadores. Otros cantos y bailes aragoneses.] [ ${ }^{*} 2^{\mathrm{a}}$ ed., 1895; $3^{\mathrm{a}}$ ed. con introducción y estudio por Antonio Ezquero. Zaragoza: DP, Dto de Publicaciones, 1994. 320. pp.] (B, R)

232. Masoliner Martínez, Juan Ramón. "Le «danse» de Hijar (Province de Teruel)," Résumés du Congrès International des Arts Populaires, Prague, 1928 (París, 1930), p. 121. [También en Arte Populaire, vol. II, p. 188.] [Torner: La danza de Hijar es conocida en gran parte de Aragón. Constituye un drama sagrado en el cual se trata de probar a la Virgen el amor de su pueblo. Para ello se simula una nueva invasión de los infieles que 
intentan robar la imagen de la Virgen. Los soldados cristianos se oponen y entablan con aquéllos una batalla. Vencen los cristianos y celebran el triunfo con la ejecución de varias danzas. Acompaña la música a esta Memoria, así como diversidad de fotografías de distintos momentos de esta representación.] $(\mathbf{B}, \mathbf{R}, \mathbf{S})$

233. Pedrell, Felipe. "Tema alegre (conjecturas sobre el origen de la jota)," Lírica nacionalizada: estudios sobre folk-lore musical (París: Paul Ollendorf, 1913), pp. 155-59. [También en Apéndice II de vol. II de su Cancionero musical popular espanol (pp. 83-86).]

234. Ribera, Julián. La música de la jota aragonesa. Ensayo histórico. Madrid: Inst. de Valencia de don Juan, 1928. 161 pp. (B, R, S, To)

235. Ruiz de Velasco, Ruperto. Cantos populares de España. La jota aragonesa. Estudio crítico descriptivo sobre su música. (Firmada Zaragoza: Febrero de 1892). [*Copia escrito a mano. Este exemplar es propiedad del Exmo. Sr. D. Francisco Asenjo Barbieri. Justo Blanco. Precedido por A.S.A. Sr. la Serenisma señora infanta $D^{a}$ Isabel de Borbón y Borbón (pp. i-ii). La jota aragonesa (17 pp., que coordina con pp. 1-9 del original; Guitarra; ejemplos de jotas, 9 pp., que coordina con pp. 10-14; continuación del ensayo (13 pp., que coordina con pp. 15-18).] (B, R, S)

\section{Asturias}

236. Llano Roza de Ampudia, Aurelio de. Del folklore asturiano: mitos, supersticiones, costumbres. Con un prólogo de Ramón Menéndez Pidal (pp. v-xii). Madrid: Talleres de Voluntad, 1922. xx, 277 pp. [Torner: De pág. 231 a 262 describa los siguientes bailes y danzas: de pandero, giraldilla, de la raposa, la geringoza, el rebudixu, el pelindango, el pericote, el corri-corri, danza prima.] [*Reimp. Oviedo: IEA de la DP, 1972/1977.] (B, R)

237. Tuñon y Qurós, Elias G. "Consideraciones sobre la antigua danza prima en Asturias," en Protasio González Solís y Cabal, Memorias asturianas (Madrid: Diego Pacheo Latorre, 1890), pp. 25962. (B, R, S)

238. Varela y Silvari, José María. "Asturias: su música y danzas populares," Alhambra, XX/455 (Gra- nada, 1917), 108-11. [Cap. II de su libro inédito: La música popular en España..] $(\mathbf{B}, \mathbf{R}, \mathbf{S})$

\section{Castilla}

239. Guzmán Ricis, Antonio. "Dos canciones y dos danzas populares de la provincia de Palencia," Résumés du Congrès International des Arts Populaires, Prague, 1928 (París, 1931), p. 120. [También en Arte Populaire, Vol. II, p. 154.] [Torner: Ejemplos inéditos de música popular.] $(\mathbf{B}, \mathbf{R}, \mathbf{S})$

\section{Cataluña}

240. Capdevila Massana, Manuel. De la sardana. Barcelona: Gráficos de Francisco Genovés, 1925. 100 pp. (Biblioteca la sardana, 1) (2 ed., Barcelona, 1948. 104 pp.; amb un proleg de A. Janeri Feliu (pp. 9-12).] [*El fons del fons (pp. 9-26); El punteig (pp. 29-46); La compatabilitat (pp. 47-79); Els cents sonsells de consell del «Foment» (pp. 8398).] (B, R, S)

241. Capmany i Farrés, Aureli. El ball popular a Catalunya: El Contrapàs (historia y modo de bailarlo). Barcelona: Ed. Políglota, 1922. 38 pp. (Minerva col-leció popular dels coneixements indispensables editada per Consell de Pedagogia de la Mancomunitat de Catalunya, vol. XXXVIII.) $(\mathbf{R}, \mathbf{S})$

242. - Com es balla la sardana. L'històrica, la tècnica, l'estètica. Il-lustrada amb dibuixos i plànols per aprendre de comptar, repartir, treure i repuntejar a l'estil empordanès i selvatà per... Barcelona: Salvador Bonavía, 1922. 95 pp. $\left[2^{\mathrm{a}}\right.$ ed., 1924; $3^{\text {a }}$ ed., 1928.] (B, R)

243. - La dansa a Catalunya. Barcelona: Barcino, 1930. 2 vols. [160, 148 pp., respect.) [*Vol. I: Capítulos: Introducció (pp. 5-17); I) De la dansa en general (pp. 19-36); II) Les danses religioses (pp. 37-45); III) Les danses senyorials (pp. 47-59); IV) Les danses populares catalanes: Generalitats (pp. 61-66); V) Els mestres catalans de dansa (pp. 6782); VI) La sardana; Vol. II: VII) El contrapàs (pp. 81-88); VIII) El ball pla (pp. 89-134); IX) Ball cerdà (pp. 135-45).] (B, Cr, R, S)

244. Castellà y Raich, Gabriel. "Igualda. Comparsas o balls populars", $R M C$, II/20 (1905), 155-57; II/21 (1905), 171-73; II/22 (1905), 191-93. [Torner: 
Descripción y música de los bailes de los Cercolets, Nanos, Pastorets, Bastoners, Gegants, Cavallets, La Moxinganga, Ball dels Diables (comparsa). La Patera (reminiscencia de los antiguos dramas sagrados).] (B, R, S, T)

*245. Explicació del modo y usanza de ballar lo contrapás llarch a la moda Empurdanesa ab tots les Seguits Llarchs, Curts, Tencats, Girats y Rodadas (Vich, s.a.). (B)

F. P. Balls populars catalans. (veáse Pujol, Francisco, núm 255)

246. Gallostra, José, Senzill tractat de com se ballan, comptan y reparteixen las sardanas. Gerona: $\mathrm{Pa}-$ cíano Torres, s.a. 20 pp. +2 hojas.) (B)

247. González Grases, Pedro. "Las danzas del Panadés," Résumés du Congrès International des Arts Populaires, Prague, 1928 (París, 1930), p. 121. [También en Arte Populaire, Vol. II, pp. 192-93.] [Torner: Estas danzas que se conservan en el Panadés (Barcelona) son más bien cuadros históricos o biblicos de carácter popular que se representan al aire libre. El autor de esta Memoria da una lista de estas danzas en número de catorce, entre las que se destacan la de los diablos, la de gitanos, la de moros y cristianos y la del Niño pródigo.] (B, $\mathbf{R}, \mathbf{S})$

248. Grahit i Grau, Josep. Les sardanes. Estudio de la danza catalana. Pròleg de Carles Rahola (pp. 68). Gerona: s.i., 1913. 29 pp. [ $2^{\mathrm{a}}$ ed., 1915; $3^{\mathrm{a}}$ ed. aumentada 1920. (B, R, S)

249. Insenser i Bertran, Antoni. "El Panadès, Balls, Dansas y Comparses populars," $R M C, \mathbf{I} / 6$ (1904), 117-19; I/7 (1904), 140-43; I/8 (1904), 168-71; I/9 (1904), 186-89; I/11 (1904), 228-29); I/12 (1904), 252-57; II/13 (1905), 1-2; II/15 (1905), 51-53; II/16 (1905), 75-76. [Torner: Es trabajo extenso e interesante. Describe y acompaña las melodías de los siguientes bailes: Ball pla, Bulangera, Xirongu, Ball de bastons (con las figuras la dragona, lo rotllet, la ayrosa, l'any nou, lo 4 de desembre. la buida-sachs, la pavana, el brunzit, a lloba, la diana, el rigodón, la inglesa y la revessa), la Moxiganga, Ball de cercolets, Ball de pastorets, Ball de gitanas, Ball de panderets, Ball de figuetaires, Balls de pastorel-li, Ball de cotoninas; las comparsas El Drach, L'Aliga, Els xiquets de Valls, Els diables; y los cuadros históricos Ball de Sant Julía, Ball de moros y cristians, Ball d'en Serra- llonga, Ball de mal-casats, Els gegants, La mulas$s a .].(\mathbf{B}, \mathbf{R}, \mathbf{S})$

250. Langdon-Davies, John. Dancing Catalans. Londres y Nueva York: Jonathan Cape, 1929. 220 pp. [Torner: Se describen en los seis capítulos de este libro la sardana, la cobla y los instrumentos populares de que ésta se compone.] (B)

Maspons y Maso (véase Maspons y Camaras, Jaime, y Joseph Masó y Goula, núm 251)

Modo, en que se deu ballar lo contrapás curt; y pot servir també per lo contrapás sardá, ab tots seguits, que se contenen per ballarlo, com se refereixen en lo present exemple (véase núm. 256).

251. Maspons y Camarasa, Jaime, y Joseph Masó y Goula. El ball de les gitanes en el Vallés (Cataluña). Conferencia donada en el «Centro Excursionista de Catalunya» el día 25 de juliol de 1906. Barcelona: Tip. «L'Avenç», 1907. [N.B. Torner mencionó Maspons y Masó, mientras que Homero Serís mencionó el autor como Francisco de Maspons y Labrós.] (B)

252. Montsalvatge i Castany, Jordi, y Josep Aleu i Massanet. La sardana. Su história, importancia y exposición de las reglas que deben conocerse para bailarla según los sistemas ampurdanes y selvatà. Prefacio de Jaime Soler (pp. 7-9). Olot: Imp. y Librería de Juan Bonet, 1895. 115 pp. + 5 diagrams. (B)

253. Nadal, Lluis B. "Balls populars catalans. Ballet, ball cerdà i esquerrana," RMC, I/4 (1904), 77-79. [Torner: Descripción coreográfica y música.] (B, $\mathrm{R}, \mathrm{S})$

254. Piera Gelabert, Mercedes. "La danza de los gitanos del Vallés," Résumés du Congrès International des Arts Populaires, Prague, 1928 (París, 1930), p. 120. [También en Arte Populaire, Vol. II, p. 192] [Torner: Además de la descripción acompañan a esta Memoria los distintos momentos musicales. Más que de una danza, se trata en realidad de un espectáculo. Se celebra en la Plaza Mayor del pueblo en los días del Carnaval y toman parte en él varios grupos: el Capitán, los Diablillos, los Viejos, las Viejas, los Novios y su cortejo. Comprende los siguientes números musicales: Introducción, Paseo y Marcha, Cachucha, Contradanza, Schotish y Jota..] (B, R, S)

255. Pujol, Francisco. "Balls populars catalans. Danza y ball de Ciri a Castelltersol," $R M C, \mathbf{I} / 3$ (1904), 
52-54. [Torner: Descripción coreográfica y transcripción musical.] (B, R)

256. Ros y Vilaplana del Lloch de Sant Gregori. Jaime [Jaume]. Modo, en que se deu ballar lo contrapàs curt; y pot servir també per lo contrapàs sardá, ab tots seguits, que se contenen per ballarlo, com se refereixen en lo present exemple. Gerona: Agustí Figaró Estamper Real, en las Ballesterías, s.a. Hoja de una página. (B)

257. Sansalvador, Antoni. La Patúm. Barcelona: Antoni López, 1916. 172 pp. [Torner: Descripción de fiestas en Berga y música de la Patúm, baile de figuras de esta comarca catalana.] $(\mathbf{B}, \mathbf{S})$

*258. Suñol y Baulenas, Gregori. "Una dansa dels romeus al segle XIV," Revista Montserratina (1910). (B)

259. Vigo, Enric. Aplec de balls populars del Pallars. Barcelona: Centre Excursionista de Catalunya L'Avenç, 1909. 22 pp. (B, R, S)

260. Zaldívar, José. "Las danzas populares catalanas," Résumés du Congrès International des Arts Populaires, Prague, 1928 (París, 1930), p. 120. [También en Arte Populaire, Vol. II, pp. 190-91.] [Torner: Las danzas populares catalanes son muy numerosas y variadas y aunque muchas hayan sido olvidadas se conservan todavía unas doscientas.] $(\mathbf{R}, \mathbf{S})$

\section{Galicia}

261. Couselo Bouzas, José. "Los juegos y las danzas en las fiestas compostelanas," BRAG, XX/ 170-71 (1925), 44-47. (B, S)

262. Montes, Eugenio. "Estética da Muiñeira," Nos, núms. 13-14 (Orense, 1 de noviembre de 1922), 1-15. (B)

*263. "Música popular gallega. Danza de las espadas en Redondela," Galicia Diplomática, núm. 6 (1897).

\section{Valencia}

264. Echevarría, F. Cantos y bailes de Valenica (Valencia: n.p., 1912 [*Copia existe en la Biblioteca de la Residencia de Estudiantes (Madrid). Su descripción, según una comunicación de su bibliotecario Sr. D. Alfredo Valverde, es la siguiente: En la primera página está impreso «Valencia». Cons- ta de 84 páginas, pero no existen datos editoriales en la portada ni tampoco hay colofón. Hasta la página 21 el texto introductorio menciona los cantos y bailes principales de la provincia de Valencia y da paso a la descripción de algunas "diversiones, costumbres y representaciones pantonímicas" resaltadas como epígrafes que son: Danza de las Torres, El Torneo, Baile de Torrente, Baile de los Infantillos del Colegio del Patriarca de Valencia, Diágolos, La cantá dels segos (transcribe el romance escrito por el dominico P. Mulet "De Nelo el tripero," El Viático, La Paella, La benedición del hinojo). A continuación consta una "Descripción e ilustraciones de los cantos y bailes" donde aparecen las partituras de Albáa, El chiste, Jota del carrer, Jota valenciana, La Alicantina, El ú y el dós, Canción, La xaquera vella, La magrana, Marcha de los enanos, Toque de dulzaina y tambor, Danza de los enanos, La mogiganga, Danza de Bocayrente, Baile del copeo, Melodía de dulzaina y El faitó. Finalmente en la página 66, comienza "Relación y explicación históricas de la solemne procesión del Corpus."] (B, Cr, R, To)

265. Fogués, Francesc. "Los bailes de Carcagente," $A C C V$, Primera época, VI/15 (Enero-marzo, 1933), 1-8. [Torner: Descripción de los bailes dels bastonets, del Sabre, dels arquets, de la cartxofa, dels pastorets i de les pastoretes, de les quatre parts del mon, dels tornejants. Cita además el dels negritos, el de les peregrins y el dels serranos.] (B, R)

266. López-Chavarri, Eduardo. "Lo ball dels Nanos," Cuentos Lírics (Valencia: Emprenta Domenech, 1907), pp. 153-60 (2 ejemplos musicales). [Torner: Descripción, con la música de una de las danzas antiguas del Corpus en Valencia.] [Véase también $R M C$, IV/44 (1907), 166-68.] (R, $\mathbf{S}, \mathbf{T})$

267. - . "La danza popular valenciana," $A C C V$, Primera época, III/5 (1930), 5-22. [Torner: Discurso en el Centro de Cultura Valenciana. Contiene: La danza i el seu aspecte popular. La danza com a ritme i com a expressió. La dansa com a germanor. La dansa i la música. Esplai i Seny. La dansa valenciana es de noble germanor. La dansa popular es una estilització. Danza popular i estil popular. Ritmes d'actutuds i de coloracions. La música de la dansa valenciana. El barroquisme del segle 
XVIII. Les actitudes en la dansa de Valencia. La dansa popular actual.] $(\mathbf{B}, \mathbf{R}, \mathbf{S})$

\section{Vascongadas}

268. Donostia, José Antonio de. "Las danzas vascas," Résumés du Congrès International des Arts Populaires, Prague, 1928 (París, 1930), p. 45. [Torner: Hay un gran variedad de danzas vascas. Cada provincia posee las suyas. Toman parte en ellas casi exclusivamente los hombres y constituyen más bien un ejercicio de agilidad y fuerza: danza de las espadas, de los bastones, etc. Las danzas acompañan los cortejos municipales así como las procesiones religiosas. Se danza en la iglesia delante de la Virgen y en la calle delante del Santísimo Sacramento.] (B, R)

269. - . Notas breves acerca del Txistu y de las danzas vascas. Bilbao: Santa Casa de Misericordia, 1933. Folleto. (B)

270. Gascue, Francisco. "El aurresku en Guipúzcoa a fines del siglo XVIII según Iztueta," $E A$, V/117 (1915), 659-74; V/118 (1915), 680-93; V/119 (1915), 715-28; V/120 (1915), 743-59. [Torner: Contiene trece melodías y algunas consideraciones sobre el compás 5/8.] [Reimp. también como folleto. San Sebastián: Martín, Mena y C.a, 1919.] (LC, R, T, To)

271. Giese, Wilhelm. "Bailes tradicionales de origen antecristiano entre los vascos de hoy," RIEB, XVII (1926), 616-19. (B, R)

272. Irigoyen, Juan de. "El baile llamado de la Caxarranca. Antecendentes históricos e incidentes curiosos a que dió lugar en la villa de Legueito en los comienzos del siglo XVII," RIEB, XVIII (1927), 152-59. (B, R)

273. Iztueta y Echeverría, Juan Ignacio de. Guipuzcoa'ko dantza gogoangarrien condaira edo historia beren soñu zar, eta itz neurtu edo versaoquin: Baita berac ongui dantzatzeco iracaste edo instruccionae ere. Obra balio andicoa eta chit premiazcoa... San Sebastián: Ignacio Ramón Baroja, 1824. [20] vi, 185 pp. [Reproducido por la Sociedad de Estudios Vascos due recueil musical de Iztueta paru en 1826; Bordeaux: Imp. de Landais, 1929.] [*J.A. Quijera 1993:50, nota 1: "Posteriormente se han realizado traducciones y ediciones bilingües... la edición de 1968, primera edición bilingüe que se realizó en base a la segunda edición en lengua vasca (era) publicada en Tolosa en 1895. La obra, bien conocida por todos los estudiosos del folklore vasco, recoge una valiosísima información sobre las diferentes danzas que a finales del XVIII y comienzos del XIX sustentaban por periodos festivos guipuzcoanos, además de abundantes notas sobre el modo de ejecución de las melodías y las danzas [circulares]." Reimp. San Sebastián: Euskal Edit. Elkaerta, 1968 y 1990, 359 pp. y Tolosa: E. López, 1995. 206 pp. [Torner: Historia de los antiguos bailes de Guipúzcoa; reglas para ejecutarlos y cantarlos en verso; bailes, juegos y otras diversiones del país; maneras y orden de ejecución de los bailes de plaza en días de fiesta mayor y en domingos, las tocatas con que se bailaban antes y los versos que se les aplicaban en diferentes circunstancias, etcétera.] (Cr, L-C, To)

274. - Euscaldun anciña anciñaco ta are lendabicico etorquien danzta on irtci pozcarri gaitzic gabecoen soñu gogoan-garriac beren itz neurtu edo versoaquin (Danzas de Guipúzcoa). 52 transcripciones musciales por D. Pedro Albéniz. San Sebastián: Baroja, 1826. 36 pp. [*Donostian, Iganacio Ramón Barojaren, Moldizteguian 1828 garren urtean eguina. Exemplare manuscrit, daté 1827 et 1828 , du mème ouvrage de Iztueta, conservá la Bibliothèque Nationale, Départament de la Musique. $4^{\circ} \mathrm{O} 823$. Contiene algunas danzas de las espadas.] [Reimp. como Gupuzkoako Dantzak. San Sebastián: Euskalkas Kuntzaren Argitaldiak (Sociedad de Estudios Vascos), ca. 1927. 55 pp. Edición comenzada por J.C. de Cortazar y terminada por J.A. de Donostia] [Torner: De los antiguos vascos y del primer origen de sus danzas estimuladas-serias-alegres y sin tâche. Las melodías con los versos.] (L-C, R, R')

275. Larramendi, Manuel de. "Corografía de Guipúzcoa. Del cuerpo, espíritu, ingenio e inclinación de los guipuzcoano," Euskal-Erria, LIII/2 (1905), 511-20. [*J.A. Quijera 1993:51, nota 2: Esta importante obra referida a la vida guipuzcoana de la primera mitad del XVIII fue redactada por su autor en el 1754 quién muriera doce años más tarde. Sin embargo, el libro no vio la luz por primera vez hasta 1882 , cuando había transcurrido más de un siglo de la muerte de Larramendi. Aquí 
(la próxima es la cuarta edición) que salió a la calle en 1969.] (B, L-C)

276. Olazarán de Estella, Hilario. Euskalerriaren Dantzak. Mutil-Dantza Baztán. San Sebastián: Arilla, 1925. 12 pp. (para piano). [Torner: Precede a esta versión del Mutil Dantza (Baile de mozos) del Baztán una descripción ninusciosa de cada uno de los pasos y movimientos de la danza.] (B)

277. - . El baile de la Era. Danza popular de Estella (Navarra). Para piano. Barcelona: Boileau y Barnasconi, s.a. 2 hojas, +22 pp. [Reimp. Pamplona y San Sebastián: Arilla, 1929.] [Torner: Prólogo explicativo.]

278. - Ingurutxo. Danza vasca popular de Leiza (Navarra). Pamplona: Arilla, 1931. ix, 27 pp. (para piano). [I. Soka-dantza (Danza de la soga) (pp. 2-14); II. Ingu-ruaundi (Danza circular grande) (pp. 15-18); III. Ingurutxikí (Danza circular pequeña) (pp. 19-27) [Torner: Prólogo explicativo. Según el autor es esta la "danza mixta más importante del folklore vasco."] (B)

\section{Addendum}

279. Memoria de D. José González Torres de Navarra, que "presentó al Gobierno (14 de marzo de 1799) en solicitación de protección para forma una colección de música característica española, recogiendo de viva voz la canciones antiguas y modernas que se pudieran encontrar y tomando nota de su provincia." [*Para su texto, véase Nicolás Álvarez Solar-Quintes, "Un madrileño prefolklorista y un nuevo método de música," AIEM, II (1967), 111.]

280. Modo fácil para aprender el ayre Bolero en la guitarra y arreglar la voz. Madrid: Imp. de Fernández y comp., s.a. (véase núm. 69).

281. Villanueva, Jaime. Viaje literario a las iglesias de España. Le publica con algunos observaciones Don Joaquín Lorenzo Villanueva. Madrid: Imp. Real, 1803-1852. 22 vols. ['De vol. IV figura la obra a nombre de Fr. Jaime Villanueva] [Torner: Contiene un buen número de noticias referentes a... representaciones medievales ... que pertenecen a la origen de nuestro teatro lírico.] (B, C)

\section{Índice I: Abreviaciones}

$\mathrm{CEH}=$ Centro de Estudios Históricos (Madrid)

$\mathrm{CSIC}=$ Consejo Superior de Investigaciones Científicas

DP $=$ Diputación Provincial

IEA = Instituto de Estudios Asturianos (Oviedo)

IEM = Instituto Español de Musicologia (Barcelona)

JAEIC = Junta para Ampliación de Estudios e Investigaciones Científicas (Madrid)

RABASF $=$ Real Academia de Bellas Artes de San Fernando (Madrid)

RAH $=$ Real Academia de Historia (Madrid)

UME = Unión Musical Española

\section{Resumen del Congresos}

Art populaire. Travaux artistiques et scientifiques $d u$ ler Congrès es Arts Populaires (Prague, 1928). París: Êdicions Ducharte, 1930. 2 vols.: 38-39, 229, 232, 239, 247, 254, 260, 268

Résumés du Congrés Internactional des Arts Populaires (Prague, 1928). París: Institut Internationalde Coopération Intellectuelle, 1930: 38-39, 107, 122, $229,232,239,247,254,260,268$

\section{Periódicos}

ACCV $=$ Anales del Centro de Cultura Valenciana (Valencia) 265, 267

AIEM = Anales del Instituto de Estudios Madrileños (Madrid) 279

Alhambra (Granada) 238

Almanaque de Ferrol (La Coruña) 191

Analecta Montserratensia (Montserrat) 157, 159

Archivo, El. Revista Literaria Semanal (Denia) 41

Arte Español (Madrid) 185

Arxiu de tradicions populars (Barcelona) 13, 133-34

$A U C h=$ Anales de la Universidad de Chile (Santiago) 84

BABASL = Boletín de la Academia de Bellas Artes de San Luis (Zaragoza) 228

$B C E C=$ Butlletí del Centre Excursionista de Catalunya (Barcelona) 139, 168

BCMHAN = Boletín de la Comisión de Monumentos Históricos y Artísticos de Navarra (Pamplona) 192 BHi $=$ Bulletin Hispanique (París) 43, 74

BILE = Boletín de la Institución Libre de Enseñanza (Madrid) 96 
BRABASF = Boletín de la Real Academia de Bellas Artes de San Fernando (Madrid) 20

$B R A G=$ Boletín de la Real Academia Gallega $(\mathrm{La}$ Coruña) 161, 190-91, 261

BRAH = Boletín de la Real Academia de Historia (Madrid) 146

Bulletin de l'Académie Royale des Sciencies, des Lettres et des Beaux-Arts de Belgique (Bruselas) 81

Canción Popular, La (Madrid) 73

$C D=$ La Ciudad del Dios (El Escorial) 63

Correspondencia Musical (Madrid) 20, 72

Cullera, 2

Diario de Barcelona (Barcelona) 183

$E A=$ Euskalerriaren Alde (San Sebastián) 78, 207, 270

Eco Musical, El (La Coruña) 179

España Musical, La (Barcelona) 179

$E U C=$ Estudis Universitaris Catalans (Barcelona), 135

Euskal-Erria (San Sebastián) 192, 275

Excursions (Barcelona) 35

Galicia Diplomática (Santiago de Compostela) 174, 263

Galicia Histórica (Santiago de Compostela) 160, 218

Iberia (Bordeaux) 97

Ideal Gallego, El (La Coruña) 162

$I G A=$ IIustración Gallega y Asturiana (Madrid) 62

$I M H A=$ Ilustración Musical Hispano-Americana, La (Barcelona) 22, 116

Larousse Mensuel (París) 135

$M L=$ Music and Letters (London) 170-71, 227

MSH = Música Sacro-Hispana (Bilboa y Vitoria) 11, 131

Nos (Orense) 262

Noticiero Sevillano, El (Diario Independiente de Noticias, Aviso y Anuncios) (Sevilla) 7

PMA $=$ Proceedings of the Musical Association (Londres) 173

Porvenir, El (Diario Polítcio de Sevilla) 50

RABM = Revista de Archivos, Bibliotecas y Museos (Madrid) 10, 46, 100

REcl $=$ Revista Eclesiástica (Barcelona) 106

Revista Montserratina (Montserrat] 158, 258

Revue al-Fikr (Túnez) 1

Revue Tunisienne (Túnez) 1

RevMus = Revue Musicale, La (París) 61, 136

RFE = Revista de Filología Española (Madrid), 165

$R G M=$ Revista y Gaceta Musical (Madrid) 193, 201
RIEB $=$ Revue International de Ètudes Basques (ParísSan Sebastián) 9, 56, 77, 80, 121, 175, 188-89, 202, 271-72

Ritmo (Madrid) 85, 106, 113

RMB $=$ Revista Musical Bilbao (Bilbao) 190

RMC $=$ Revista Musical Catalana (Barcelona) 19, 36, 139-40, 187, 244, 249, 253, 255, 266

RMHA = Revista Musical Hispano-Americana (Madrid) 184

$R O=$ Revista de Occidente (Madrid) 95

Ruscino (Perpignan) 26

$R y F=$ Razón y Fé (Madrid) 16

SIMG = Sammelbände der Internationalen Musik-

Gesellschaft (Leipzig) 125-26

Tribune de Saint-Gervais, Bulletin mensuel de la Schola Cantorum (París) 127

Ultreya (Santiago de Compostela) 47

Vida Cristiana (Barcelona) 6

Vida Gallega (Havana) 198

$Z R P h=$ Zeitschrift für romanische Philologie (Halle) 153

\section{Índice II: Onomástico}

Abd al-Wahab [Abdu-l-Wahab], Hasan Husnî 1

Abellán, Antonio María 2

Adalid Gurrea, Marcial del (1826-1881) 3

Aguilar, Emanuel Abraham (1824-1904) 4

Aguilar y Tejera, Agustín (n. 1890) 5

Alcover y Maspons, Juan (1854-1926) 117

Aleu i Massanet, Josep 252

Amades Gelat, Joan (1890-1959) 187

Anglés Pamies, Higinio (1888-1969) 6

Apraiz Buesa, Ángel de (1885-1956) 188-89

Arana Martija, José Antonio 14

Arana Pérez, Ramón de (s. XIX) 190-91

Aranzadi Unamuno, Telesforo de (1860-1945) 8-9, 192

Arco Garay, Ricardo del 10

Argain 11

Arnaudas Larrodé, Miguel (1869-1936) 12, 228

Arrieta Corera, Emilio (1821-1894) 88

Artero, José (1890-1961) 12

Atienza Madrano, Antonio 109

Azkue Aberasturi, Resurreción María de (1864-1951)

14-15

Baixauli y Biguer, Mariano (1861-1923) 16

Balaguer y Cirera, Victor (1824-1901) 17 
Baldelló Benosa, Francesc de Paula (1887-1977) 18

Barberá, Josep 19

Barbieri, Francisco Asenjo (1823-1894) 20-22, 42, 101, 174, 194, 196, 199, 203, 235

Barra, Eduardo de la (1839-1900) 23

Bello, Andrés (1781- 1865) 24

Benot, Eduardo (1822-1927) 25

Bergnes, Pablo (Pau) 26

Bermudo, Fray Juan (1510-1560+) 195

Bertrán Bros, Pau Pablo (1853-1891) 27

Blasco Medina, Francisco Javier (n. 1857) 28

Bofarull Saratorio, Manuel de (1816-1892) 196

Borbón y Borbón, María Isabel (1851-1931) 235

Bosch Humet, Eusebio (1860-1947) 197

Bretón Hernández, Tomás (1850-1923) 32, 98

Briz Fernández, Francesch Pelay (1839-1889) 29

Brown, Irving (1888-1940) 30

Caba Landa, Carlos (1899-1976) 31

Caba Landa, Pedro (n. 1900) 31

Cairo, Manuel 198

Calleja Gómez, Rafael (1870-1938) 32

Campo Zabaleta, Conrado del (1878-1953) 37

Camps i Mercadal, Francisco 33

Candi y Casanovas, Candi[do] (1844-1911) 29

Capdevila Massana, Manuel (n. 1910) 240

Capmany i Farrés, Aurelio (1868-1954) 35, 219, 241 43

Cardils, Fra. 100

Carreras y Bulbena, José Rafael (1860-1931) 36

Carreras y Candi, Francisco (1862-1937) 167, 219

Castellà y Raich, Gabriel 244

Castrillo Hernández, Gonzalo (1876-1957?) 37-39

Cejador y Frauca, Juilio (1864-1927) 40

Collet, Henri (1885-1951) 43

Correas, Gonzalo (ca. 1571-1631) 45

Correia López, Edmundo (n. 1898) 46

Cotarelo Valledor, Armando (1880-1950) 47

Cotarelo y Mori, Emilio (1857-1936) 221

Couselo Bouzas, José 261

Chabás, Roque (n. 1844) 41

Chapí Lorente, Ruperto (1851-1909) 32

Charbonnel, Raoul 220

Chaves Nogales, Manuel (n. 1897) 224

Chía, Juliàn de (1818-1898) 42, 199

D’Abranca, Francesc (véase Camps i Mercadal, Francisco)

Daux, L'abbé Camille (1844-1917) 48

Davillier, Charles (1823-1883) 49 de Sola, David Aaron (1825-1882) 4

Demófilo (véase Machado Álvarez, Antonio)

Díaz Cassou, Pedro 51

Díaz de Valle, Lázaro 193

Díaz Rengifo, Juan (1553-1613) 52

Domínguez Berrueta, Juan (n. 1866) 229

Donostia, José Antonio de (1886-1956) 53-55, 268-69

Doré, Gustave (1832-1883) 49

Echegaray Corta, Carmelo de (1865-1925) 56

Echevarría, F. 264

Elústiza Ganchegui, Juan Bautista de (1885-1919) 57

Escalada y Carabias, Ramón 58

Espadaler Colomer, Joan Baptista (1878-1917) 59

Espina Velasco, Juan de (s. XVII) 204

Ezquero Esteban, Antonio (n. 1964) 231

Fabiani y Díaz de Cabria, Juan 60

Falla, Manuel de (1876-1946) 61

Fernández Alonso, Benito 62

Fernández Núnez, Manuel (n. 1883) 63-64

Fernández Vallejo, Felipe Antonio 65

Ferrer Ginard, Andreu (1887-1975) 66

Figueras Pacheco, Francisco 67

Filgueira Valverde, José (1906-1996) 68

Fischer, Christian August (1771-1829) 69

Flores Laguna, José (n. 1817) 20, 70-72

Florit Nin, Francesc 33

Fogués, Francesc 265

Font de Anta, Manuel (1895-1936) 73

Foulché-Delbosc, Raymond (1864-1929) 74

Fuentes Agulló, Francisco 75

Fuentes y Ponte, Javier 76

Gallostra, José 246

García-Abrines, Luis 212

García-Arista y Rivera, Gregorio 230

García de Rengifo, Diego (pseud. Joseph Vicens), 52

García López, Mariano 51

García y Ramos, J. 222

Garnault, Paul (n. 1856) 202

Garrido, Fanny 3

Gascue Murga, Francisco (1848-1920) 77-80, 270

Gevaert, François-Auguste (1828-1908) 81

Giese, Wilhelm (n. 1895) 271

Gil García, Bonifacio (1898-1964) 82

Gómez Rodriguez, Jerónimo 83

González Grases, Pedro 247

González Solís y Cabal, Protasio 237

González Torres de Navarra, José (n. 1759) 279

Grahit i Grau, Josep (883-1960) 248 
Guzmán Ricis, Antonio (1896-1944) 239

Hanssen, Federico (1857-1919) 84

Hemsi, Alberto (1898-1975) 85

Henríquez Ureña, Pedro (1884-1946) 86

Herrera y Chiesanova, Adolfo 87

Hurtado, José 88

Ibarra y Ruiz, Pedro (1858-1954) 89-90

Insenser i Bertran, Antoni (1859-1920) 249

Inzenga Castellanos, José (1828-1891) 91-93

Irigoyen, Juan de 272

Irruarízaga Aguirre, Luis (1891-1928) 94

Iztueta y Echeverría, Juan Ignacio de (1767-1845) 273-74

Jessurun, Elias 4

Kahn, Máximo José (pseud. Medina Azara) 95

Koeckert, M. Gustave (n. 1861) 96

Lahose-Barrelet, Mina 97

Langdon-Davies, John (n. 1897) 250

Larramendi, Manuel de (1690-1766) 275

Ledesma Hernández, Dámaso Blas (1866-1928) 98

López Almagro, Antonio (1829-1904) 51

López-Chavarri Marco, Eduardo (1871-1970), 37, 99, 266-67

Lorenzo Villanueva, Joaquín 281

Lozano González, Antonio Félix (1853-1908) 231

Ludwig, Friedrich (1872-1930) 159

Llabrés y Quintana, Gabriel (1858-1928) 100-01

Llano Roza de Ampudia, Aurelio de 236

Llongueras Badía, Juan (1880-1953) 102-03

Llorens de Serra, Sara 104

Llovera, Josep María 6

Machado y Álvarez, Antonio (1846-1893) 50

Manterola Beldarrain, José de (1849-1884) 105

Margellí, Antonio 106

Martin Códax (s. XIII) 185

Martín González, Casto 107

Martínez Hernández, Antonio 108

Más y Prat, Benito (1846-1892) 222

Masó y Goula, Joseph 251

Masoliner Martínez, Juan Ramón 232

Maspons y Camarasa, Jaime (197-1934) 251

Medina Azara (véase Kahn, Máximo José)

Méndez Bejarano, Mario (1857-1931) 262

Menéndez Pidal, Ramón (1869-1968) 86, 205, 236

Millet i Pagès, Luis (1867-1941) 110-11

Minos 223

Mitjana Gordon, Rafael (1869-1921) 112-14

Anuario Musical, 59 (2004)
Molins (Marqués de) (véase Roca de Togores y Carrasco, Mariano)

Montolíu de Togores, Manuel (1877-1961) 115

Montsalvatge i Castany, Jordi 252

Moral León, Francisco de P. (b. 1879) 5

Mulet, P. 264

Muneta, Jesús María 12

Nadal, Lluis B. 253

Nassare, Fr. Pablo (ca. 1655-ca. 1730) 206

Noguera Balaguer, Antonio (1860-1904) 116-17

Núñez de Prado, Guillermo 118

Ocón y Rivas, Eduardo (1833-1901) 119

Olazarán Salanueva de Estella, Hilario (1894-1973) 207-08, 276-78

Olmeda de San José, Federico (1865-1909) 120

Ormaechea, Nicolás de 121

Ortiz Díaz, Daniel Luis 122

Otaño Eugenio, José María Nemesio (1880-1956) 123

Otero Aranda, José (1860-1934) 224

Pabanó, F.M. 225

Palau Boix, Manuel (1893-1967) 124

Pedrell Sabaté, Felipe (1841-1922) 44, 87, 123, 125 37, 209, 233

Perpiñán, Claudiano Phelipe 90

Piera Gelabert, Mercedes 254

Pol Juan, Antonio (Un Conrador) (1875-1933) 138

Pont Llodrá, Antoni Jusep (1852-1931) 97

Pujol Pons, Francisco (Francesc) (1878-1945) 139-40, 255

Puyol y Alonso, Julio (1865-1937) 141

Rahola, Carles (1882-1939) 248

Requeno Vives, Vicente (1743-1811) 210

Ribera y Tarragó, Julián (1858-1954) 63, 142-46, 159, 234

Riemann, Hugo (1849-1919) 147

Rivas Gómez, J. 5

Roca de Togores y Carrasco, Mariano (Marqués de Molins) (1812-1899) 148

Roda López, Cecilio de (1865-1912) 211

Rodríguez Guisado, José 5

Roma, Josefina 13

Ros y Vilaplana del Lloch de Sant Gregori, Jaime [Jaume] 256

Rosa y López, Simón de la (n. 1846) 226

Ruiz de Lihory, José (Baron de Alcahalí) 149

Ruiz de Velasco, Ruperto (1858-1897) 231, 235

Saldoní y Remendo, Baltasar (1807-1889) 150

Salinas, Francisco de (1513-1590) 151 
Saltó, Joseph (1817-1868) 29

Sansalvador, Antoni 257

Sanz, Gaspar (1640-1710) 212

Sbarbi y Osuna, José María (1834-1910) 152

Schuchardt, Hugo (1847-1927) 153

Serra i Boldú, Valeri (1875-1938) 13, 154

Serrano y Fatigati, Enrique (1845-1918) 213

Soler, Jaime 252

Soler Chacón, Gaspar 90

Sopeña, Luis 224

Soriano Fuertes y Piqueras, Mariano (1817-1880) 155, 179,214

Subirá Puig, José (1882-1980) 85, 108, 156

Suñol y Baulenas, (Sunyol), Gregori [Gregorio] María (1879-1946)157-59, 258

Tafall y Abad, Santiago (1858-1930) 160-62

Tejada, Carlos S. de 163

Torner, Eduardo Martínez (1888-1955) 164-67

Tort i Daniel, Jacint E. 168

Trend, J[ohn] B[rande] (1887-1958)169-73, 227

Tuñon y Qurós, Elias G. 237

Urquijo Ibarra, Julio de (1871-1838) 175

Valverde Durán, Joaquín (1846-1910) 217

Valladar, Francisco de Paula (1852-1924) 176

van der Straeten, Edmond (1826-1895) 177

Varela Lenzano, Indalecio 178

Varela Silvari, José María (1848-1926) 179, 238

Verdú, José (ss. XIX-XX) 180

Vidal, Pierre (1848-1929) 181

Vidal Rodríguez, Manuel 182

Vidal y Valenciano, Cayetano (1834-1893) 183

Vigo, Enric 259

Villa-amil y Castro, José 218

Villalba Muñoz, Luis (1873-1921) 43

Villar, Rogelio (1875-1937) 184

Vincens, Joseph (véase García de Rengifo, Diego)

Vindel Álvarez, Pedro (1865-1921) 185

Ximénez [Jiménez] Cos, Eduardo (1824-1900) 186

Zaldívar, José 260

\section{Índice III: Toponímico}

Alicante 67, 179

Andora 13

Andalucía 5, 7, 30-31, 57, 61, 95, 118, 132, 143, 153, $172,176,179,222-27$

Aragón 10, 12, 13, 179, 188, 228-35

Asturias 88, 164, 179, 236-38
Baleares 33, 66, 97, 100, 116-17, 131, 138, 140, 179

Baztán (Vascongada) 276

Berga (Cataluña) 257

Burgos 120

Carcagente (Valencia) 265

Castellterçol (Barcelona) 255

Castilla 37, 46, 58, 79, 98, 120, 179, 239

Castilla la Vieja 38-39

Cataluña 13, 18-19, 26-27, 29, 34, 36, 44, 59, 102, $104,111,115,129,140,154,168,169,179,181$, $187,240-60$

Catedral de Huesca 10

Catedral de Sevilla 226-27

Catedral de Toledo 21

Ciri (Barcelona) 255

Elche 41, 75-76, 87, 89-90, 113, 126-28, 148, 170, 183

Estella (Navarra) 277

Extremadura 82

Fuenterrabía (Vascongada) 175

Galicia 3, 47, 50, 62, 68, 91, 144, 160-62, 169, 171, 178-79, 185, 190-91, 218, 261-63 (véase tambíen Santiago de Compostela)

Gandía 16

Gerona 42, 199

Granada 61, 176

Hijar (Teruel) 12, 232

Huesca 10

Jardín de Versalles 216

Játiva (Valencia) 16

Jumilla (Murcia) 2

Legueito (Vascongada) 272

Leiza (Navarra) 278

León 64, 141, 179, 184

Londres 4

Málaga 118

Mallorca 13, 97, 100, 116-17, 131, 138

Menorca 33

Montserrat (Cataluña) 27, 34bis, 157-58

Murcia 2, 51, 92, 179-80

Navarra 192, 277-78

Palacio de Gelmirez (Santiago) 198

Palencia 239

Peña Aguilera (Toledo) 107

Pinadés (Cataluña) 247

Portugal 108

Provence 36

Redondela (Galicia) 263

Roselló 13, 181 
Salamanca 98

San Martial de Marratxi (Mallorca) 131

Santander 32, 122-23

Santiago de Compostela 48, 70-72, 161-62, 174, 182, 198,261

Sardenya 13,181

Sevilla 5, 7, 223-24, 226-27

Teruel 12, 232

Tlemcen 163

Toledo 21, 65, 107

Valencia 13, 16, 28, 93, 101, 124, 149, 179, 186, 26467 (véase tambíen Elche)

Valle de Iguna (Santander) 122

Vascongada 8-9, 11, 14-15, 53-56, 77-78, 80, 121, $175,179,192,202,268-78$

Zaragoza 235

\section{Índice IV: Materias}

Aires nacionales 119

Alalá 62

Alfarabi (= Al-Fârâbî) (m. 950) 214

Alfonso X, el Sabio (1252-1284) 6, 43, 169

Alió Brea, Francisco (1862-1908) 130

Antología musical 108

Árabe (la música):1, 79, 142, 145, 163, 169, 214-15, 229

Archivo de la Corona de Aragón 196

Archivo Municipal de Gerona 42, 199

Armonía 39

Aurora 2, 51, 94

Auto lírico-religioso 87

Auto sacramental 10

Axelehi, Cadí Mahamud Ibrahim (= Al-Shalahî, Muhammad Ibrâhîm (s. XIV) 214

Bailes y danzas 99, 114, 179, 219-78, 224 (regional); 49, 222-27 (andaluces); 228-35 (aragoneses); 23638 (asturianos); 97, 116-17, 138 (baleares); 184, 239 (castellanos); 59, 157, 181, 240-60 (catalanes); 91, 261-63 (gallegos); 92 (murcianos); 67, 93, 124, 264-67 (valencianos); 8-9, 14, 77, 121, 268-78 (vascos)

Bailes (tipos):

baile del copeo (valenciano) 264

baile de los Infantillos del Colegio del Patriarca 264

ball de bastons (catalán) 249

ball dels Diables (catalán) 244

Anuario Musical, 59 (2004) ball des Nanos 244 (catalán); 266 (valenciano)

ball cerdà (catalán) 243, 253

ball pla (catalán) 243, 249

bulangera (catalán) 249

cavallets (catalán) 244

caxarranca (vasco) 272

cobla (catalán) 250

comparses (catalán) 249

contrapàs (catalana) 241

contrapàs curt (catalana) 245, 256

contrapàs llarch (catalana) 181, 245

contrapàs sardà (catalana) 256

corrandes (catalanes) 181

corri-corri (asturiano) 236

de bastones (vasco) 268

de bastoners (catalán) 244-45

de Ciri (catalán) 255

de cotonines (catalán) 249

de esquerrana (catalán) 253

de figuetaires (catalán) 249

de flamencos (andaluz) 222

de gitanos (andaluz) 225; (catalán) 247, 249, 251, 254

de la cartxofa (valenciano) 265

de la Era (vasco) 277

de la Patúm (catalán) 257

de la raposa (asturiano) 236

de L'Àliga (catalán) 249

de les peregrines (valenciano) 265

de les quatre parts del mon (valenciano) 265

de los Infantillos del Colegio del Partriarca de Valencia 264

de mal-casats (catalán) 249

de moros y cristianos 67 (alicantino); 247, 249

(catalán)

de mozos 276

de palillos (andaluz) 222

de panderets (catalanes) 249

de pandero (asturiano) 236

de pastorel·li (catalán) 249

de pastorets (catalán) 244, 249, 265

de Sant Julià (catalán) 249

de Torrent (valenciano) 186, 264

del circolets (catalán) 244, 249

del Drach (catalán) 249

de les pastoretes (catalán) 244; (valenciano) 265

del cercolets (catalán) 244, 249

del Corpus 223, 266 
del Sabre (valenciano) 265

dels arquets (valenciano) 265

dels bastonets (valenciano) 265

dels negritos (valenciano) 265

dels serranos 265

dels tornejants (valenciano) 265

d'en Serrallonga (catalán) 249

diables, Els (comparsa) (catalán) 249

farruca (andaluza ) 224

garrotín (andaluz) 224

giraldilla (asturiana) 236

gracia de Sevilla, La (andaluza) 224

gegants (catalán) 244, 249

gerigonza (asturiana) 236

guajiras (andaluces) 224

jota 200,254

jota aragonesa $228-35$

jota valenciana 186,264

jota de carrer 186, 264

manchegas (castellanos) 224

marianas (andaluces) 224

moxiganga $221,244,249,264$

mulassa (catalana) 249

ole bujague, El (andaluz) 224

panaderos (andaluz) 224

patera (catalana) 244

pelindango (asturiana) 236

pericote (asturiano) 236

peteneras (andaluzas) 224

seises, Los (de la Catedral de Sevilla) (andaluz) 226-27

sevillanas (andaluces) 224

soleares (andaluces) 224

soleares de Arcas (andaluces) 224

tango (andaluz) 224

xiquets de Valls (catalán) 249

xirongu 249

vito, El (andaluz) 224

Ballades 181

Biblia Goda 65

Bibliografías 30, 38, 68, 99, 145, 150

Bohemios españoles 179

Borja, San Francisco de (1510-1572) 16

Cairo, Manuel (Canónigo) 198

Cancionero de Herberay 86

Cancionero musical de Palacio (CMP) 21, 86

Cancionero musical popular español (de Pedrell) 137
Cancioneros 164 (asturiano); 120 (burgales); 181 (catalana, sarda); 82 (extremeño); 98 (salmantino); $14,53,105$ (vasco)

Cançoner Popular de Catalunya, Obra de,. Materials 34

Cançoner popular de Nadal 103

Canciones (tipos):

amorosas (vasca) 14

báquicas (vasca) 14

de cuneras (vasca) 14

de oficio (vasca) 14

de ronda (vasca) 14

del pandero (Roselló, Sardegna) 181

epitalamios (vasca) 14

festivas (vasca) 14, 105

infantiles (vasca) 14

narrativas (vasca) 14

religosas (vasca) 11, 14; (catalana) 18

sin palabras (vasca) 14

Canciones/Arias (títulos):

"Albaa" 264

“A saltado está mi pecho" (aria) 200

“Alevoso nîño engañoso Dios" (minuet) 200

"Clarines" 200

"Cupidillo desleal" (tonada) 200

"De los zelos los desvelos" (minuet) 200

"Después que tebi una noche" (tonada) 200

"Diágolos" 264

"El bon caçador" (canción catalana y balear) 140

"El caçador i la pastoreta" (canción catalana y balearica) 140

"El chiste" 264

"El Dios de los raios" (aria) 200

"El faitó" 186, 264

"El mariner" 115

"El paño maruno" 186

"El punto de la Habana" 186

"El Torneo" 264

"El ú y el dós" 186, 264

"El Viático" 264

"Filiz divina" (tonada) 200

"Jota valenciana" 186

"La Alicantina" 186, 264

"La benedición del hinojo" 264

"La gaita francesa" 200

"La magrana" 264

"La Paella" 264

"La xàquera vella" 186, 264 
"La magrana, danza" 186

"Lamentazión de la Reina de Umgría" 200

"Les Albáes" 186

"Oies oies manguilla" (solo humano) 200

"Oyes, Belisa" 200

"Para procesiones" 186

"Que quieres amor maltratame" (tono humano) 200

"San Juan de Lima" (menuette) 200

"Yo soy maestro de coches" (tonada humana) 200

Canciones/Cantos populares (estudios): 96, 117, 135-

36, 167 (españoles); 33, 66, 116-17, 140 (baleares); 37-39 (castellanos); 19, 26, 34bis, 35, 111, $115,129-30,140,168$ (catalanes); 82 (extremeños); 178 (gallegos); 124 (valencianos); 134 (entre los vihuelistas)

Canciones/cantos populares: 108, 119 (españoles); 118 (andaluces); 88, 164 (asturianas); 66 (baleares); 120 (burgalesas); 107, 120 (castellanas); 27, 29, 59, 104, 181 (catalanas); 82 (extremeñas); 3, 50 (gallegas); 73, 225 (gitanas); 64, 141, 184 (leonesas); 97, 138 (mallorquinas); 33 (menorquinas); 51, 92, 180 (murcianas); 239 (palentinas); 32 (santanderinas); 12 (turolensas); 93, 186 (valencianas); $14,53,55,105$ (vascas)

Canciones líricas $(C M P) 21$

Canciones populares religiosas 11 (vascas); 18, 110, 158 (catalanas); 28 (valencianas)

Canciones sefardíes 85

Cançó catalana 168

Cansons del pandero 181

Cantaores (andaluces) 118

Cantares singogales 4, 95

Cante andaluz 132

Cante flamenco 95, 118, 132, 153, 169, 222

Cante jondo 30-31, 61, 95, 169

Cantigas de Amigo (s. XII) 185

Cantigas de Santa María (s. XIII) 6, 43, 63, 106, 133, $142-43,145,159,169,194,213$

Canto de la Sibila 21-22, 65, 117, 131, 139

Canto de órgano 206

Canto llano 206

Cants de la Passió 102

Cants dels romeus 157

Capiteles con músicos (s. XII) 198

Carceleras 118

Catedrales: 10 (Huesca); 21 (Toledo); 226-27 (Sevi1la)
Cervantes (la música en) 57, 211

Ciegos 161

Cifras para harpa (ss. XVII-XVIII) 200, 228

Clérigos 46

Clavé, Josep Anselm (1824-1874) 59

Cobles de desperta 154

Códax, Martin (poeta de la lírica galaico-portuguesa) (s. XIII) 185

Colegial de Gandía 16

Compás de 5/8 8-9, 78, 270

Consuetas 44 (Elche); 100 (Mallorca);

Consueta de Juy 100;

Consueta de la Representació de la tentació que fonch feta a Ntr. Sr. Xpt. 100

Convento de Religiosas Clarisas de Játiva 16

Coplas sefaradíes 85

Cordaes, Les (Alicante), 67

Corpus Christi 7, 223, 264, 266

Criterio etnográfico 133

Cuaderna vía (poemas de) 46

Cuaresma 51

Cuentos (vascos) 14; (gitanos) 225

Cultura musical catalana (s. XVI) 130

Danzas 99, 219, 224 (regionales); 67 (alicantinas); 222-27 (andaluzas); 228-35 (aragonesas); 236-39 (asturianas); 239 (castellanas); 240-60 (catalanas); 92, 261-63 (gallegas); 97, 119-20 (mallorquinas); 93 (murcianas); 94, 124, 186, 264-67 (valencianas); 14, 268-78 (vascas)

Danzas (tipos):

aurresku (vasca) 270

bolero 69,280

cachucha 254

chaconas 228

contradanza 254

corrandes 181

corri-corri (asturiana) 236

dansa de la muerte 157

dansa de la primera veu 157

dansa moral 157

danses religioses (catalanas) 243

danses senyorials (catalanas) 243

danza circular grande (vasca) 273, 278

danza circular pequeña (vasca) 278

danza de Bocayrente (valenciana) 264

danza de Hijar (turolense) 232

danza de la soga (vasca) 278 
danza de las Torres (valenciana) 264

danza de los enanos (valenciana) 264

danza prima (asturiana) 236-37

de espadas 263 (gallega); 268, 274 (vasca)

de gitanos (catalana) 247

de la caxarranca (vasca) 272

de los bastones (vasca) 268

de los diablos (catalana) 247

del niño pródigo (catalana) 247

del pandero (asturiana) 236

dels romeus (catalana) 258

gallardas 228

geringoza (asturiana) 236

giraldilla (asturiana) 236

girats (catalana) 245

inguruandi (vasca) 278

ingurutxo (vasca) 278

marcha de enanos 264

moros y cristianos (alicantina) 67; catalana) 247, 249

mutil-danza (vasca) 276

paseo y marcha 254

rebudixu (asturiana) 236

rodada (catalana) 245

sardana (catalana) 59, 240, 242-43, 246, 248, 250, 252

schotish 254

zarabanda 228

zortzico (vasca) 8-9, 77-78, 121

De Musica Libri Septem (de Francisco Salinas) (s. XVI) 125,151

Declaración de instrumentos musicales (de Fray Juan Bermudo) (s. XVI) 195

Diccionario biográfico 149-50

Diferencias 200

Don Quijote (la música en) 211

Drama lírico 17 (Tragedia de Santa Inés, s. XIII); 41, 126-28

Drama litúrgico 16, 244

Duque de Gandía 16

\section{Elegías 14}

Encina, Juan del (1468-1529/30) 169

Endechas 14 (vascas); 86

Entremeses 221

Epitalamios 14 (vascos)

Escuela muscia (de Pablo Nassare) 206

Escultura 51, 173, 198
Estado de la música en España 81

Estilo de canciones castellanas 39

Estrambotes $(C M P) 21$

Estribillos 122

Estudio comparativo 146

Estudios musicales 57, 112, 117, 130

Fantasía 12, 278

Felipe III (1598-1621) 193

Felipe IV (1621-1665) 193, 201, 204

Festes de carrer, Les (Alicante) 67

Fiesta de agosto (véase el Misterio de Elche)

Fiesta de San Alonso (Mallorca) 117

Fiestas 8, 10, 154, 199, 230, 257, 261, 273

Flamenco 31, 95, 118, 132, 153, 169, 222

Folías/folies 27, 200, 228

Folklore 33 (de Baleares); 51 (de Murcia); 273 (vasco); 130 (catalán); 171 (gallego)

Folklore musical 34, 57, 80, 82, 85, 99, 125, 129-30, $133,156,164$

Fornelis, N'Andreua 139

Frottolas $(C M P) 21$

Gaiteros (en Galicia) 218

Gamas célticas 80

Gitanos 30-31, 73, 118, 179, 225, 247, 251, 254

Goigs 18, 154

Gónzalez Torres de Nava, José (n. 1759) 279

Goya (la época de) 60

Granada, historia de la música en 176

Herencia, Patricio (anticuario) 216

Herrera (Cardenal) 198

Herroche, Cristóbal 203

Hidalgo, Juan (1614-1685) 201

Himnodia del Roser 154

Himnos de los peregrinos 182

Himnos hebraicos 4

Historia de la música española 155; 196 (en la Corte del rey de Aragón D. Juan I)

Historia de la música religiosa y profana en España 171

Iglesia de Mallorca 100

Iglesia de Toledo (historia de la) 65

Iglesia parroquial de Santa María de Elche 87

Igualda 244

Infantiles 14 
Influencia de la música árabe 79, 145, 169, 229

Influencias del romance en el canto popular hispano 133

Influencia de las melodías gregorianas 121

Instrucciones de música (de Gaspar Sanz) 212, 228

Instrumentos musicales 42, 99, 186-218, 250

Instrumentos (tipos): alboka 192; arpa 195-96, 200, 206, 228; bajoncillo 193; bandurria 203; bombarda 196; chalamía 196; cítara 186, 196, 206; clavicémbalo 206; clavicordio 206; clavi-harpa 201; claviórgano 206; concha 203; cornamusa 187, 196; donsaina 186; dulzaina 186, 195, 264; espineta 206; exaquier 196; flatulentos 206; flauta 195, 217; gaita 190-91, 208, 218; galoubet 202; guitarra 186, 206, 212, 228, 231, 235; guitarró 186; jábeca (o jabega) 196; laúd 203, 219; monocordio 206; neo canon 196; octavilla 186; órgano 195-96, 206, 216; piano-violonchelo 216, rabel 196; rabena 196; rota 196; tabolet 186; tamboril 186; tamboriles de cuerdas 188-89; tambourin 202; tamburo 210; tiorvia 203; trompeta 196; txistu 207-08, 269; 'ud arabe 215; vihuela 195, 206; vihuelas de arco 203; viola 196; violones 203; xalamía (ó xelemía) 196

Isasi, José de (organista) (ss. XVI-XVII) 203

Iztueta Echebarría, Juan Ignacio (1767-1845) 270

Jácaras 221

Juan I (Rey de Aragón) (1379-1390) 196

Judíos sefardíes 4, 85, 95

Judíos portugueses 4

Juegos 261, 273

Juglares (joglars, jograis) 36, 46, 99, 205

Lengua castellana 45

Lírica nacionalizada (de Pedrell) 129

Lírica popular antigua 40

Lírica portuguesa 46

Loas 221

Llibre Vermell (s. XIV) 34bis, 157, 258

Madrigales 169, 173

Marcha de los enanos 264

Manuscritos

a) de la Biblioteca Nacional, Madrid: 215 (Ms. 334); 200, 228 (Ms 816); 186 (Ms. 1020); 216 (Ms. 14.009); 203 (Ms. 14.017); 196 (Ms.
14.060); 196, 199 (Ms. 14.068); 204 (Ms. 14.075); 274 (Ms $4^{\circ} \mathrm{O} 823$ )

b) de la Biblioteca Nacional. Lisboa: 204 (Ms. H.6.38)

Mayos (Fiesta de) 68

Melodías pentatónicas 147

Melodías tetracordas 147

Métrica 24, 56, 109, 144, 151,

Minnesinger 143

Minstrels (ministrils) 36, 193

Minuettes 200

Misales gótico y latino 65

Misterios 10, 23, 101, 154, 175

Misterio de Adam y Eva 101

Misterio de El Rey Herodes 101

Misterio de Elche 41, 44, 75-76, 87, 89-90, 113, 126-28, 148-49, 170, 183

Misterio de la Pasión 175

Misterio de los Reyes Magos 23

Misterio de Sant Cristofol 101

Misteris del Rosari 154

Modalidad / tonalidad 39, 147, 160

Morales, Alonso de (corneta) 203

Morales, Cristóbal de (1500-1553) 169

Mozárabes 169

Muiñeira 144, 262

Música andaluza medieval 143

Música aus Pays-Bas 177

Música popular 57, 172, 179 (andaluza); 67, 179 (alicantina); 13, 179 (aragonesa); 88, 164, 179, 238 (asturiana); 66, 116-17, 138, 179 (balearica); 37$39,58,120,141,179184$ (castellana); 13, 29, 34$35,59,69,104,111,115,129-30,179,181$ (catalana); 58, 60, 79, 83, 96, 99, 108, 114, 119, 133-37, 146, 179 (española); 82 (extremeña); 3, 50, 91, 144, 160, 171, 178 (gallega); 51, 92, 180 (murciana); 32, 123 (santandesa); 28, 93, 124, 179, 186 (valenciana); 14-15, 54-55, 77-80, 179 (vasca)

Música folklórica 33, 80, 82, 85, 99, 125, 129-30, 133, 156,164

Músicos flamencos en España 177

Músicos holandeses en España 177

Nacionalismo 59, 117, 120

Navidad 65, 103

Orfeó Català 129

Organología 187-218 
Pasacalles 200

Pasión 102, 175

Pasión de Cuaresma 51

Pastors y la música 181

Peregrinación a Santiago de Compostela 48, 70-72, 161-62, 174, 182

Picaud, Magister Americão 71

Poemas medievales castellanas 46

Poesía castellana 24-25, 40, 52. 86

Poesía juglaresca 205

Poesías árabes 215

Pregones 57

Procesiones 51, 264

Puerta Santa (Catedral de Santiago de Compostela) $161-62$

Refranero general español (de J.M. Sbarbi) 152

Rendición de la música en España 173

Representaciones populares dramáticas (véase viaje literario, núm. 281)

Ritmo 39-40, 121, 160, 164, 267

Rojas Carrión, Juan de (violero) 203

Romancero 47 (gallego); 51, 169

Romances 14 (vascos); 85 (judéo-español); 21 (CMP), $32,64,82,98,120,125,133,137,151,164-66$

"De Nelo el tripero" 264

Rosario de la Aurora 51, 94

Ruedas 8, 216

Ruiz de Velasco, Ruperto 231

Saetas 5, 51

Salinas, Francisco (1513-1590) 125, 151

Salve de la Aurora 51

San Francisco de Borja 16

Seguidilla 24-25, 40, 45, 49, 50, 52, 74, 84, 86, 109, $152,155,200,220$

Semana Santa 5, 16, 51, 102

Serrano, José Enrique 101

Sibila (véase Canto de la Sibila)

Siguirillas gitanas 118

Siglo IX 173

Siglo X 173, 213
Siglo XI 173, 213

Siglo XII 173, 185, 189, 198, 213

Siglo XIII 17, 173, 213 (véase las Cantigas de Santa María)

Siglo XIV 34bis, 42, 157, 173, 196, 199, 214, 258

Siglo XV 10, 16, 21, 42, 100, 128, 173, 199, 221

Siglo XVI 10, 16, 21, 28, 42, 83, 99-100, 125, 130, $135,169,173,199,221,231$

Siglo XVII 42, 83, 99, 101, 173, 203-04, 221, 228,

Siglo XVIII 83, 173, 221, 228, 267, 275

Soleares 118

Tabalatura 215

Teatro español 23

Teatro medieval 41

Teatro musical 99, 128, 281

Tocatas populares 116-17 (Baleares); 237 (vascas)

Tonadas 104, 154, 200

Tonadillas 228

Tonalidad / modalidad 39, 147, 160

Tonos divinos 201

Tonos humanos 200-01

Toque de dulzaina y tabor 264

Trobadores 36, 99, 143

Troveros 143

Truchado, Fr. Raimundo (s. XVII) 216

Tumba del Apóstal (Santiago de Compostela) 182

Ultreja (canto de los peregrinos flamencos) 20, 71-72, 174

Valdés, Francisco (s. XVII) 193

Versificación 25, 86, 109

Viajes a España 49, 69, 281

Victoria, Tomás de (1548-1611) 169

Vihuelistas 134, 169, 215

Villancicos 21, 169

Visigodos 169

Voto, Antonio (guardajoyas de S.M.) 203

Zarzuela 228 